\title{
Kernos
}

Revue internationale et pluridisciplinaire de religion grecque antique

8| 1995

Varia

\section{Mythes et cultes de la cité d'Aptera (Crète occidentale)}

\section{Gérard Capdeville}

\section{OpenEdition \\ Journals}

\section{Édition électronique}

URL : http://journals.openedition.org/kernos/587

DOI : $10.4000 /$ kernos.587

ISSN : 2034-7871

\section{Éditeur}

Centre international d'étude de la religion grecque antique

\section{Édition imprimée}

Date de publication : 1 janvier 1995

Pagination : 41-84

ISSN : 0776-3824

\section{Référence électronique}

Gérard Capdeville, "Mythes et cultes de la cité d'Aptera (Crète occidentale) », Kernos [En ligne],

8| 1995, mis en ligne le 11 avril 2011, consulté le 20 avril 2019. URL : http://journals.openedition.org/ kernos/587 ; DOl : 10.4000/kernos.587 


\title{
Mythes et cultes de la cité d'Aptera
}

\author{
(Crète occidentale)*
}

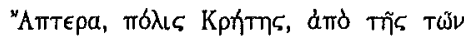

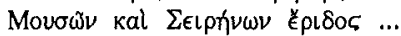 \\ (STEPH. BYZ., s.u. “A $A \tau \epsilon \rho a, 107,8 \mathrm{M}$ )
}

Aptera $^{1}$, ou Aptara ${ }^{2}$, fut une cité importante située à l'entrée du golfe de

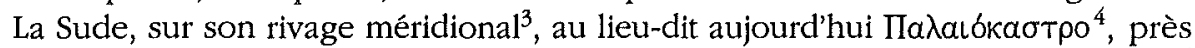

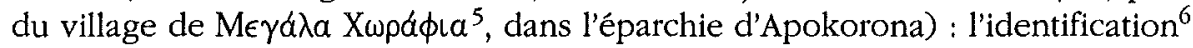
en a été assurée par la découverte d'un mur à inscriptions portant divers décrets. Elle possédait un port, Kisamos, à l'est sur la même côte ${ }^{7}$, et peut-être un second, Minoa ${ }^{8}$, sur la rive opposée du golfe ${ }^{9}$, sur la grande péninsule de l'Akrotiri ${ }^{10}$. Maîtresse du meilleur mouillage de l'île, Aptera fut une ville marchande prospère ${ }^{11}$, comme en témoignent, pour l'époque hellénistique, les nombreux proxènes qu'elle honora.

Comme plusieurs cités crétoises, Aptera possède un héros éponyme, Apteros ou Apteras ${ }^{12}$. Mais ce n'est que dans la Chronique d'Eusèbe, traduite par Jérôme - et dans les ouvráges qui en dépendent ${ }^{13}$ - qu'il est explicitement donné comme le fondateur de la ville, à une date correspondant à 1503 avant J.- C. ${ }^{14}\left(44 \mathrm{c} \mathrm{Helm}^{2}\right)$ :

In Creta regnauit Apteras, qui et urbem condidit.

En l'occurrence il s'inscrit dans la chronologie « haute » des rois légendaires de l'île ${ }^{15}$, à la suite notamment de Crès ${ }^{16}$ et de Cydon $^{17}$, avant Astérios ${ }^{18}$ et Minos $^{19}$.

On peut tenir pour assuré que cette tradition, littérairement si fragile, était en revanche bien conservée dans la cité, puisque celle-ci représenta volontiers au revers de ses monnaies ${ }^{20}$ un héros guerrier, sans nom, mais avec parfois le monogramme $\mathrm{A}^{21}$ et surtout l'épithète $\pi \operatorname{To\lambda }\left(\operatorname{lot}_{\kappa} \varsigma^{22}\right.$, hapax qu'il ne faut sans

La présente étude est conçue comme la première d'une série de monographies consacrées aux mythes et aux cultes de diverses cités crétoises. - Les notes de cet article se trouvent à la fin du texte (p. 55-84). 
doute pas comprendre ${ }^{23}$ comme signifiant simplement « habitant de la cité ${ }^{24}$, mais plutôt comme équivalent de $\pi$ Toגıoṽ $\chi 0 \varsigma^{25}$, « maître, protecteur de la cité ${ }^{26}$ (Fig. 1, p. 54)

Ce héros casqué, nu ${ }^{27}$ ou revêtu d'une cuirasse ${ }^{28}$ selon les émissions, et armé le plus souvent d'une lance ${ }^{29}$, porte toujours un bouclier, sur lequel figure parfois une étoile ${ }^{30}$. Mais surtout il est, sur les premières émissions ${ }^{31}$, associé à un arbre, vers lequel il lève la main droite ${ }^{32}$, geste indéniable de dendrolâtrie ${ }^{33}$, qui inscrit nettement le personnage dans le contexte religieux « minoen ${ }^{34}$.

C'est aussi dans ce même contexte que se situe la légende dont il est l'un des personnages principaux, ses amours tragiques avec Eulimène ${ }^{35}$, fille de Cydon, séduite par Lycastos et sacrifiée par son père sur l'ordre d'un oracle, selon le récit conservé par Parthenios (Erotica, 35), peut-être d'après

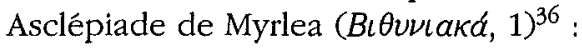

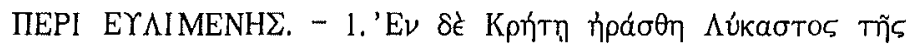

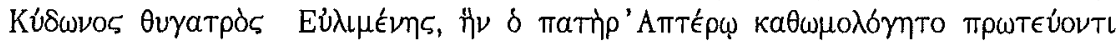

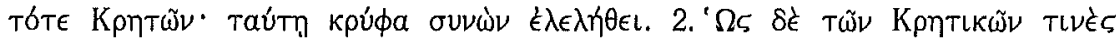

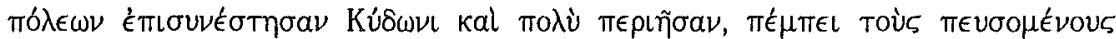

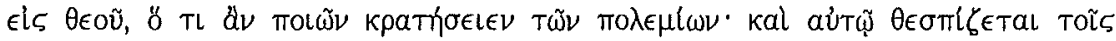

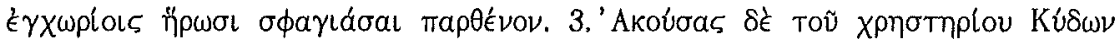

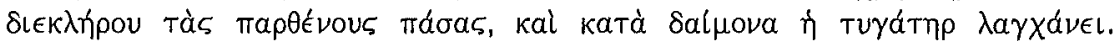

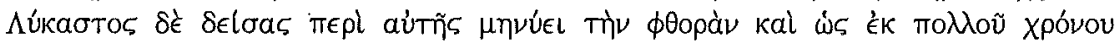

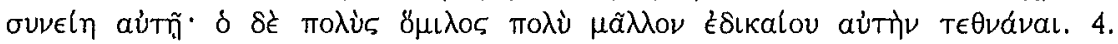

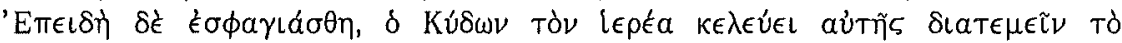

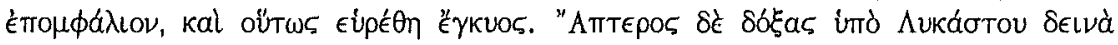

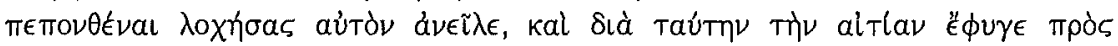

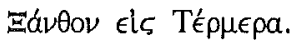

Au-delà de ses péripéties romanesques ${ }^{37}$, l'histoire fournit diverses informations qui permettent de préciser le portrait du héros. C'est tout d'abord

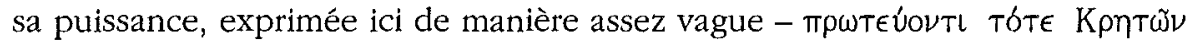
- et qui, cadrant assez mal avec avec une situation où c'est Cydon qui semble le personnage le plus important, en tant que suzerain de plusieurs cités, peut refléter discrètement une autre version, où Apteras apparaissait explicitement comme le maître de l'île, ainsi que l'indique Eusèbe.

Mais plus significative encore que cette question de primauté apparaît la constatation que les trois personnages masculins sont chacun l'éponyme d'une cité : Cydon, de la puissante cité de Cydonia ${ }^{38}$, voisine d'Aptera, avec qui les relations durent constamment osciller entre rivalité et alliance ${ }^{39}$, avant que la plus grande ne domine définitivement la plus petite ${ }^{40}$, comme cela se produisit en bien des cantons de l'île; Lycastos ${ }^{41}$, d'une autre cité, homonyme ${ }^{42}$, connue d'Homère $(I l ., 2,647)^{43}$, mais absorbée ensuite par Cnosos et enjeu de luttes entre cette dernière et sa rivale Gortyne ${ }^{44}$. 
Chronologiquement - et compte non tenu des contradictions d'Eusèbe - le nom de Cydon permet encore de situer les événements à la période «minoenne", puisque celui-ci passait pour être l'un des petits-fils du mythique souverain de $\operatorname{Cnosos}^{45}$. Et l'atmosphère même de la fable correspond bien à cette époque, puisque l'on y retrouve une certaine liberté sexuelle ${ }^{46}$ et la pratique de l'union prématrimoniale secrète ${ }^{47}$, qui apparaît dans d'autres mythes remontant à la même époque, mais «normalisés » à l'époque grecque, par exemple les légendes concernant l'hiérogamie de Zeus et Héra, attestées aussi bien en Crète - notamment au Theren, près de $\operatorname{Cnosos}^{48}$ - que dans certaines îles comme $\operatorname{Naxos}^{49}$ ou Samos ${ }^{50}$, qui furent soumises à l'influence de la «thalassocratie » crétoise ${ }^{51}$.

Au reste, s'il fallait une autre preuve de l'imprégnation «minoenne » de la région d'Aptera, on la trouverait dans le nom de l'un des ports voísins déjà évoqué, un des nombreux Mivứa ${ }^{52}$ qui parsèment les côtes de la mer Égée et de la Méditerranée orientale ${ }^{53}$.

Une autre tradition sur la fondation existait pourtant, qui la situait à une époque plus récente, celle des Nóotol, des « Retours » de la guerre de Troie. On en trouve la trace chez Étienne de Byzance (s.u. "A

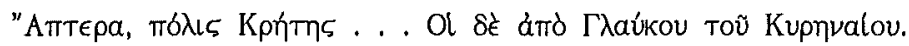

Qui est ce Glaucos de Cyrène ? Un élément de réponse est sans doute fourni par un récit du vieux scholiaste de Lycophron, repris par Tzetzes (in Alex., 874 / 283, 19 Scheer), qui le présente comme un des fils d'Antènor, accompagnant Ménélas lors de son retour de Troie ${ }^{54}$ et ayant fait naufrage «près de Cyrène » :

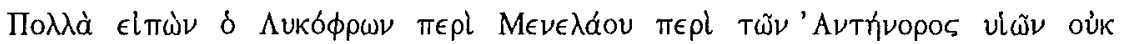

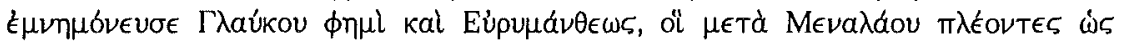

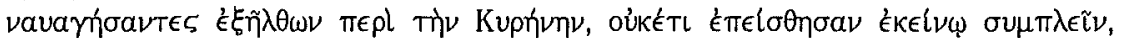

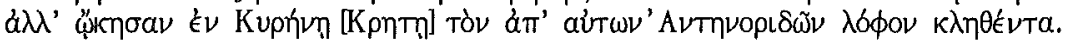

Ce texte elliptique et incertain pose plusieurs problèmes. Tout d'abord sur l'identité du personnage ${ }^{55}$, qui porte un nom très fréquent dans les légendes de toute l'Égée : il s'agirait ici d'un fils du prince troyen Antènor ${ }^{56}$, qui avait protégé Ulysse et Ménélas lorsque ceux-ci, avant la guerre, étaient venus - en vain - réclamer la restitution d'Hélène et de ses bijoux ${ }^{57}$, comme le raconte Apollodore (Epit., 3, 28-29) :

28. ' А

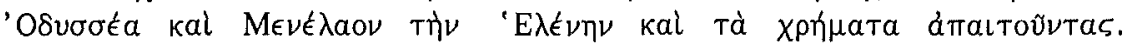




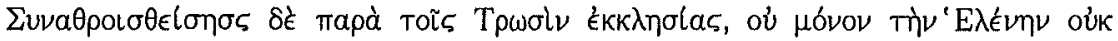

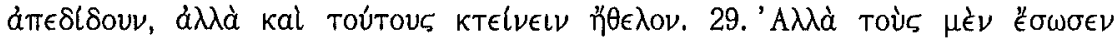

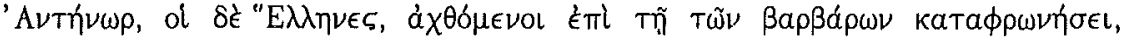

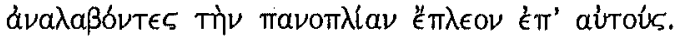

- ce qui lui avait valu de voir sa maison épargnée au moment du sac de Troie ${ }^{58}$ et certains de ses enfants sauvés par les vainqueurs; ce fut notamment le cas pour Glaucos, reconnu par Ulysse et Ménélas ${ }^{59}$, toujours d'après Apollodore (Epit., 5, 21) :

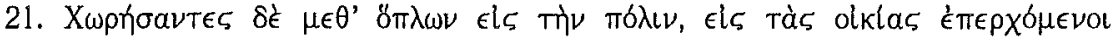

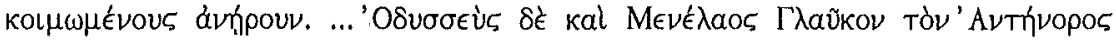

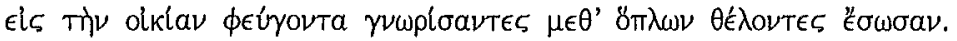

L'autre difficulté concerne la localisation du naufrage. Le texte de la scholie

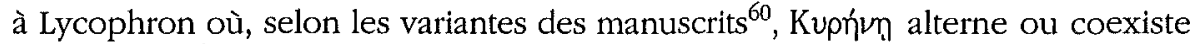
avec K $\rho \eta \dot{\tau} \eta^{61}$ a pu faire supposer l'existence d'une cité appelée Cyrène en Crète, bien qu'il n'y en ait aucune autre attestation ${ }^{62}$. En revanche, les Anténorides étaient bien connus et même honorés d'un culte héroïque dans la

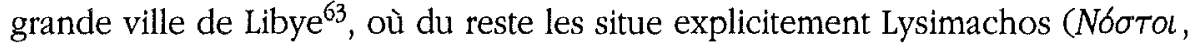
$\left.F G H, 382 \mathrm{~F}^{6}\right)^{64}$, cité dans la scholie ${ }^{65}$ à la suite du passage précédent (in Alex., 874 ( 283, 24 S) :

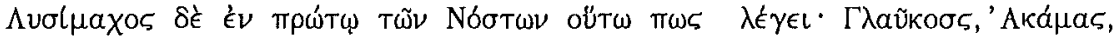

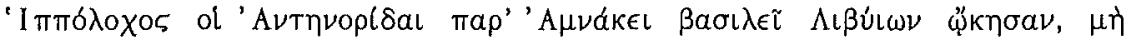

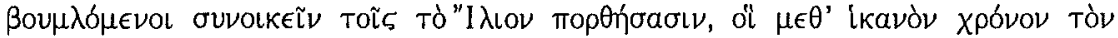

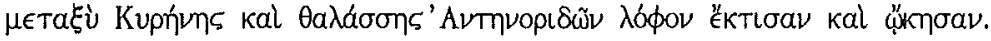

Et de fait, c'est bien auprès de la Cyrène libyenne que se trouvait la colline consacrée aux héros, qui apparaît dans les deux versions ${ }^{66}$.

On peut donc se demander si la notation d'Étienne de Byzance ne repose pas sur de multiples confusions ${ }^{67}$ : l'existence d'un Glaucos, fils de Minos ${ }^{68}$, aurait pu amener la confusion avec un autre Glaucos ${ }^{69}$, célèbre dans une cité dont les liens avec la Crète étaient anciens ${ }^{70}$ et étroits ${ }^{71}$; mais comme il était difficile de penser qu'après un débarquement et une installation en Libye, celuici était reparti vers la Crète, certains - scholiastes ou copistes - ont pu imaginer une Cyrène crétoise.

Cependant, au-delà des incertitudes sur le véritable trajet du « second » fondateur, il reste l'existence d'une tradition sur une origine plus « récente » de la ville. Celle-ci n'est pas nécessairement en contradiction avec la première $^{72}$, puisqu'elle peut correspondre à l'établissement de nouvelles populations en un lieu déjà colonisé $e^{73}$. L'absence de tout lien onomastique entre la cité et ce nouvel œciste s'accorde sans mal avec cette hypothèse ${ }^{74}$. 
Pour mémoire, il convient de citer une dernière légende, attestée par Pausanias $(10,5,9-10)$, et selon laquelle le nom de la cité proviendrait, par adjonction d'un A initial, de celui de l'architecte du second temple de Delphes ${ }^{75}$, Ptéras ${ }^{76}$, dans l'une des trois versions de la construction de ce temple :

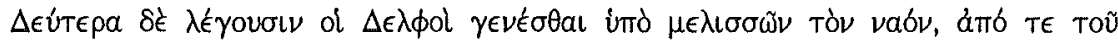

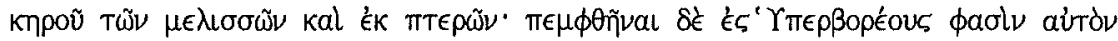

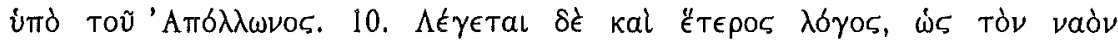

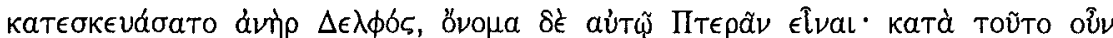

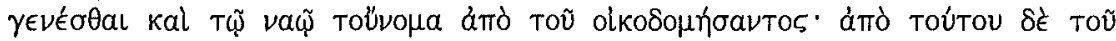

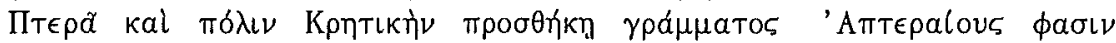

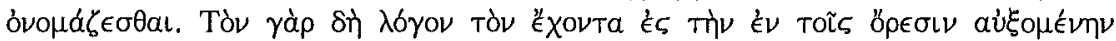

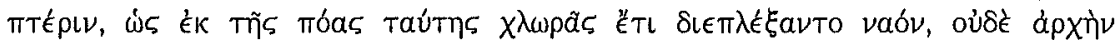

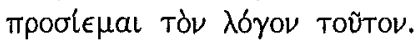

Le caractère tout à fait improbable de l'étymologie ${ }^{77}$, l'absence de toute donnée chronologique et de tout détail sur l'événement - au point qu'il n'apparaît même pas que Ptéras fût allé en Crète - semblent indiquer qu'il s'agit là d'une explication fabriquée à Delphes $^{78}$, sur la base d'une ressemblance approximative des noms et des fortes affinités, attestées par ailleurs ${ }^{79}$, entre le grand sanctuaire et la grande île $\mathrm{e}^{80}$.

L'esquisse de «communauté mythologique » que dessine l'histoire d'Eulimène et d'Aptéros, se retrouve dans d'autres légendes : Aptera connaît les mythes propres à la Crète de l'ouest, dont elle est l'une des cités principales. Mais elle manifeste aussi son originalité au travers d'une légende qui lui est propre.

Le morcellement des communautés crétoises, dû au relief montagneux, a eu pour effet de multiplier les localisations des grands mythes de l'île, et parfois les noms de leurs personnages.

La Crète de l'ouest, particulièrement accidentée, n'a pas échappé à ces variations. Comme les autres régions, elle possède ses montagnes sacrées ${ }^{81}$, qu'elle peuple de divinités diverses, au premier rang desquelles les Dactyles.

Notre documentation ne conserve pas trace d'un mythe de la naissance de Zeus, analogue à celui qui avait triomphé sur l'Ida ${ }^{82}$, sans effacer complètement 
les traditions locales de Lyttos $^{83}$, du Dictè oriental ${ }^{84}$ ou d'ailleurs ${ }^{85}$. On peut supposer que, pour les États de l'ouest, la grande montagne du centre - dont était proche Lycastos - a fait disparaître toute autre localisation.

Mais les éducateurs du dieu, eux, sont restés présents, les Dactyles Idéens, dont l'épithète devait sans doute à l'origine les qualifier seulement comme «forestiers " ${ }^{86}$, avant de les rattacher à l'Ida par excellence. Et ces Dactyles ont aussi conservé leur activité essentielle, la métallurgie, exercée ici dans la

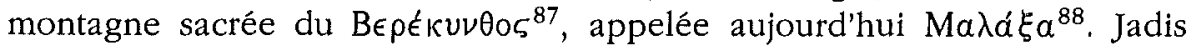
recouverte d'une abondante végétation, ce massif recèle notamment une " gorge aux cent grottes », longue de $3,5 \mathrm{~km}$ et profonde de $400 \mathrm{~m}$, au sud du village de Malaxa : ce fut un lieu de refuge et sans doute d'initiation, et c'est $1 a^{89}$ que l'on peut supposer la localisation des ateliers légendaires des Dactyles ${ }^{90}$, attestés par Diodore de Sicile $(5,64,5)$, d'après plusieurs historiens locaux ${ }^{91}$ :

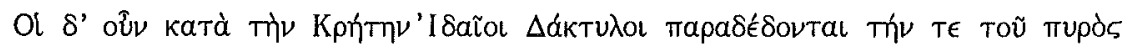

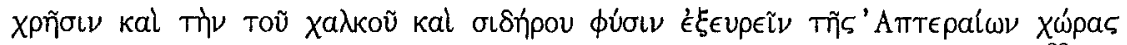

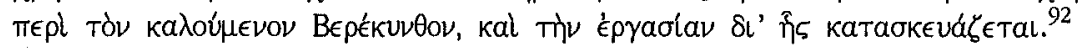

Beaucoup plus caractéristique de la région est Dictynna ${ }^{93}$, la grande déesse

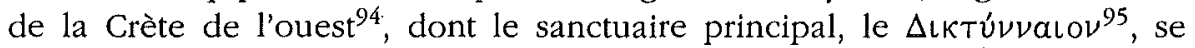
trouvait sur la longue presqu'île du Titupos, à l'ouest de Cydonia ${ }^{96}$.

À Aptera, l'existence d'un culte ancien de Dictynna est attesté par un nom

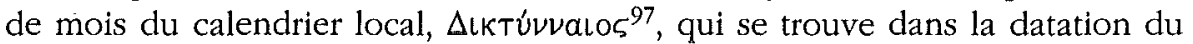
premier décret accordant l'asylie à Téos, en 201 av. J.- C. (IC , 2, 3, 1, lin. 1213) :

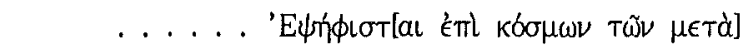

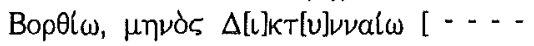

Ce nom de mois, qui est ici au génitif, comporte apparemment un suffixe « récent ${ }^{98}$. Mais s'il est possible que la forme ait été effectivement rajeunie, cela n'enlève pas sa valeur au témoignage, puisque l'on sait que, par leur variété même et la présence de nombreux termes préhelléniques, les calendriers des cités crétoises sont des documents particulièrement conservateurs. Avec son suffixe à nasale géminée, le nom de la déesse apparaît bien comme « pré-hellénique » ${ }^{99}$.

Pour son mythe toutefois, on ne peut remonter plus haut que Callimaque (H. Dian., 189-205) ${ }^{100}$, qui raconte comment Britomartis, compagne préférée d'Artémis, étant poursuivie par Minos, sauta dans la mer pour lui échapper et 
fut recueillie dans des filets de pêcheurs, prenant dès lors un autre nom, qui

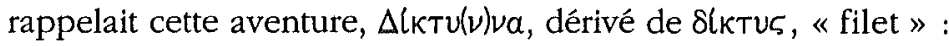

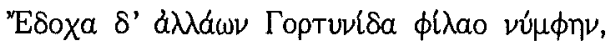

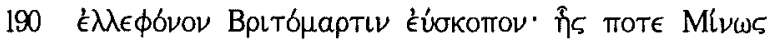

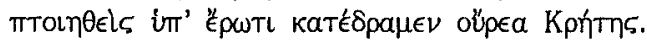

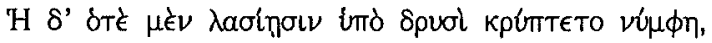

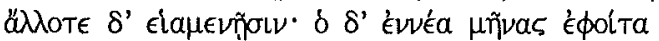

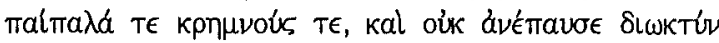

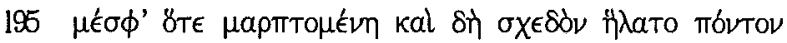

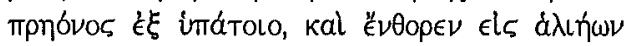

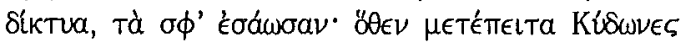

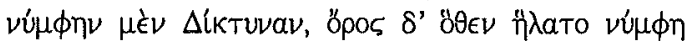

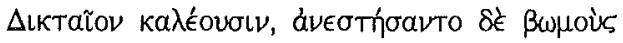

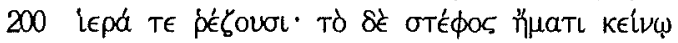

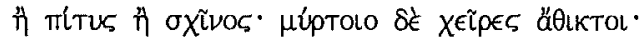

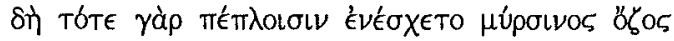

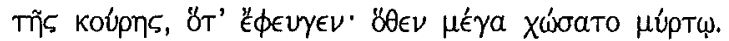

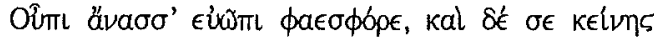

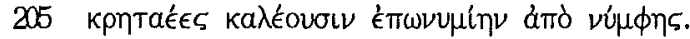

Si ce récit paraît avoir inspiré quelques mythographes encore plus récents ${ }^{101}$, il a en revanche, dès l'antiquité, suscité aussi la suspicion. Ainsi Diodore de Sicile $(5,76,4)$ ne croit pas qu'une déesse ait pu avoir à ce point besoin du secours de simples mortels, ni du reste que le sage Minos ait pu se conduire de manière aussi scandaleuse ${ }^{102}$; Strabon $(10,4,12,479 \mathrm{C})$, lui, conteste les données géographiques, en remarquant que le mont Dictè d'où aurait sauté la nymphe est bien éloigné du sanctuaire même de Dictynna, au pays des Cydoniens ${ }^{103}$.

Ce n'est pas le lieu de discuter ici de l'ensemble des problèmes complexes que pose cette divinité, et notamment de ses rapports avec Britomartis et Artémis. On retiendra seulement que ses seules représentations figurées certaines, des monnaies de l'époque impériale portant son nom, la montrent à la fois comme chasseresse $\mathrm{e}^{104}$ et courotrophe $\mathrm{e}^{105}$. Malgré leur date récente, ces monnaies peuvent être considérées comme fiables, d'une part parce qu'elles visent manifestement à présenter une divinité spécifique de l'île ${ }^{106}$, indépendamment des constructions de mythographes extérieurs, d'autre part parce que leurs indications peuvent être en partie recoupées par d'autres données.

C'est ainsi que le nom même de la déesse n'est sans doute pas à rattacher à SlkTUs ${ }^{107}$ comme le voudrait une étymologie probablement imaginée à Athènes ${ }^{108}$, mais plutôt à l'oronyme typiquement crétois $\Delta\left(\kappa \tau \eta^{109}\right.$, entendu ${ }^{110}$ comme pouvant s'appliquer à n'importe quelle «montagne sacrée ${ }^{111}$ et non comme le nom d'un massif particulier ${ }^{112}$. Dictynna apparaît ainsi comme 
fonctionnellement comparable à $\mathrm{Ida}^{113}$, autre «nymphe » associée à une montagne désignée elle aussi par un mot qui fut d'abord un nom commun ${ }^{114}$.

Comme cette dernière, elle a donc dû faire partie des nombreuses nourrices ${ }^{115}$ que les légendes crétoises, en leurs diverses localisations, attribuaient au jeune dieu que les Grecs continentaux identifièrent à Zeus et dont plusieurs grottes de l'île pouvaient passer pour avoir abrité les enfances. Callimaque (H. Iou. [1], 45) évoque du reste explicitement dans cette fonction des nymphes $\Delta \iota \kappa т a \tilde{a}$, qu'il situe précisément au pays des Cydoniens, et qui sont donc en quelque sorte la «monnaie » de la principale divinité de la région.

C'est également en tant que «montagnarde» que Dictynna pouvait naturellement être représentée comme chasseresse ${ }^{116}$. Encore convient-il de noter qu'il n'y a là probablement qu'un affaiblissement du type de la Mótvıa Onpũv, l'un des aspects les plus constants de la Grande Déesse crétoise ${ }^{117}$ dans ses diverses incarnations ${ }^{118}$. Mais c'est aussi par cette qualité que s'explique le rapprochement avec Artémis effectué par les Grecs du continent, qu'il s'agisse d'une simple association, comme chez Callimaque ${ }^{119}$, ou d'une complète identification ${ }^{120}$, couramment admise par nos sources les plus récentes, pour qui Dictynna n'est plus qu'une épithète typiquement crétoise d'Artémis ${ }^{121}$. En Crète même une telle confusion ne s'est jamais produite ${ }^{122}$; mais on peut se demander si la chasseresse grecque n'a pas, en certains lieux, pris tout simplement la place de Dictynna ${ }^{123}$.

À Aptera, l'antique déesse crétoise ne survit, comme on l'a vu, que dans un nom de mois. Il semble cependant qu'elle ait conservé un lieu de culte près du port voisin de Minoa - que celui-ci ait ou non appartenu à Aptera à certaines

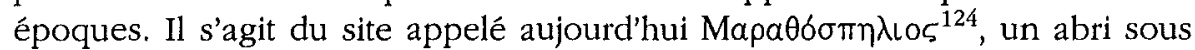
roche précédé d'une aire, où se dressent deux rochers séparés par un étroit passage; le plus grand des deux rochers, qui présente la silhouette d'une femme acéphale en robe, est creusé de petites niches, qui devaient servir pour le dépot d'offrandes et de statuettes votives.

Même si certains aménagements sont d'époque mycénienne ou archaïque $^{125}$, l'occupation du lieu doit remonter à l'époque «minoenne » ${ }^{126}$, comme l'indiquent le nom du port et celui de la grotte ${ }^{127}$, et aussi la présence de tessions MR III à la fois au site tout proche de Limni et de l'autre côté de la passe, de part et d'autre d'Aptera ${ }^{128}$. On y vénérait sans doute une divinité de la fécondité de caractère rupestre, ce qui correspond bien à la figure de Dictynna, telle que l'on a pu l'esquisser. Peut-être était-elle accompagnée d'un parèdre masculin ${ }^{129}$, comme au grand Dictynnaion, où la tradition hésite entre $\operatorname{Pan}^{130}$ et Tityros ${ }^{131}$ - qui ne sont probablement que des interpretationes récentes d'un dieu crétois méconnu, compagnon de la déesse n'ayant plus conservé que son aspect champêtre et pastoral ${ }^{132}$. 
Il n'est pas impossible que Dictynna ait été aussi honorée un temps dans l'une des grottes situées à proximité immédiate de la ville: l'une d'elles, appelée aujourd'hui $\Lambda a \chi T a p l \delta \epsilon \varsigma$, contient une concrétion calcaire en forme d'idole, qui a pu servir d'image de culte ${ }^{133}$. Mais son caractère trop « sauvage » et peut-être aussi trop «local » a sans doute amené son effacement dans la cité même ${ }^{134}$ : le nom du mois est son unique trace explicite à époque historique et c'est sa concurrente panhellénique qui semble avoir triomphé.

De fait, le seul temple qui soit attesté épigraphiquement est celui d'Artémis Aptera, mentionné dans le second décret pour l'asylie de Téos postérieur à 170 av. J.- C. -, comme étant le lieu où ce document et celui qui l'avait précédé devaient être exposés (IC, 2, 3, 2, lin. 33-36):
.... . 'Ava

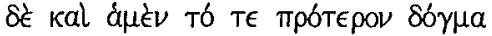
35

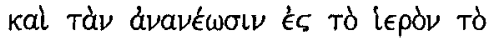

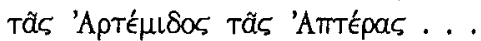

Cela signifie sans doute qu'il s'agissait alors du principal sanctuaire urbain, mais le fait que le premier décret n'y eût pas été placé d'emblée laisse supposer que cet usage était récent ${ }^{135}$. Le sanctuaire d'Artémis évoqué dans l'inscription doit sans doute être reconnu dans le grand temple à deux cellae étudié par H. Drerup ${ }^{136}$. Mais la dualité du culte est un indice supplémentaire de son ancienneté.

L'identité du nom de la cité et de l'épithète de la déesse - qui n'est attestée qu'ici - implique nécessairement un lien entre les deux; mais il faut alors se demander qui a donné son nom à l'autre. Si l'on part de l'épithète, on est naturellement tenté d'admettre le sens que lui confère son étymologie apparente, "sans ailes ": il qualifierait le type iconographique de l'Artémis locale, probablement en tant qu'héritière de la Пótvıa onpờ minoenne ${ }^{137}$.

Mais cette interprétation se heurte à de nombreuses difficultés : tout d'abord elle n'est possible que pour une population hellénophone, ce qui interdit précisément de faire remonter l'épithète à l'époque minoenne; ensuite, elle n'aurait de sens que par opposition à un type ailé de la même déesse, qui, justement, n'apparaît jamais en Crète ${ }^{138}$; et puis il faudrait admettre que la cité a été nommée d'après une épithète purement descriptive et non d'après le nom de la déesse, ce qui serait un cas unique ${ }^{139}$. Quant à la forme même du mot, elle pose aussi un double problème : le féminin régulier de l'adjectif est

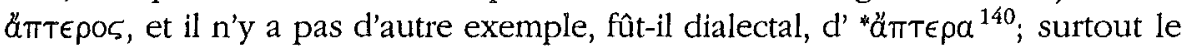


vocalisme médian du nom de la cité est originellement en $\alpha$, ce qui ruine toute possibilité de rapport ancien avec un mot de la famille de $\pi т \epsilon \rho \delta v$.

Il est donc plus vraisemblable que ce soit Artémis qui ait emprunté l'épithète à la cité, ou plus précisément à l'ancienne divinité qu'elle a supplantée en tant que poliade ${ }^{141}$, et qui portait comme épithète le nom de la cité $^{142}$. Celle-ci devait être Dictynna, qui, en tant que chasseresse, lui offrait une succession facile ${ }^{143}$. Et c'est probablement une fausse étymologie qui a provoqué l'altération du vocalisme du nom de la ville, comme de l'épithète.

Pour toutes les sources, cette étymologie est en relation, non pas avec une simple statue de culte, mais bien avec un mythe tout à fait original et propre à la cité. C'est en effet à Aptera qu'est située la légende ${ }^{144}$ de la confrontation entre les Muses et les Sirènes ${ }^{145}$, qu'évoquent, avec des détails qui se complètent, Étienne de Byzance (s.u. "A $A \tau \epsilon \rho a, 107,8 \mathrm{M}$ )

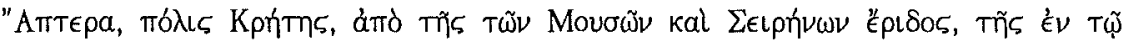

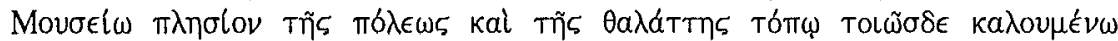

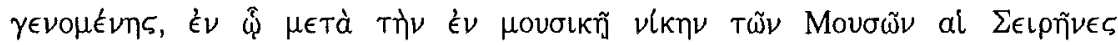

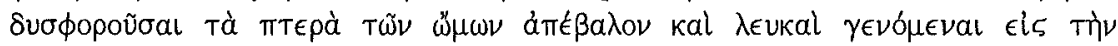

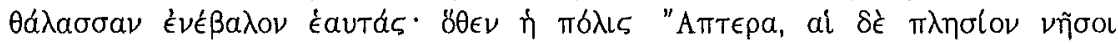
$\Lambda \in \cup \kappa a l$.

et le vieux scholiaste de Lycophron ${ }^{146}$, repris par Tzetzes (in Alex., 653 / 218, 15 Scheer) :

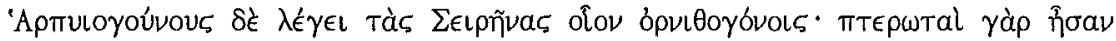

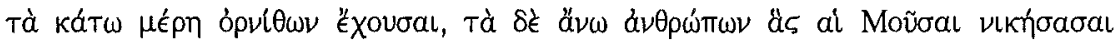

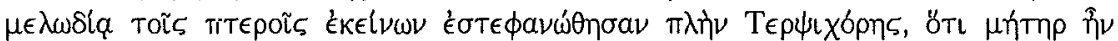

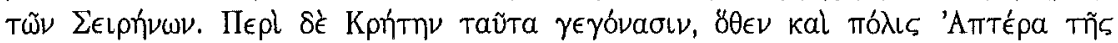

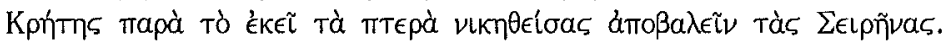

L'attestation tardive ${ }^{147}$ de cette légende a fait penser à une pure création intellectuelle d'époque hellénistique ${ }^{148}$, qui aurait été imaginée pour expliquer la présence d'une couronne de plumes sur certaines statues ${ }^{149}$, et localisée à Aptera ${ }^{150}$ grâce à une approximation étymologique ${ }^{151}$, qui expliquait le nom de la cité comme une référence à la perte de leurs ailes par les Sirènes.

Mais il est difficile de croire que tout soit aussi gratuit ${ }^{152}$ On sait en effet combien sont nombreux dans le monde grec les exemples de

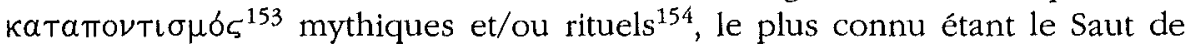
Leucade ${ }^{155}$. Dans tous les cas, le site est caractérisé par des "roches blanches $»^{156}$, considérées comme une porte des Enfers ${ }^{157}$. 
Or il existe précisément au large d'Aptera, près du port de Minoa, trois petites îles appelées $\nu \tilde{\eta} \sigma o l \quad \Lambda \epsilon u K \alpha \iota^{158}$ et la note d'Étienne de Byzance suggère que ce sont les trois Sirènes qui ont été ainsi pétrifiées ${ }^{159}$. On peut penser qu'à tout le moins c'est la présence de ces îles, considérées comme des dépendances d'Aptera, qui a permis la mise en forme de la légende ${ }^{160}$. Les Sirènes convenaient assez bien, à la fois par leur nombre ${ }^{161}$ et par le fait que d'autres récits les concernant ${ }^{162}$ comportaient déjà un plongeon ${ }^{163}$ dans la mer $^{164}$; quant à la perte de leurs plumes, elle fournissait une explication plausible, selon les critères de l'époque, au nom de la cité. Enfin le choix du groupe vainqueur a pu être suggéré, en plus des traits communs qui permet-

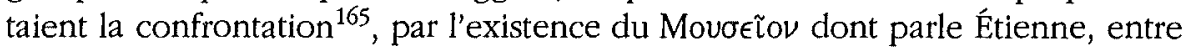
la cité et la mer.

Cependant le mythe d'Aptera fonctionnait sans doute comme altiov d'un rituel analogue à celui que l'on observe sur d'autres « Roches Blanches », à savoir le saut effectif d'êtres humains dans la mer. Mais pour préciser la valeur

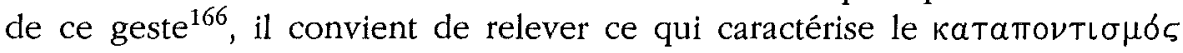
légendaire d'Aptera : le saut dans la mer n'est pas individuel, il concerne un groupe de trois personnages féminins; et il intervient à la suite d'une compétition musicale.

Or l'une des significations possibles du saut, particulièrement dans le contexte crétois, c'est d'être l'une des épreuves du processus d'initiation des jeunes gens : c'est le cas par exemple pour Thèsée ${ }^{167} \mathrm{ou}$, par transposition, pour Glaucos ${ }^{168}$. On sait d'autre part que cette initiation se déroulait au sein de

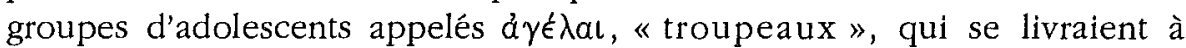
diverses compétitions, notamment de course à pied et de danse ${ }^{169}$. On peut donc se demander si la mésaventure des Sirènes d'Aptera ne correspond pas à un un rituel comparable, mais destiné aux jeunes filles ${ }^{170}$, et dans lequel la musique aurait joué un rôle central ${ }^{171}$.

Il est bien difficile de déterminer quand - ou jusqu'à quand - de telles initiations féminines ont pu avoir lieu. Nos sources ${ }^{172}$ ne nous informent que sur les initiations masculines et encore nous révèlent-elles à quel point elles ont dégénéré à l'époque hellénistique ${ }^{173}$. Il n'en reste pas moins qu'un processus parallèle a dû anciennement exister pour les jeunes filles, puisque a longtemps subsisté au moins l'aboutissement commun : les mariages simultanés pour les adolescents des deux sexes appartenant aux classes d'âge correspondantes ${ }^{174}$.

Ces considérations conduisent à admettre que la légende des Sirènes d'Aptera n'est pas une invention d'époque récente ${ }^{175}$, mais qu'elle contient au moins un noyau de grande antiquité, comme tous les récits qui se situent autour de Roches Blanches ${ }^{176}$. Et c'est vraisemblablement sa popularité qui a suggéré

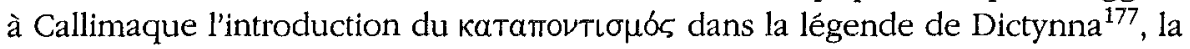
déesse la plus importante de la région, honorée anciennement dans la cité. 
De fait, cette popularité s'était même étendue au-delà de la Crète, puisque la légende servait à Coronée, en Béotie ${ }^{178}$ pour expliquer pourquoi la statue de culte d'Hèra ${ }^{179}$ portait des Sirènes dans la main ${ }^{180}$ : les guides locaux, informateurs de Pausanias $(9,34,4)$ prétendaient que c'était Hèra qui avait incité les Sirènes à défier les Muses ${ }^{181}$ :

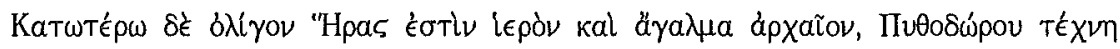

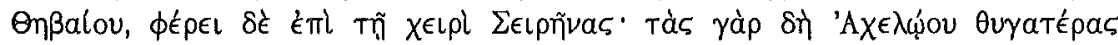

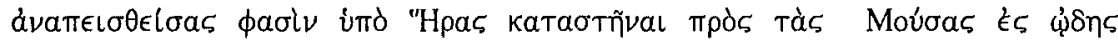

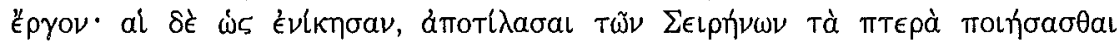

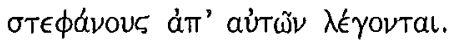

mais peut-être cela signifiait-il plutôt que les «troupeaux » de jeunes filles à initier étaient placées sous la protection de celle qui était alors la déesse la plus importante du panthéon grec $^{182}$.

D'autres divinités étaient honorées à Aptera, mais sans que l'on ait beaucoup d'informations sur elles ${ }^{183}$.

Les monnaies ${ }^{184}$ nous font connaître les principales, Hèra ${ }^{185}$ et Zeus ${ }^{186}$ tout d'abord, le second apparaissant aussi sous l'aspect de Zeus Ammon ${ }^{187}$; une certaine ferveur pour ce dieu peut être attestée par l'anthroponyme théophore

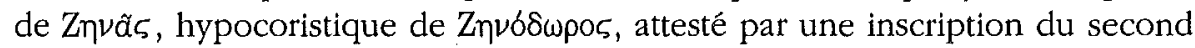
siècle ap. J.-C. (IC, $2,3,46)$. C'est Hermès qui apparaît au revers de la monnaie de Zeus ${ }^{188}$, tandis qu'un autre type ${ }^{189}$ représente Apollon, avec une lyre ${ }^{190}$.

Des traces de dévotion particulière apparaissent aussi pour deux déesses: Eleuthyia ${ }^{191}$, objet d'une dédicace signalée par C. Wescher - qui n'a malheureusement relevé que le nom de la divinité ${ }^{192}$ - et aujourd'hui perdue $(I C, 2$, 3 , 22); et Hygie ${ }^{193}$ (Fig, 2), dont une statue acéphale en marbre d'époque hellénistique, provenant d'Aptera ${ }^{194}$, est conservée au musée de La Canée ${ }^{195}$.

Enfin Aptera célébrait des jeux, dont le vainqueur recevait une couronne. La seule attestation figure dans un décret $(I C, 2,3,4 \mathrm{C})$ en l'honneur d'Attale II de Pergame (159-138 av. J.- C.), à qui il est proposé de voir les privilèges qui

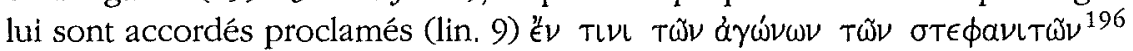

L'expression suggère qu'il s'agit d'une manifestation célébrée assez fréquemment pour qu'il ne fût pas nécessaire de prévoir à l'avance une date précise, mais en même temps suffisamment solennelle pour que le roi pût se sentir particulièrement honoré d'y être fêté - et d'y recevoir notamment la 


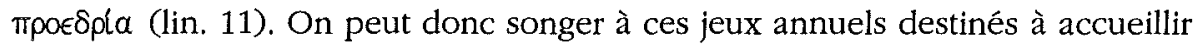
les jeunes citoyens au sortir de leur période d'initiation ${ }^{197}$, qui nous sont connus dans bien d'autres cités crétoises ${ }^{198}$. On sait que c'est à cette occasion qu'étaient renouvelés les serments aux traités internationaux ${ }^{199}$ : en l'occurrence, il s'agit d'un autre genre d'acte, mais qui vise aussi à assurer de bonnes relations avec une puissance étrangère ${ }^{200}$.

Malgré la relative faiblesse de la documentation, littéraire, épigraphique et archéologique, la cité d'Aptera présente bien, sur le plan religieux, ce que l'on peut attendre d'une cité crétoise moyenne. On y distingue toutes les composantes habituelles: souvenirs encore très vivants de l'époque minoenne, adoption plus ou moins formelle des grandes divinités grecques, développement de légendes hellénistiques.

La richesse de sa vie religieuse est sans doute allée de pair avec la prospérité économique que lui valait sa situation privilégiée; c'est aussi cette dernière qui explique probablement que s'y soient fixés successivement le mythe de Dictynna, en concurrence avec Cydonia, puis celui des Sirènes, auquel la cité, favorisée par son nom même, fut cette fois la seule à prétendre.

Université de Paris IV - Sorbonne

Gérard CAPDEviLLE

1 , rue Victor Cousin

F - 75005 PARIS

Nous remercions Monsieur Paul Faure pour les précisions topographiques et toponymiques qu'il a bien voulu nous fournir. 

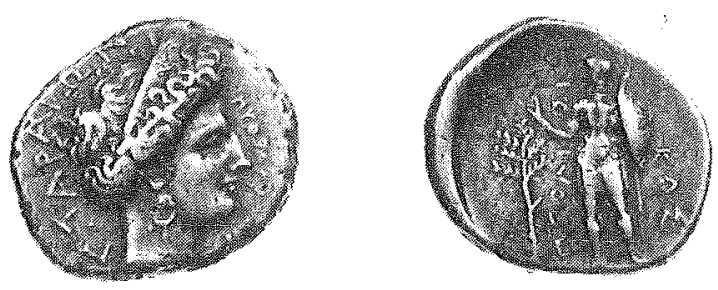

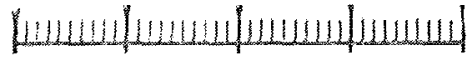

Fig. 1 : Monnaies d'Axos : Tête de femme (Artémis Aptera ?)

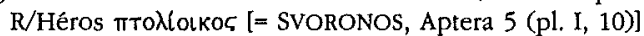

(Bibliothèque Nationale de France, Cabinet des Médailles $n^{\circ}$ inv. FG 4).

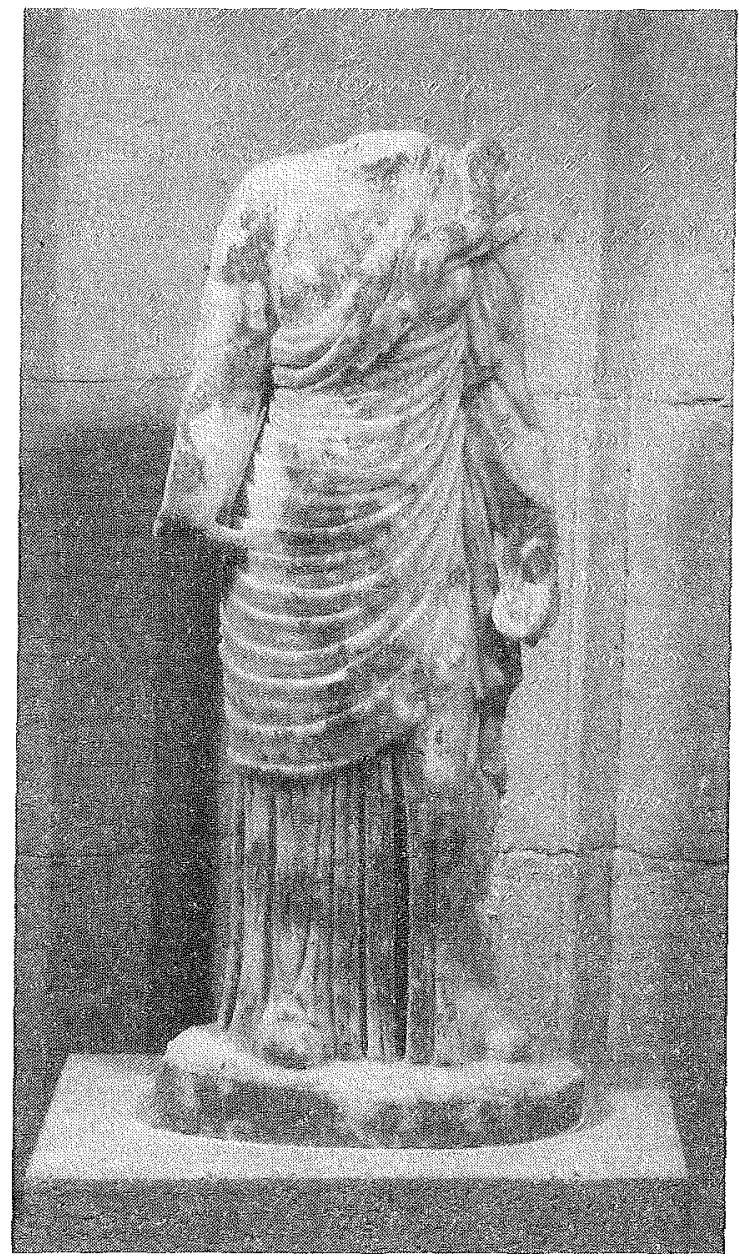

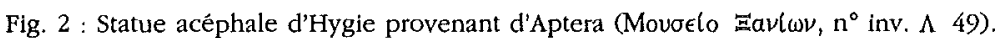


1 Sur cette citê, v. la notice de M. GuARDuCCI, Inscriptiones Creticae, Rome, 1935-1950 [cité IG] II. Tituli Cretae Occidentalis (1939), 3 Aptera, p. 9-13.

2 La forme la plus autorisée du nom paraît avoir été “Atrapa, comme l'atteste la quasi-totalité des monnaies portant l'ethnique au génitif (éventuellement abrégé) : AMTAPAI $N$. L'unique exception, avec AITEPAI NN, correspond au premier des types recensés par J.-N. SVORONOS, Numismatique de la Crète ancienne, accompagnée de l'Histolre, la Géograpble et la Mythologie de l'Tle. I. Description des monnales. Histoire et géograpble, Mâcon, 1890 [réimpr. avec Addenda

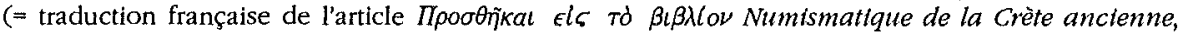
in $E A, 1889$ [1890], 193-212 + pl. 11-13), Bonn, 1972; cité Numismatique], s. u. Aptéra, 11-24, p. 14-15, $\mathrm{n}^{\text {os }} 1-4(=\mathrm{pl} .1,7-9)$; mais on sait que l'auteur n'indique explicitement aucune chronologie dans son classement. Du reste, c'est le type que G. LE RIDER, Monnates crétolses du $V^{e}$ au $f^{e r}$ siècle av. J.-C. (= Études Crétolses, 15), Paris, 1966 [cité Monnates], p. 36, classe le dernier dans son inventaire des monnaies d'Aptera appartenant au "Trésor de 1953 " ( ${ }^{\text {os }} 273-274=$ pl. IX, 16-17), mais là encore sans indication chronologique relative; plus loin (p. 190), l'auteur mentionne Aptera parmi les cités qui n'ouvrent un atelier monétaire qu'après 330 av. J.- C., en commençant par la surfrappe de monnaies étrangères. Comme ses émissions cessent avant la conquête romaine, toutes les monnaies connues se groupent donc dans un laps de temps assez court, ce qui rend difficile l'appréciation de cette variante unique. - Les inscriptions, en revanche, fournissent souvent le nom de la cité ou l'ethnique avec un $\epsilon$; mais ceci vaut surtout pour les textes gravês à l'étranger, comme les décrets pour l'asylie de 'Téos retrouvés dans cette île $(I C, 2,3$ Aptera, 1, lin. 10; 2, lin. 1, 2, 26, 47, 52, 55-56), alors que le décret en l'honneur d'Attale II de Pergame, gravé localement $(I C, 2,3,4 \mathrm{C}$, lin. 4) porte' A $\pi$ Tapal $\omega \nu$. Particulièrement significatif sur ce point est le décret d'Aptera en l'honneur d'un médecin de Cos, gravé dans cette île $(I C, 2,3,3)$, où la suscription (lin. 1), due aux

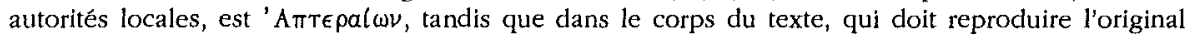

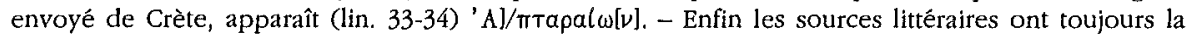
forme en $\epsilon$ ( $v$. les textes cités ou mentionnés dans les notes $3,9,11$ ), à l'exception d'HESYCHIUS (s.u.'A donc penser - avec notamment $M$. GUARDUCCI, $I C, 2,3$, p. 9 (cf. p. 16, 17) - que le vocalisme originel, $a$, a été, dans l'usage, modifié sous l'influence des diverses explications étymologiques (v. ci-dessous), tandis que la graphie ancienne restait celle des documents officiels (contra M. BrLE, Le dialecte crétols ancien. Étude de la langue des inscriptions. Recueil des inscriptions postérteures aux IC [ $=$ Ecole Françalse d'Atbènes. Ëtudes Crétolses, 27], Athènes - Paris, 1988 [cité BILE], p. 80, qui affirme, mais sans donner d'argument, que «la forme de base semble en $e$ »). Les hypothèses sur l'origine «pré-hellénique» du mot (v. e.g. A. FICK, Vorgriechiscbe Ortsnamen als Quelle fur die Vorgeschichte Griechenlands, Göttingen, 1905, p. 17-18, qui rapproche le nom de

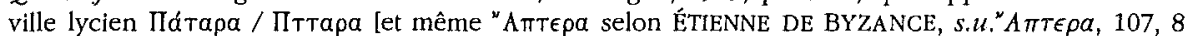
$<15>$ Ml; A. MAIURI, Studi sull'onomastica cretese (I), in RAL, S. 5a, 19 (1910), 329-363, p. 335-336, qui propose le thrace "A $\beta \delta \eta \rho \alpha$ [attesté comme nom d'une ville des Sintiens par STRABON, 12, 3, 20, $550 \mathrm{Cl}$ ), ou sur d'éventuelles correspondances dans le monde étrusque (v. e.g. A. KANNENGIESSER, Aegälsche, besonders kretische Namen bei den Etruskern, in Klio, 11 [1911], 26-47, p. 27, qui cite les Aptronii mentionnés sur deux inscriptions funéraires de Préneste [CL, 14, 3063-3064]), sont trop fragiles pour apporter un argument dans un sens ou dans l'autre. - Le village moderne, situé à

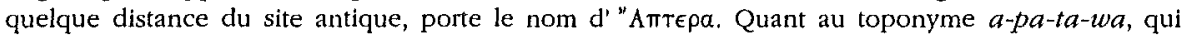
figure sur plusieurs tablettes «mycéniennes» de Cnosos (KN Ce 144, lin. 2; C 902, lin. 9; Co $909+$ $7133+7835$, lin. 1; dérivés a-pa-ta wa-ja: V 7670 B; a-pa-ta-wa-jo: Am 826, lin. 1; v. J. CHADWICK, L. GODART, J.T. KIlleN, J.-P. OlIVIER, A. SACCONI, I.A. SAKELlARAKIS, Corpus of Mycenaean Inscriptions from Knossos [= Incunabula Graeca, 88], 1, Rome, 1986, p. 65, 366, 371; 323; cf. en dernier lieu L. GODART, Y. TZEDAKIS, Témoignages archéologiques et épigraphlques en Crète occidentale du Néolitbique au Minoen Récent III B [= Incunabula Graeca, 93], Rome, 1992, p. $195 ; 222-224 ; 254-256 ; 259-266$ ), il confirmerait l'ancienneté du vocalisme $a$, si l'on était sûr qu'il s'agisse bien de cette cité, malgré la finale différente; il faudrait alors envisager un ancien -Amtapfa (cf. M. VENTRIS, J. CHADWICK, Documents in Mycenaean Greek. Three Hundred Selected Tablets from Knossos, Pylos and Mycenae, with Commentary and Vocabulary, Cambridge, 1956 [2nd. ed. Cambridge, 1973], n ${ }^{\text {os }} 47$ [= Am 826], p. 179-180; 83 [= C 902], p. 211-212 [cf. p. 213]). 
3 La localisation de la cité est indiquée par divers témoins anciens, les plus précis étant STRABON $(10,4,13,479 \mathrm{C})$ sans doute d'après ARTÉmIDORE (cf. F. LASSERRE, éd. CUF, 1971, Notice,

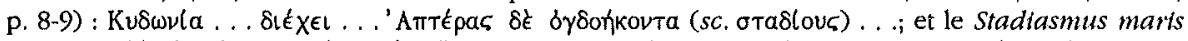

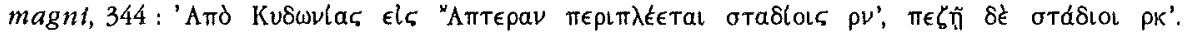
PLINE (N.H., 4, 59), la cite parmi les villes côtières de la Crète : Oppida elus insigna ... Cydonea Minolum Apteron ... En revanche, la mention assez vague du PS. SCYLAX (Peripl., 47) - Прд $\zeta$

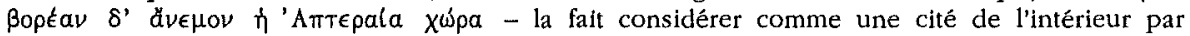

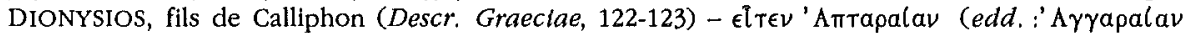

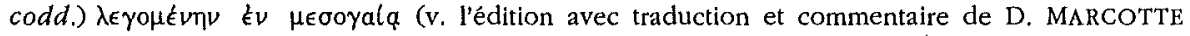
[= Académie Royale de Belgique. Classe des Lettres, Fonds René Draguet, 6], Louvain, 1990, qui semble ignorer [p. 182], que les ruines ont été identifiées !) - et PTOLÉMÉE $(3,15,7)$, qui la cite

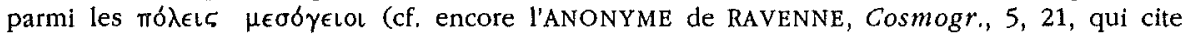
simplement Abtera [sic] parmi les villes de Crète, dans une séquence ... Lappa Abtera Cydonea Cisamos ...). En fait, si la cité elle-même est sur une éminence à quelque distance de la côte, son territoire comporte un long tracé de rivage (v. n. suiv.).

4 Ces ruines ont toujours frappé les voyageurs, notamment les murailles cyclopéennes, qui sont parmi les plus belles de la Crète - et aussi les énormes citernes d'époque romaine : voir déjà le récit de voyage (entre 1415 et 1418 ) de Chr. BUONDELMONTI, Descriptio insule Candie, publié pour la première fois par F. CORNARO, Creta Sacra, t. 1, Venise, 1755, 77-109 (pour le site, lin. 520530 de l'Édition critique [avec traduction] par M.-A. VAN SPITAEL [et Commentaire de P. FAURE], Heracleion, 1981), qui les prend pour les ruines de Minoa (v. ci-dessous) - et tombe dans l'une des citernes ! - et celui (1583-1584) de Nicolas RADZIWILL, Peregrinatio Hierosolymitana, BraniewoBrunsberg, 1601 - évoqué par B. RUTKOWSKI, Les antiquités crétoises dans la relation d'un voyageur polonais du XVF stècle, in $B C H, 92$ (1968), 85-96, qui cite, p. 95-96, le passage (daté du 7 décembre 1583) concernant notre cité, restée anonyme. On a encore une description chez R. POCOCKE, A Description of the East and some other Countries, Londres, 1743-1745, 2, 1 (1745), p. 262, qui propose aussi d'y reconnaitre Minoa et remarque surtout les citernes. L'identification, proposée par R. PASHLEY, Travels in Crete, Londres, 1837 [réimpr. Amsterdam, 1970], p. 36-60 (spec. p. 42-49), après un minutieux examen des textes et des monnaies trouvées sur place, a été confirmée grâce au mur d'inscriptions découvert par le premier véritable archéologue à avoir étudié le site, C. WESCHER, Rapport sur les foulles d'Aptère adressé à Son Excellence M. Duruy, Ministre de I'Instruction Publique, in Arcbives des Missions Scientifiques et Littéraires. Cboix de Rapports et Instructions, $2^{\mathrm{e}}$ s., 1, 1864, 439-444; Foutlles d'Aptère. Découverte d'inscriptions crétotses, Lettre adressée à $M$. le directeur de la Revue Archéologique, in $R A$, NS 10 (1864), 75-78 (cf. la synthèse de L. MARIANI, Antichità cretesi, in MonAL, 6 (1895), 153-348, c. 208-210 [+ pl. VIII : photos des muraillesl. - Les premiers travaux importants n'ont cependant été effectués que lors de l'occupation allemande au cours de la seconde guerre mondiale: voir les deux rapports de H. DRERUP, Palaokastro-Aptara. Bericbt laber etne Untersuchung und Vermessung des Stadtgebietes et Zweizelliges Heillgtum in Aptara, ap. F. MATZ (Hsg.), Forschungen auf Kreta 1942, Berlìn, 1951, 89-98 (+ pl. 66-70); 99-105 (+ pl. 71-75). Plus récemment, des fouilles ont été menées par St. ALEXIOU en 1958 (v. G. DAUX, Chronique des foullles et des découvertes archéologiques en Grèce en 1958, in $B C H, 83$ [1959], 567-793, p. 749-753). Toutes les trouvailles significatives, inscriptions et statues, sont rassemblées au musée de La Canée ( $v, G$. DAUX, Chronique des fouilles et des découvertes archéologiques en Grèce en 1957, in BCH, 82 [1958],

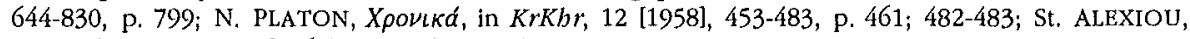

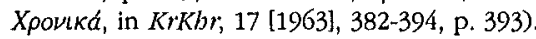

5 Ce village est situé à l'emplacement de la nécropole de la cité antique (cf. M. GuARDUCCI, IC, 2, 3, p. 9).

6 Les décrets mis au jour par C. WESCHER ont été publiés par B. HAUSSOULIER, Inscriptions d'Aptéra (Crète), in $B C H, 3$ (1879), 418-437; ils sont reproduits par M. GUARDUCCI, $Y C, 2,3, \mathrm{n}^{\text {os }} 4 ; 6-13$. Le mur sur lequel ils étaient fixés a aujourd'hui disparu (cf. G. DAUX, o.c. [n. 4] in BCH, 83 [1959], $567-793$, p. 750). Quelques autres décrets ont été découverts postérieurement $\left(I C, 2,3, \mathrm{n}^{\text {os }} 5 ; 14-15\right)$, ainsi qu'un fragment de traité avec Cydonia (cf. N. PLATON, o.c. [n. 4], p. 482-483; G. DAUX, ibid., p. $752=$ BILE 36 ). 
7 Les seules indications sur ce port sont fournies par STRABON (10, 4, 13, $479 \mathrm{C})$ : 'A

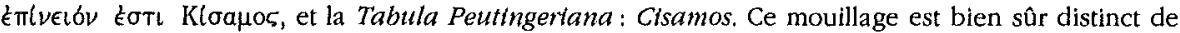

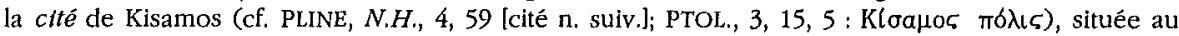
fond du golfe de Myrtilo, entre les deux grandes péninsules du nord-ouest de la Crète (sur cette cité, v. la notice de M. GUARDUCCI, IC, 2, 8 Cisamos, p. 94-97). Selon P. FAURE, La Crète aux cent

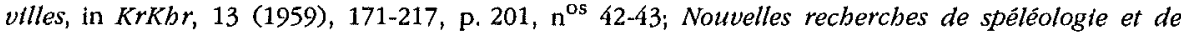

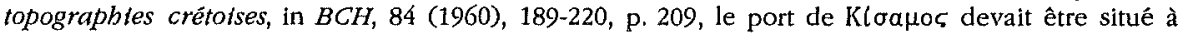

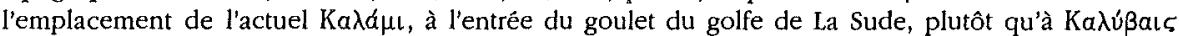
(Kalyves), l'emplacement habituellement désigné (v. R. PASHLEY, o.c. [n. 4], 1, p. 48-49; L. MARIANI, o.c. [n. 4], 6, 1895, p. 208; suivis par M. GUARDUCCI, IC, 2, 3, p. 11), mais qui ne bénéficie pas de la protection naturelle de la presqu'île de l'Akrotiri. - Sur le nom, également «pré-hellénique », v.

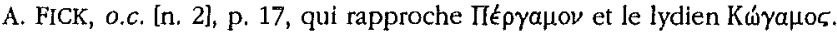

8 La forme n'est pas assurée : PLINE (N.H., 4, 59) donne Minolum; PTOLÉMÉE $(3,15,5)$

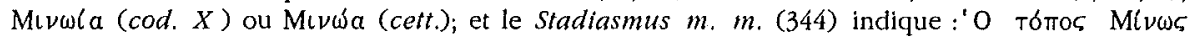

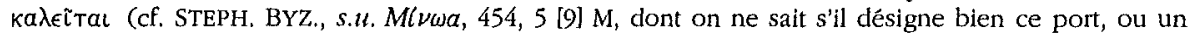
autre (v. infra, n. 53]). - Le site correspond à la baie située au pied du village actuel de $\Sigma$ TE $\rho v^{\prime} \zeta$ et

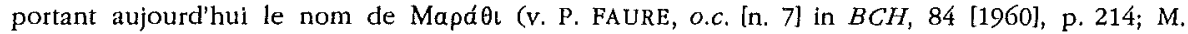

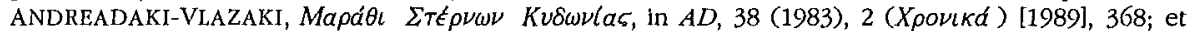
infra, p. 48; c'est par erreur que M. GUARDUCCI, $I C, 2,3$, p. 11 - peut-être par une mauvaise lecture d'une carte de PTOLÉMÉE - attribue ce nom à l'une des îles situées au large de ce port).

9 L'affirmation de l'appartenance de Minoa au territoire d'Aptera semble avoir reposé à l'origine sur une interprétation forcée du texte de PLINE $(N . H .4,59)$, qui énumère: Oppida elus insigna Pbalasarna Elaea Cisamon Pergamum Gydonea Minoium Apteron Pantomatrium ... -, les premiers commentateurs ayant compris Apteron comme un génitif de l'ethnique, ce qui, somme toute, n'est guère vraisemblable, puisqu'il n'y a aucun nom double dans le reste de la liste. Cependant, même s'il s'agit d'une transcription du nom de la cité, cela n'exclut pas que le port ait pu appartenir à Aptera. La seule objection est venue de M. GUARDUCCI, Contribull alla topografla della Creta occidentale, in RFIC, NS 14 [=64] (1936), 153-162, p. 159-161 (résumé dans IC, 2, 3 Aptera, Vicinla Apterae, p. 11;2, 10 Cydonia, 1, comm. ad lin. 12 [p. 117]), qui a noté que, dans une inscription de Cydonia, datant vraisemblablement de la deuxième moitiê du $\operatorname{II}^{\mathrm{e}}$ s. av J.-C. (IC, 2,10 Cydonia, 1), et accordant des concessions de terres à des proxènes, l'une des parcelles était située

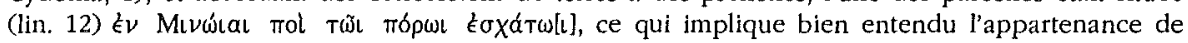
cette localité à Cydonia. Mais, curieusement, cette objection n'a guère été prise en considération par les autres commentateurs. Il est vrai qu'à la possession de ce port semble liée celle des îles $\Lambda \in$ UKal, le mópos de l'inscription désignant vraisemblablement le détroit qui sépare les îles du continent. Or si, dans la logique de son raisonnement, M. GUARDUCCI, o.c. in RFIC, NS 14 (1936), p. 161-162 (cf. IC, 2, 3 Aptera, p. 10-11; 10 Cydonia, p. 106; 117), les attribue à Cydonia, la localisation à Aptera du mythe des Sirènes, qui leur est associé, comme on le verra ci-dessous, paraît plaider en faveur d'Aptera. M. GUARDUCCI exclut la possibilité d'une possession seulement temporaire de Muvóa par Cydonia, en notant que cette cité était plus puissante qu'Aptera. Mais c'est peut-être privilégier indûment une évolution linéaire des rapports entre ces deux cités, alors que tout ce que l'on connaît de l'histoire de la Crète abonde en retournements de situation. Ainsi, dans cette même inscription de Cydonia, une autre parcelle est située (lin. 15) $k \pi l \Lambda \iota t \pi a ́ p a l$, ce qui implique aussi l'appartenance de cette localité à Cydonia; pourtant l'ethnique double $\Lambda ı$ trapaíos Koŕs apparaît dans une inscription d'époque hellénistique du sanctuaire de Pan à Redesiye, dans le désert arabique (publ. par F. PREISIGKE, Sammelbucb Griechischer Urkunden aus Ägypten, 1, Strasbourg, $1915, \mathrm{n}^{\circ} 4057$, p. 278 , d'après W. SCHWARTZ, Die Inschriften des Wïstentempels von Redesiye, in NJPbP, 153 [1896], 145-170, $n^{\circ} 16$, p. 160-161), ce qui indique qu'à un certain moment Lipara a dû être une cité indépendante, comme le propose L. ROBERT, Études épigraphiques et phllologiques $(=$ BEHE IV, 272), Paris, 1938, p. 251[-252], n. 8. On peut aussi penser au grand temple de la déesse Dictynna, sur la presqu'île du Rhodopou, qui semble avoir appartenu alternativement à Cydonia et à Polyrhenia (v. la notice de M. GuARDUCCI, IC, 2, 11 Dictynnaeum, Historica, p. 129), au point qu'à quelques lignes d'intervalle STRABON $(10,4,12-13,479 \mathrm{C})$ en attribue le contrôle à l'une puis à l'autre cité, sans relever la contradiction. 
10 Ce qui a été dit à la note précédente laisse à penser combien il est difficile de préciser jusqu'où pouvait s'étendre l'arrière-pays dépendant d'Aptera. Il faut tenir compte de l'existence, au nord, de la petite cité d' 'Iorol (v. infra, n. 72), identifiée par P. FAURE, o.c. [n. 7] in BCH, 84 (1960),

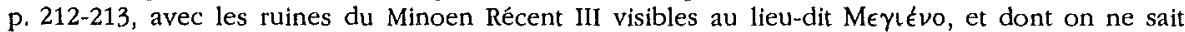
combien de temps elle préserva son indépendance. Mais c'est Cydonia qui, de toute façon, devait contrôler la majeure partie de la presqu'île, et notamment l'isthme, dont elle occupait le côté occidental, tout en possédant sans doute un port sur le côté oriental, au fond du golfe de La Sude (cf. P. FAURE, ibid., p. 214).

11 Les commentateurs - p. ex. J.-N. SVORONOS, Numismatique, p. 10 - notent qu'elle n'a guère fait parler d'elle dans l'histoire. Elle avait cependant, comme Lyttos et d'autres cités crétoises (v. PAUS., 4, 19, 4), fourni à Sparte des archers, commandés par le Lacédémonien Euryalos, lors de la guerre de Messénie, au VII ${ }^{\mathrm{e}}$ s. av. J.- C. (PAUS, , 4, 20, 8 : то mercenaire d'Aptera, topujours dans le camp spartiate, lors de la guerre contre Pyrrhus, en 273-272 (cf. PluT., Pyrrb., 30, 6, cité infra, n. 198). Mais la cité elle-même reste très discrète. Elle ne figure pas parmi les signataires des traités avec Milet en 260 - alors que ses voisines Cydonia et Phalasarna sont parmi les alliées de $\operatorname{Cnosos}(I C, 1,8$ Cnosos, 6, lin. 39) et Polyrhenia associée à Phaistos (IC, 1, 23 Phaistos, 1, lin. 67). Sa seule intervention connue dans les événements crétois est son passage forcé du camp de Cnosos, alliée des Étoliens, à celui de Polyrhenia et de Lappa, alliées de Philippe et des Achéens, après la destruction de Lyttos, en 220 (POLYBE, 4, 55, 4). Elle fait ensuite partie des cités quil accordent par deux fois (201 et c. 170) l'asylie à Téos (IC, 2, 3 Aptera, 1; 2), puis signe le traité avec Eumène de Pergame en 183 (IC, 4, Gortyna, 179, lin. 4 : 'Aтtapaĩo).

12 La forme 'A la forme dans le mythe (cf. infra, p. 42). Sur ce personnage, v. O. JESSEN, s.u. Apteros 2, in RE, 2 (1895), 287; et aussi U. HÖFER, s.u. Pteras, ap. W.H. ROSCHER, $L M, 3$ (1897-1909), 3259-3261, c. 3261; G. RADKE, s.u, Pteras, in $R E, 23,2$ (1959), 1485-1488, c. 1487. - La faiblesse des attestations littéraires et l'absence de généalogie pourraient suggérer une création ad $b o c$, selon un procédé utilisé ailleurs pour justifier un nom de ville sans étymologie; cependant, si c'était le cas, il faudrait situer cette création à haute époque, puisque le héros est associé aux origines mêmes de la crète. On peut aussi se demander s'il n'y a pas eu, à date plus récente, une certaine confusion avec Aster(i)os, autre souverain mythique de Crète (v. infra, n, 18; 30).

13 Cf. GEORGES LE SYNCELLE (Cbron., 157 a / 296, 19 Dindorf / 184, 4 Mooshammer) : Kptíns

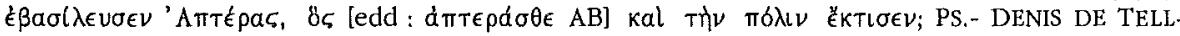
MAHARÉ (cité ici dans la traduction latine du texte syriaque par J.-B. CHABOT [= CSCO, 121], Louvain, 1949, p. 18, lin. 32) : Anno DXIV condita est Creta et in ea regnaut Apterus (ed. :'AлtEpas in app.), qui ipse eam condidit (l'année indiquée, calculée depuis Abraham, correspond à 1502 avant l'ère chrétienne, puisque la naissance du Christ est datée de l'an 2016 après Abraham [p. 45, lin. 4-5]). On a l'impression qu'au fil des traductions successives se produit une certaine confusion entre la Crète tout entière et la cité précisément fondée par Apteras.

14 Eusèse ne fournit qu'une seule date pour Apteras, alors qu'il en donne plusieurs pour certains personnages ou certains événements; ainsi l'enlèvement d'Europe est successivement daté de 1444 (Chron. can., $47 \mathrm{~g} \mathrm{Helm}^{2}$ ), 1434 (47 1), 1318 (53 e), 1286 (55 e)

15 On sait que l'une de des sources d'EUSÈBE fut le travail d'ÉRATOSTHÈNE de Cyrène, une cité dont les liens avec la Crète étaient anciens et étroits (cf. infra, p. 44). Selon A. BURN, Dates in early) Greek bistory, in JHS, 55, 1935, 130-146 (spéc. p. 141), ÉRATOSTHÈNE aurait reconstitué la chronologie des événements antérieurs à $500 \mathrm{av}, \mathrm{J} . \mathrm{C}$. - date des premières ouvres historiques, avec notamment HÉCATÉE DE MILET -, en adoptant une durée moyenne de 40 ans par génération, au lieu du chiffre plus réaliste de 30 ans, d'où des écarts de plus en plus grands, au fur et à mesure que l'on remonte dans le temps, entre les dates ainsi calculées et celles qui pouvaient être fournies par des synchronismes extérieurs. D'autres systèmes ont sans doute existé, ce qui expliquerait les dates multiples pour les événements les plus importants.

16 Cres est considéré comme le premier roi et l'éponyme de l'île (cf. DIOD. SIC., 5, 64,1; ANAXIMANDRE, 'Howodoyla (?), $F G H, 5 \mathrm{~F} 2 \mathrm{~J}$ = ap. PLIN., N.H., 4, 58 et SOLIN., 11, 4; STEPH. BYZ., s.u. KpnTm, 383, 21 [384, 1] M; ISID., Or, 14, 6, 15; EUST., in DION., Perleg., 498; v. J. TAMBORnINo, s.u. Kres, in $R E, 11,2$ [1922], 1714; H. VON GEISAU, s.u., in KP, 3 [1969], 337). EUSĖBE lui attribue 
successivement trois dates : 1962 av. J.-C. (Cbron, can., $22 \mathrm{c} \mathrm{Helm}^{2}$ ), 1957 (22 d), 1887 (26 f); cf. SYNCEL., 105 a / 196, $14 \mathrm{D} / 119,24 \mathrm{M} ; 125 \mathrm{~d} / 236,19 \mathrm{D} / 145,19 \mathrm{M}$.

17 Cydon, éponyme de Cydonia (v. infra, p. 42), n'apparaît qu'à une seule date : 1546 av. J.-C. (40 1); pourtant la mythologie le considérait comme un petit-filsde Minos (v. n. 45), daté par

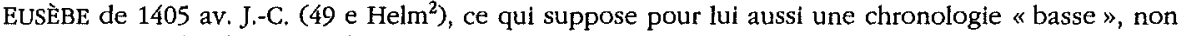
reprise ici par le chronographe.

18 Le nom de ce personnage est attesté sous diverses formes :'A $\sigma \tau \epsilon \rho l \omega \nu$ (HES., $\Gamma \nu \nu a \iota \kappa \omega \nu$

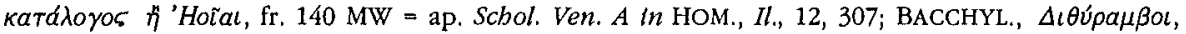

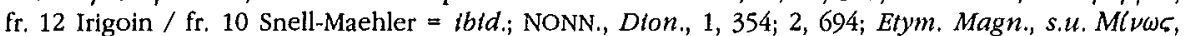

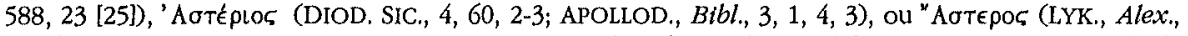
1301); v. K. WERNICKE, s.u. Asterion 5, in RE, 2 (1895), 1784-1785 (cf. ID., s.u. Astertos 2, ibid., 1786). Selon la version la plus courante, il épousa Europe après la naissance de Minos, Sarpédon et Rhadamanthe, engendrés par Zeus, et il fut leur père nourricier; selon EuSÈBE, qui date son avènement de 1446 ( $47 \mathrm{f}$ ), c'est lui qui fut le véritable père des trois frères, après son mariage avec Europe en 1444 ( $47 \mathrm{~g}$ ); cf. SYNCELL., $152 \mathrm{~d} / 289,2 \mathrm{D} / 179,2 \mathrm{M}$ (qui présente les deux versions). V. R.F. WILLETTS, Cretan Cults and Festivals, Londres, 1962 [cité CCF], p. 166-167.

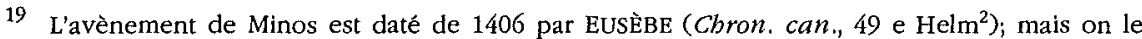
retrouve en 1285 (55 e), à propos de l'enlèvement d'Europe; 1250 (57 a), pour l'établissement de la thalassocratie; 1232 (58 a), avec Thésée et le Minotaure; 1215 (58 d), comme législateur; 1204 (59 g), pour sa mort en Sicile. L'écart entre la première date et les autres pourrait correspondre à deux personnages différents, version rare dans la tradition antique (présentée comme telle par PLUTARQUE, Th., 20, 8, qui cite comme seule source des Naǩlaká anonymes; cf. DIOD. SIC., 4, 60, 3; Marmor Parium, FGH, 239 A 11, lin. 21-23; A 19, lin. 34), mais souvent retenue par les modernes, malgré les incertitudes qui subsistent dans la répartition des événements (cf. encore SYNCELL., 158 b / 298, 16 D / 185, 8 M; 163 a / 308, 2 D / 191, 5 M; PS.-DENIS, p. 21, lin. 17 Chabot [802 ap. Abraham $=1214$ av. J.-C.]).

20 V. J.-N. SVORONOS, Numismatique, p. 14-15, n $\mathrm{n}^{\text {os }} 1-5\left(=\right.$ pl. I, 7-10); p. 16, $\mathrm{n}^{\circ} 15$ (= pl. I, 19); p. $18-19, \mathrm{n}^{\text {os }} 24-30$ (= pl. I, $\left.27-30\right) ;$ p. $20, n^{\text {os }} 39-41$ (= pl. II, 1-2); p. 22-23, n ${ }^{\text {os }} 53-59$ (= pl. II, 11-12); Addenda, p. 361, $n^{\circ} 7$ (= pl. 11, 8); G. LE RIDER, Monnates, p. 36, n ${ }^{\text {os }} 268-274$ (= pl. IX, 12-17); p. 112, $\mathrm{n}^{\circ} 1$ ( $=$ pl. XXVIII, 3); pour le premier exemplaire cité $\left(\mathrm{n}^{\circ} 268\right)$, qui fait partie du «Trésor de

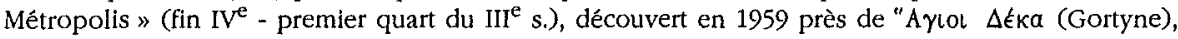
cf, aussi I. VAROUCHA-CHRISTODOULOPOULOU, Acquisitions du Musée numismatique d'Atbènes, in $B C H, 84$ (1960), 485-503 (+ pl. VII-X), p. 490, m 1 (= pl. IX, 1). - Le droit de ces monnaies - sauf les $\mathrm{n}^{\text {os }}$ 39-41 de SVORONOS (Apollon, cf. infra, p. 52 et n. 189) - représente une tête féminine coiffée

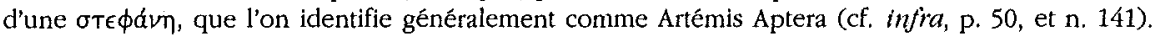

21 V. J.-N. SVORONOS, Numismatique, p. 14-15, $\mathrm{n}^{\circ} 2$ (= pl. I, 9); G. LE RIDER, Monnates, p. 36, $\mathrm{n}^{\text {os }}$ 271-272 (= pl. IX, 14-15), L'ethnique de la cité figurant déjà au droit, on peut éventuellement considérer que le monogramme désigne le personnage.

22 V. J.-N. SVORONOS, Numismatique, p. 14-15, nos $1-2$ et $5(=$ pl. I, 7; 9; 10); G. LE RIDER, Monnaies, p. $36, \mathrm{n}^{\text {os }} 268-274$ (le $^{\circ} 274$ n'a plus que des traces). J.-N. SvORONOS mentionne aussi des variantes, mais si ПTOAIOITO $\Sigma$ est effectivement bien visible sur le $n^{\circ} 3(=$ pl. I, 8), la forme IITOAIOSTOY, attribuée au $n^{\circ} 4$ (non vue par l'auteur et non représentée), est sans doute due à une mauvaise lecture des premiers exégètes (v. J. ECKHEL, Doctrina numorum veterum, Vienne, 17921798, 1, 2 [1794], p. 304).

23 Contrairement à G. LE RIDER, Monnaies, p. 36, 112 - suivi par M. BILE, o.c. [n. 2], p. 156, n. 343 -, mais avec la plupart des commentateurs antérieurs (e.g. J.-N. SVORONOS, o.c. [n. 2] in $E A$ [1889], p. $196=$ Numismatique, $A d d$., p. 361, n 7; U. HÖFER, l.c. [n. 22]; M. GUARDUCGI, $I C, 2$, p. 13 [absent chez R.F. WiLLETTS, $C C F$ ), nous ne pensons pas qu'il s'agisse du nom même du héros représenté, mais d'un qualificatif exprimant ses liens avec la cité.

24 Tel est le sens proposé par H.G. LIDDELL, R. SCOTT, A Greek-English Lexicon (ed. H.S. JONES, R. McKENZIE), Londres, 1940, s.u. mToגlolkos, p. 1548 : "dweller in the city ».

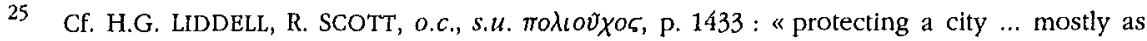
epith. of the guardian deity of a city ", avec de nombreuses références, épigraphiques et littéraires. 
[D.] RAOUL-ROCHETTE, Lettre à M. le duc de Luynes sur les graveurs des monnaies grecques, Paris, 1831, 4, n. 1 (avec fig. p. 49), avait déjà évoqué la possibilité que la légende des monnaies d'Aptera

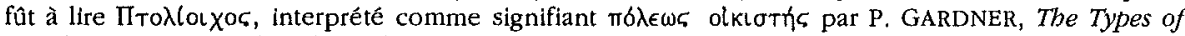
Greek Coins, an archaeological essay, Cambridge, 1883 [réimpr, sous le titre : Arcbeology and the Types of Greek Coins, Chicago, 1965], p. 164 (+ pl. IX, 11) et W. WROTH, A Catalogue of the Greek Colns in the British Museum. Crete and the Aegean Islands, Londres, 1886 [cité BMCC Crete], Introd., p. XXX-XXXI; $\mathrm{n}^{\mathrm{os}} 8,1-3\left(=\right.$ pl. 2, 3-5; cf. $\mathrm{n}^{\circ} 10,1=$ pl. 2, 10), suivis par U. HÖFER, o.c. [n. 12], c. 3261

26 Pour l'initiale, M. BILE, o.c. [n. 2], p. 156, n. 343, note que le crétois ne connaît que $\pi \delta \lambda_{\iota \varsigma}-$

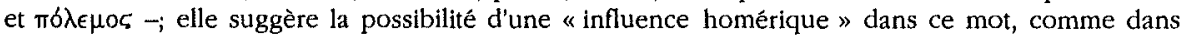
l'épiclèse d'Héraclès (attestée à l'accusatif) $\Pi$ to $\lambda\left(\pi \circ \theta_{0}[\nu](I C, 2,19\right.$ Phalasarna, 7 , lin. 3 [fin du IV

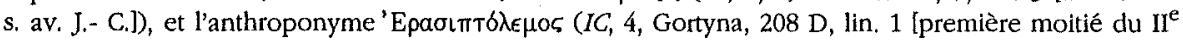
s. av. J.- C.J). Il peut aussi s'agir d'un (faux ?) archaïsme, destiné à ennoblir la tradition en la « vieillissant".

27 Cf. J.-N. SVORONOS, Numismatique, p. $14, \mathrm{n}^{\circ} 1\left(=\right.$ pl. I, 7); p. 16, $\mathrm{n}^{\circ} 15(=$ pl. I, 19); p. 18-19, $\mathrm{n}^{\text {os }} 24-30$ (= pl. I, 27-30); p. 20, nos 39-41 (= pl. II, 1-2); G. LE RIDER, Monnates, p. 36, no $274(=$ pl. IX, 17)

28 Cf. J.-N. SvORONOS, Numismatique, p. 14-15 n²-5 (= pl. I, 8-10); p. 22-23, nos 53-59 (= pl. II,

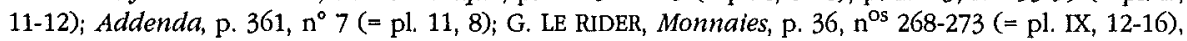
p. $112, \mathrm{n}^{\circ} 1$ (= pl. XXVIII, 3).

29 Cf. J.-N. Svoronos, Numismatique, p. 14-15, $\mathrm{n}^{\text {os }} 2-5$ (= pl. I, 8-10); p. 16, $\mathrm{n}^{\circ} 15$ (= pl. I, 19); p. $18-19, \mathrm{n}^{\text {os }} 24-30$ (= pl. I, 27-30); p. $20, \mathrm{n}^{\text {os }} 39-41$ (= pl. II, 1-2); p. 22-23, nos $53-59$ (= pl. II, 11-12).

30 Les monnaies où l'étoile apparaît sont de celles qui portent aussi l'épithète : v. J.-N, SVORONOS, Numismatique, p. 14-15, $\mathrm{n}^{\text {os }} 1,2,5$ (= pl. I, 7; 9; 10); G. LE RIDER, Monnates, p. 36, $\mathrm{n}^{\circ} 271$ (les autres sont mal lisibles). Cette présence sporadique de l'étoile pourrait être la conséquence d'un rapprochement plus ou moins conscient avec Aster(i)os (cf. supra, n. 18).

31 Il s'agit de la première série de J.-N. SvORONOS, Numismatique, p. $14-15, \mathrm{n}^{\text {os }} 1-5$ (= pl I, 710); Addenda, p. 361, nº 7 (= pl. 11, 8), la seule que décrit G. LE RIDER, l.c. (n. 20).

32 Les hypothèses concernant l'espèce de l'arbre sont variées : J.-N. SVORONOS, Numismatique, p. 14, $\mathrm{n}^{\circ} 1$, y voit " probablement un jeune olivier »; F. IMHOOF-BLUMER, O. KELLER, Tier- und Pflanzenbilder auf Mitnzen und Gemmen des klassischen Altertums, Leipzig, 1889 [réimpr. par A. Forni, Sala Bolognese (BO), 1976), p. 56, $\mathrm{n}^{\circ} 20(=\mathrm{pl}$. IX, 20), proposent un pin, "Föhre " (pour la monnaie du type $\mathrm{n}^{\circ} 5=\mathrm{pl}$. I, $10 \mathrm{de} \mathrm{J}$.-N. SVORONOS); E.S.C. ROBINSON, Greek Coins acquired by the British Musetm in 1930-31, in NC, 5th. s., 12, 1932, 199-214 (+ pl. XVI), p. 203-204, $n^{\circ} 4$ (= pl. XVI, 4), un sapin, «fir » (pour une monnaie identique à ce même type $n^{\circ} 5$ ).

33 E.S.C. ROBINSON, o.c., p. 204, pense qu'il s'agit de l'arbre sacré de la déesse figurée au droit, auquel le guerrier rend un culte. En fait, la dendrolâtrie semble avoir précédé dans la Crète minoenne le culte de divinités anthropomorphes, auquel elle a pu rester attachée ensuite commme une relique des temps anciens. Plusieurs représentations montrent des fidèles célébrant le culte de l'arbre sacré, en dansant ou en l'arrachant rituellement: v. notamment une bague en or du Musée d'Hèraclion ( ${ }^{\circ}$ inv. 989), provenant de la nécropole d'Archanès et datant de c. 1500 av. J.-C., où l'on voit une femme et deux hommes, dont l'un arrache un arbuste planté dans un enclos (v. e.g. J. SAKEllaraKis, Musée d'Héracleion. Guide illustré du Musée, Athènes, 1980, p. 59 [+ fig. p. 61]); et une autre du même musée, mais de provenance inconnue, où les trois personnages sont des femmes (v. N. Platon, Crète [Arcbaeologia Mundi], Genève, 1968, p. 210, fig. 114). Cf. A.J. EvaNs, The Mycenaean Tree and Plllar Cult and its Mediterranean Relations, with Illustrations from recent Cretan finds, in JHS, 21, 1901, 99-204 (+ pl. V) [repr. en édition séparée, Londres, 1901]; A.W. PERSSON, The Religion of Greece in Prebistoric Times (= Satber Classical Lectures, 17), Berkeley Los Angeles, 1942, p. 24-87; M.P. NILSSON, The Minoan-Mycenaean Religion and its Survival in Greek Religion ${ }^{2}$ (= Skrlfter utgivna av kongl. bumanistiska Vetenskapssamfundet 1 Lund, 9), Lund, 1950 [cité $M M R^{2}$ ], p. 262-288 (= VIII. The Tree Cult), avec dans les trois ouvrages plusieurs reproductions de lentilles de cristal et de sceaux crétois et mycéniens. 
34 Il faut cependant noter que ce sont plus souvent des femmes que des hommes qui vénèrent l'arbre sacré, sans doute parce que celui-ci représente un principe féminin; cf. la remarque de $L$. WENIGER, Altgriechtscher Baumkultus. Untersucbungen (=Das Erbe der Alten. Schriften iber Wesen und Wirkung der Antike, NF 2), Leipzig, 1919, p. 6: «Es ist kein Zufall, daß die Baüme bei der Alten weibliches Geschlechtes sind; sie entsprechen ihrer Göttin dem Wesen nach und bringen Früchte hervor, wie ihre Mutter. »

35 Ce nom est aussi celui d'une des cinquante Néréides, sans histoire particulière, chez HÉSIODE (Th., 247) et chez APOLlODORE $(1,2,2,7)$; en revanche, il ne figure pas dans la liste donnée par HYGIN (Fab., praef., 8).

36 L'unique manuscrit de PARTHÉNIOs (Palatinus gr. 398 ) indique effectivement comme

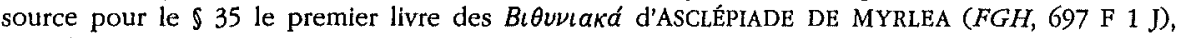
mais les commentateurs modernes (v. en dernier lieu J. STERN, Parthenius, Erottka Patbemata. The Love Stortes of Parthentus, New York - Londres, 1992, p. 95) suivent généralement l'avis de P. SAKOLOWSKI (éd. dans les Mythographi Graeci, Leipzig, 1896), qui pense (Prolegomena, p. XXV) que cela vaut en fait pour le récit du $₫ 36$, sans source dans le ms. mais qui se passe effectivement en Bithynie (FGH, 697 F 2 J) - alors que son «successeur» E. MARTINI (ibid., Leipzig, 1902) attribue sans explication la même source aux deux histoires.

37 Le rapprochement avec l'histoire de la fille du rol messénien Aristodemos (PAUS., 4, 9, 3-10), suggéré par G. RADKE, o.c. [n. 12], c. 1487, est superficiel, car la plupart des détails significatifs diffèrent.

38 Sur Cydonia, aujourd'hui Xavla (La Canée), v. la notice de M. GUARDUCCI, IC, 2, 10, p. 104116.

39 On a retrouvé un fragment d'une convention entre les deux cités, datant approximativement du IV siècle av. J.- C.; mais, à notre connaissance, seul le début en a été publié, par G. DAUX, o.c. [n. $4]$ in $B C H, 83$ (1959), p. 751-752 (= BILE, 36). Un citoyen d'Aptera figure parmi les proxènes de Cydonia auxquels cette cité accorde la concession de terres dans l'inscription déjà évoquée plus haut (IC, 2, 10 Cydonia, 1, lin. 9-10) [deuxième moitié <?> du III ${ }^{e}$ s. av. J.- C.]; cf. supra, n. 9).

40 C'est la conclusion que $\mathrm{M}$. GUARDUCCI, $I C, 2,3$, p. 12, tire de la disparition des monnaies d'Aptera dès avant la conquête romaine. Cependant la vie doit y continuer et la ville doit même retrouver par la suite une certaine autonomie, puisqu'elle sera le siège d'un évêché, sur le même

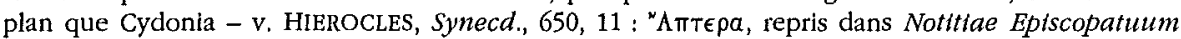
Ecclesiae Constantinopolitanae (Texte critique, introduction et notes par J. DARROUZĖS

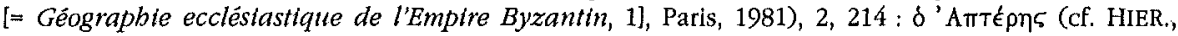

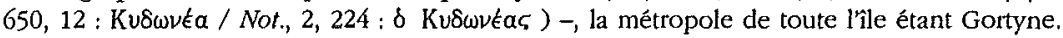

41 Le personnage est nommé comme œciste éponyme par ÉTIENNE DE BYZANCE (s.u.

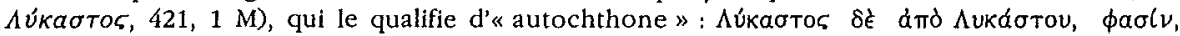
aủró $\chi$ Өovoc - tandis qu'EUSTATHE (In HOM., Il., 2, 647 / 313, 13-14) reprend le même texte, en

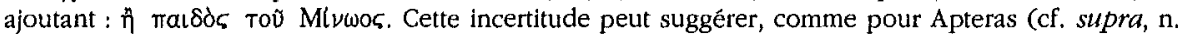
12), une création ad boc, mais également de date ancienne puisque DIODORE $(4,60,3)$ mentionne aussi un Lycastos fils de Minos et d'Itonè, fille de Lyctos, mais sans référence à la cité.

42 Sur Lycastos, v. L. BÜRCHNER, s.u. Aúkaotos 1, in RE, 13 (1926), 2266; E. MEYER, s.u. Lykastos, in $K P, 3,1969,808$. - Lycastos est mentionnée parmi les cités situées à l'intérieur des terres par PLINE (N.H., 4, 59) : ... et in mediterraneo Gortyna Pbaestum Gnosus Polyrrbenum Myrina Lycastos ... (cf. POMP. MELA, Cborogr., 2, 113; NONN., Dionys., 13, 235, qui ne donnent aucune précision sur la situation). Le site a été identifié par A.(J.] EvANS, The Palace of Minos. $A$ Comparative Account of the successive Stages of the Early Gretan Civilization as ilustrated by the Discoveries at Knossos, Londres, 1921-1936 [réimpr. Londres - New York, 1964; cité Palace], 2, 1 (1928), p. $72-74$ (plan p. 73), avec les ruines de Kanli Kastelli, au sud-sud-ouest de Cnosos. Sur l'extension de son territoire, v. les propositions de H. et M. VAN EFFENTERRE, La terminologie des bornages frontaliers, in Stuttgarter Kolloquium zur bistoriscben Geograpble des Altertums, 4, 1990 (= Geographica Historica, 7), Amsterdam, 1994, 111-125 (+ pl. IV-VIII), p. 121.

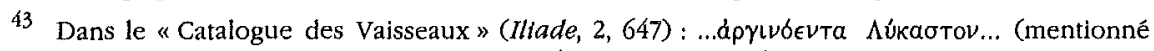

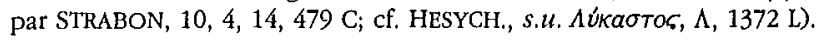


44 L'absorption de Lycastos par Cnosos est attestée par STRABON (10, 4, 14, 479 C); on peut supposer qu'elle eut lieu avant 260-250, car Lycastos ne figure pas parmi les signataires des traités conclus à ce moment avec Milet par un grand nombre de cités crétoises, sous la direction de Cnosos (IC, 1, 8 Cnosos, 6), Gortyne (IC, 4, Gortyna, 161) et Phaistos (IC, 1, 23 Phaestos, 1; cf. H.H. SCHMITT, Die Staatsvertrage des Altertums. III. Die Vertrage der griechisch-römischen Welt von 338 bis $200 v$. Cbr., Munich, 1969 [cité SVA], p. 149-153, $\mathrm{n}^{\circ}$ 482). Selon POLYBE (22, 19, 1-3), son territoire fut conquis en 189 par Gortyne, qui l'attribua à Rhaucos, mais l'arbitrage d'Ap. Claudius Pulcher le rendit à Cnosos en 184 .

45 Si une légende de Tégée faisait de Cydon un émigré de cette cité d'Arcadie en Crète (PAUS., $8,53,4)$, les diverses sources se référant aux traditions crétoises le donnaient pour le fils d'Akakallis,

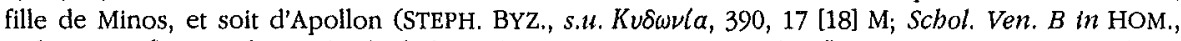
Od., 19, 176), soit d'Hermès (Schol. in THCR., 7, 12; PAUS., 8, 53, 4), qui se seraient partagé ses

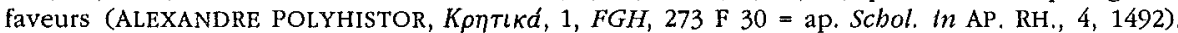
Quant à la fondation de Cydonia, elle était attribuée par certains à Minos lui-même (v. DroD., 5, 78,

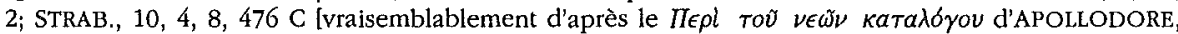
auteur mentionné au début de l'exposé sur la Crète, 10,4,3, $474 \mathrm{C}$; cf. aussi Marmor Parlum, FGH, 239 A $11=$ lin. 21-23 [cité infra, n. 92]).

46 Même si elles recouvrent probablement des pratiques religieuses ou des rituels sociaux mal compris, les aventures de Pasiphaè,-qui s'unit à un taureau, ou de sa fille Ariane, amante de Thésée, témoignent d'une liberté de mours qui ne pouvait que surprendre les Grecs du continent. Les représentations figurées, comme les foules mêlées qui assistent aux spectacles sur les fresques miniatures de Tylisos et surtout de Cnosos (v, e.g. A.[J.] EvaNS, Palace [cité n. 42], 3 [1930], p. 46-62, fig. 28-35 + pl. XVI-XVII [MR III - MR I]), paraissent confirmer une émancipation des femmes, qui contraste avec leur réclusion dans les gynécées de la Grèce classique.

47 Les coutumes de l'époque historique en Crète semblent au contraire exclure normalement ce genre de pratique, puisque après les mariages célébrés simultanément pour tous les membres d'une même classe d'âge, les jeunes épousées retournent chez leurs parents et ne rejoignent la maison de leur mari que lorsqu'elles sont en âge d'administrer leur foyer (v. ÉPHORE, 'I $\sigma$ Toplat, 4 Eúoúm, $F G H, 70 \mathrm{~F} 149 \mathrm{~J}=$ ap. STRAB., 10, 4, 20, $482 \mathrm{C}$ ).

48 V. DIOD. SIC., 5, 72, 4; cf. G.W. ELDERKIN, The Marriage of Zeus and Hera, in AJA, 41 (1937), 424-435. - On peut aussi mentionner l'hiérogamie de Dèmèter et Iasion " dans une jachère trois fols retournée », $\nu \in t \tilde{~}$

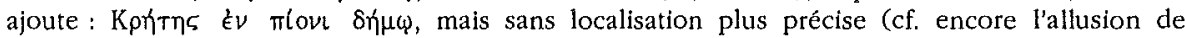
THÉOCRITE, Id., 3, 50-51).

49 V. Schol. Townl. in Il., 14, 296 a; Scbol. Ven. B, ad loc. Cet épisode était censé justifier le rite local de Naxos qui consistait à faire dormir un jeune garçon avec la fiancée la nuit précédant les noces. Mais une allusion scandalisée de CAllimaque (Aitia, 3, fr. 75, 1-5 Pfeiffer $=P$. Oxy. 1011, $1^{\mathrm{v}}$ ) suggère que, dans le mythe originel, le partenaire de la déesse était en fait le fils-amant qui apparaît comme son véritable parèdre dans la légende crétoise.

50 V. encore Scbol. Tounl. in Il, 14, 296 a; Schol. Ven. B, ad loc. Ici, la même légende justifie, plus logiquement, l'union secrète des fiancés qui, à Samos, précède normalement le mariage officiel. - Sur l'hiérogamie de Samos, v. A.B. COOK, Zeus. A situdy in Ancient Religion, Cambridge, 1914-1940 [réimpr. New York, 1964-1965; cité Zeus], 3 (1940), p. 1027-1032.

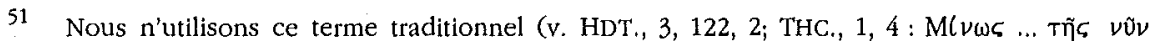

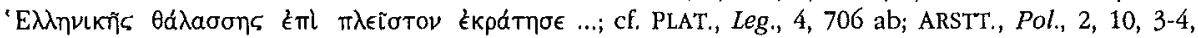
1271 b; DIOD. SIC., 4, 60, 3; 4, 79, 1; 5, 54, 4; 5, 78, 3; 5, 84, 1-2; STRAB., 10, 4, 476C; APOLLOD., Bibl., 3, $15,8)$ que pour désigner l'influence exercée par la civilisation crétoise sur les îles et les rivages de la mer Égée, sans pour autant affirmer une domination politique; cf. la mise au point de Ch. G. STARR, The Myth of the Minoan Thalassocracy, in Historla, 3 (1954-1955), 282-291; et les études de détail réunies dans The Minoan Tbalassocracy. Myth and Reality. Proceedings of the Third International Symposium at the Swedish Institute in Atbens, 31 May - 5 June, 1982, edited by R. HÄGG, N. MARINATOS (= Skrifter utgivna av Svenska Insiltutet $i$ Athen, $4^{\circ}, 32$ ), Stockholm, 1984. - Il est à remarquer que les Crétois ne figurent pas dans la «liste des thalassocraties » dressée par 
EUSÈBE (Cbron., 1, 225 Schoene / 106-107 Karst), d'après DIODORE DE SICILE (7, fr. 11) - mais la domination maritime de Minos figure dans la chronologie, pour l'an 1250 av. J.-C. (Cbron. can, 57 a Helm²). V. W. ALY, Kastor als Quelle Diodors im 7. Buch, in RhM, NF 66 (1911), 585-606, p. 598.

52 V. la liste donnée par ÉTIENNE DE BYZANCE (s.u. Mi $\nu \omega a, 454,5 \mathrm{M}$ [sic acc.]), qui en compte huit, dont une en Sicile; cf. E. BETHE, Minos, in RbM, NF 65 (1910), 200-232, p. 204-214; K. FIEHN, E. HONIGMANN, s.u. Minoa, in RE, 15 (1932), 1855-1859; M. FAUST, Das dgatsche Ortsname Mino(i)a, in $Z V S, 83$ (1969), 88-107, qui fournit l'inventaire le plus long (11 toponymes) et un commentaire linguistique sur le nom.

53 Pour la Crète, un autre port nommé Mıv心́a, appartenant à Lyttos, est mentionné par STRABON $(10,4,3,475 \mathrm{C})$, qui le situe au nord de l'isthme le plus étroit de l'île, à la verticale d'Hierapytna; PTOLÉmÉE $(3,15,4)$ le cite entre le cap Sammonion et Kamara. On ne sait auquel des

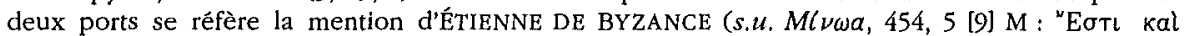
Kрп́тп५).

54 Le voyage de Ménélas et Hélène en Libye et en Égypte, au retour de la guerre de Troie, est bien entendu distinct de celui qu'Hélène aurait effectué avec Pâris en Égypte, pays où, selon certains, elle serait restée au lieu de suivre son ravisseur (cf. STESICH., Ma $\iota \nu \omega \delta l a$, fr. 192 PMG Page [citation ap. PLAT., Phaedr, 243 ab]; HDT., 2, 113-120; c'est le sujet de l'Hélène d'EuRIPIDE), bien qu'il y ait parfois confusion entre les deux (cf. l'uno évoqué par HOMÈRE ( $O d ., 4,81-89$ [ $\Lambda \mathrm{\iota} \beta u ́ q v$ au v. 85]) et son souvenir était conservé par un " Port de

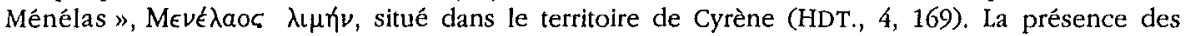
Anténorides aux côtés du couple royal est attestée par PINDARE (Pytb., 5, 82-85 [= 109-114]; cf. Schol. BDEGQ in PIND., Pyth., 5, 110 Drachmann).

55 Sur les divers héros portant ce nom, v. G. WEICKER, s.u. Glaukos 8-28 (soit 21 notices), in $R E, 7$ (1912), 1408-1417. Celui qui nous intéresse ici n'est pas mentionné dans l'lliade; le seul qui y figure est un chef lycien $(2,876 ; 16,593 ;$ cf. 12,$102 ; 16,492)$, fils d'Hippolochos $(6,119 ; 7,13 ; 12,329$; 12,$387 ; 17,140$ ) et petit-fils de Bellérophon (selon la généalogie détaillée en $6,144-211$ ); v. $G$. WEICKER, o.c., s.u. Glaukos 11, c. 1413-1414; P. WATHELET, Dictionnaire des Troyens de l'Iliade (= Université de Ltège. Bibliotbèque de la Faculté de Pbllosophle et Lettres. Documenta et Instrumenta, 1), Liège, 1988, s.u. ГגaṽKos, p. 385-393, $\mathrm{n}^{\circ} 77$.

56 V. L. BRACCESI, La leggenda di Antenore, da Trota a Padova (= Il mito e la storia, 1),

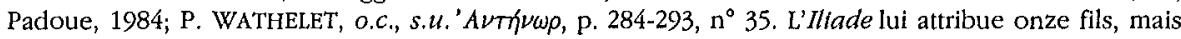
la Petite Iliade ajoute encore Glaucos et Eurymaque : c'est pourquoi ceux-ci apparaissent sur le tableau peint par POLYGNOTE d'après ce poème sur la $\lambda \hat{\epsilon} \sigma \chi \chi \eta$ des Cnidiens à Delphes et décrit par PAUSANIAS $(10,27,3)$.

57 Cette ambassade est déjà évoquée chez HOMÈre, où Antènor rappelle qu'il a hébergé chez lui les deux rois grecs (II., 3, 205-207; cf. PAUS., 10, 26, 7-8); selon les Chants Cypriens de STASINOS, il les aurait même sauvés d'un complot visant à les tuer (APOLLOD., Ep. , 3, 28-29; v. C. ROBERT, Dle griechlscbe Heldensage [= ap. L. PRELLER, Griechische Mytbologie , 2], Berlin, 1920-1926 [cité Heldensage], 3, 2, 1 [1923], p. 1005-1007). Cf. encore BACCHYLIDE ('A $\nu \tau \eta \nu o \rho l \delta a l ~ \eta n ' E \lambda \epsilon \nu \eta \varsigma$

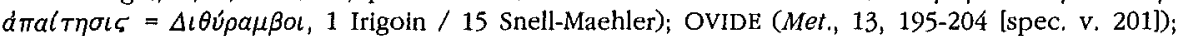
DICTYS, 11; TRIPHIODORE, 657-659; Scbol, Ven. $B$ et Townl. in HOM., Il., 3, 205 a; EUSTATHE, in HOM., $I l$, 3, 205-207 (405, 12).

58 V. Schol. BDEGQ in PIND., Pyth., 5, 110 D; D. SERV., Aen., 1, 242; TRIPHIOD., 656. Les Grecs auraient suspendu une peau de léopard à la porte de sa demeure pour qu'elle fût épargnée lors de la prise de Trole (cf. SOPH., Alar $\Lambda$ okp 6 , fr. 11 TrGF Radt [= ap. Scbol. RVET in AR., Aues, 933;

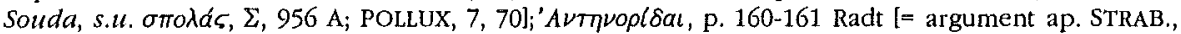
13, 1, 53, 608 C; EUST., in HOM., $1 l,, 3,205-207,405,29]$; et la description de la $\lambda \epsilon \sigma \chi \eta \eta$ des Cnidiens par PAUSANIAS, 10, 27, 3).

59 G. WEICKER, s.u. Glaucos 12, in RE, 7 (1912), 1414; P. WATHELET, o.c. [n. 55], p. $286-287$. Une autre version indiquait pourtant que Glaucos avait été chassé de sa maison par son père pour avoir accompagné Pâris lors du rapt d'Hélène (DICTYS, 3,26;5,2) et qu'il était mort sous les coups d'Agamemnon (DICTYS, 4, 7; 5, 2; HYG., Fab., 113, 2) ou d'Ajax (APOLLOD., Ep. , 5, 4). 
60 L. MALTEN, Kyrene. Sagengeschichtliche und bistorische Untersucbungen (= Pbilologiscbe Untersuchungen, 20), Berlin, 1911, p. 148 [-149], n. 3, explique comment TZETZES a modifié, dans la

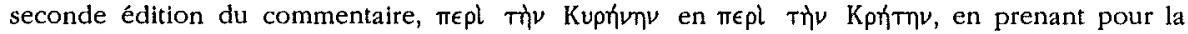
bonne leçon une faute qu'il ne se souvenait plus d'avoir lui-même corrigée en recopiant la scholie à PINDARE pour la première édition.

61 Comme le raconte HOMÈre ( $O d ., 3,286-299$ ), Ménélas lui-même avait fait naufrage en Crète, dans les environs de Phaistos, ce qui pouvait amener les mythographes postérieurs à y conduire aussi Glaucos, censé l'accompagner. Pour l'identification précise du lieu de ce naufrage, v. G. CRILE, C. DAVARAS, The possible site of Menelaus' Shipwrecks, in KrKbr, 17 (1963), p. 47-48. Cette région a pu avoir un lien privilégié avec Cyrène, puisque se trouvait non loin de là, à Lebena, le port de Gortyne, un temple d'Asclèpios, dont le culte avait peut-être été importé de Libye : v. EJ. EDElstein, L. Edelstein, Asclepios. A Collection and interpretation of the Testimonies [= Publications of the Institute of the History of Medicine, The Jobn Hopkins University. Second Sertes: Texts and Documents, 2], Baltimore, 1945, t. 2, p. 249 et n. 31, qui remarquent que les premières constructions consacrées à Asclèpios sont seulement du $\mathrm{III}^{\mathrm{e}} \mathrm{s}$, av. J.-C., les constructions plus anciennes devant être pour Apollon; contra M. GUARDUCCI, IC, 1, 17 Lebena, p. 151, 158-159, qui pense à une dépendance d'Épidaure, mais cite néanmoins PAUSANIAS $(2,26,9)$, pour qui Cyrène a été l'intermédiaire entre Épidaure et Lebena.

62 Quelques rares commentateurs ont néanmoins admis l'existence d'une Cyrène crétoise : ainsi C. ROBERT, Die Iliupersis des Polygnot ( = Halliscbes Winkelmannsprogramm, 17), Halle, 1893 , p. 80, suivi par G. WEICKER, o.c. [n. 59], in $R E, 7$, c. 1414 - bien que cette interprétation n'ait pas été reprise par son auteur dans Heldensage [cité n. 57], 3, 2, 2 (1926), 1513-1514.

63 Sur ce culte, v. L. VITALI, Fontl per la storia della religtone cyrenaica (= Pubblicazioni della Facoltà di Lettere e Filosofia della $R$. Università di Padova, 1), Padoue, 1932, p. 113-114. - La source principale, qui est le passage de PINDARE, pose un difficile problème d'interprétation, à propos duquel on verra des solutions différentes chez J. DEFRADAS, Le culte des Anténorides à Cyrène, in REG, 65 (1952), 289-301; F. VIAN, Les Anténorides de Cyrène et les Carneia, in REG, 68 (1955), 307-311 (qui nous paraît le plus convaincant); J. BRUNEL, Les Antênorides à Cyrène et l'interprétation littérale de Pindare, Pythique $V, v .82-88$, in REA, 66 (1964), 5-21; et une tentative de conciliation chez J. DUCHEMIN, Pindare, Pytbiques (III, IX, IV, V). Édition, introduction et commentaire (= Erasme, 11), Paris, 1967, ad loc. [p. 160-165]. Cf. L. BRACCESI, o.c. [n. 56], p. 74-76 (+ bibliographie critique, p. 77-78); P. WATHELET, o.c. [n. 55], p. 288.

64 Sur cet auteur à peine connu, actif semble-t-il autour de 200 av. J.-C., v. G. RADTKE, $D e$ Lysimacbo Alexandrino, Strasbourg, 1893, avec les fragments commentés; A. GUDEMAN, s.u. Lysimachos 20 , in $R E, 14$ (1928), 32-39.

65 La citation de LYSIMACHOS figure aussi, avec de menues variantes, chez un scholiaste de PINDARE (Scbol. BDEGQ in Pyth., 5, 110 D), dont l'un des manuscrits permet de restituer le nom du roi des Libyens (alors que le scholiaste de LYCOPHRON a tapa $\mu \nu a \kappa \epsilon$, , transcrit avec crux par E. SCHEER [éd., Berlin, 1958]). - Sur ce fragment, v. G. RADTKE, o.c. [n. 64], p. 15-16; 23 (= fr. XVII); A. SCHOLz, De Antenore et Antenoridis (Diss. Breslau), Trebnitz, 1911, p. 43; 50; L. MALTEN, o.c. [n. 60], p. 146-151.

66 Sur cette colline, v. F. CHAMOUX, Les Anténorides à Cyrène, in RA, 6e s., 29-32 (1948-1949) = Mélanges d'archéologie et d'bistotre offerts à Charles Picard, Paris, 1949, p. 154-161.

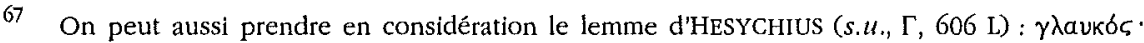

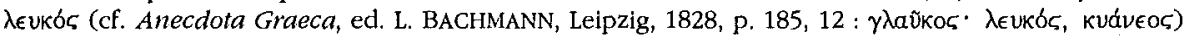
et se demander si Glaucos n'a pas été aussi attiré ici par les îles $\Lambda \in U K a l$, dont on reparlera plus loin (p. 50, et n. 158).

68 La légende de la mort et de la résurrection de Glaucos, fils de Minos, est racontée par APOLLODORE ( $B i b l, 3,3,1-2)$ et HYGIN ( $F a b ., 136$; cf. 49, 1; 251, 4), et évoquée par l'ancien scholiaste de LYCOPHRON, suivi par TZETZES (in Alex., 811), ainsi que EUSTATHE (in HOM., Il., 12, 102 / 894, 40); cf. G. WEICKER, s.u. Glaukos 23, in $R E, 7$ (1912), c. 1415-1416. Pour son interprétation, comme un rituel d'initiation, v. A.W. PERSSON, o.c. [n. 33], p. 9-24; H. JEANMAIRE, Couroi et Courètes. Essat sur l'éducation spartiate et sur les rttes d'adolescence dans l'antiquité 
bellênique, Lille, 1939 [réimpr. Salem, NJ, 1976; cité Courot], p. 444-450; R.F. WILLETTS, CCF [cité n. 18], p. 60-67; P. FAURE, La vie quotidienne en Crète au temps de Minos (1500 av. Jésus-Christ), Paris, 1973 [cité VQ], p. 166-167, 284; et en dernier lieu B. DEFORGE, Le destin de Glaucos ou l'Immortalité par les plantes, in Visages du Destin dans les mytbologies. Mélanges Jacqueline Ducbemin. Travaux et mémoires. Actes du Colloque de Cbantilly, $1^{e r}-2$ mai 1980, Paris, 1983, p. 21-39. - Un sanctuaire de Glaucos, d'époque hellénistique, a été découvert à Cnosos : v. P. CALLAGHAN, KRS 1976: Excavations at the Shrine of Glaukos, Knossos, in ABSA, 73 (1978), p. 1$30(+$ pl. 1-9).

69

Les commentateurs admettent généralement sans beaucoup d'hésitation que le fondateur d'Aptera est bien le Glaucos de la Cyrène libyenne; cf. e.g. G. WEICKER, s.u. Glaukos 16, in RE, 7 (1912), c. 1415; B. DEFORGE, o.c., p. 31.

70 Les deux versions de la fondation " historique » de Cyrène, présentées successivement par HÉRODOTE, font intervenir des Crétois : selon la tradition qu'il a certainement recueillie lui-même dans la cité (cf. 2, 32-33, où il raconte de source directe une expédition dans le désert libyen), le fondateur était BátTo5, petit-fils d'un roi d'Axos $(4,154,1-155,1)$ - la cité de Crète centrale sur le territoire de laquelle se trouvait l'antre sacré de l'Ida -, mais né à Thèra où sa mère était exilée (cf. PIND., Pyth., 5, 87-88 [= 117-118]; Schol. BDEGQ in PD., Pyth., 5, 117 D; CALlIM., H. Apol. [2], 76-96,

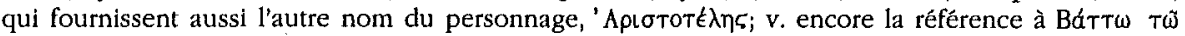

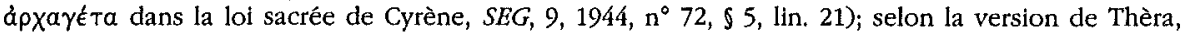
les colons partis de l'île auraient utilisé les services d'un pilote crétois originaire d'Itanos (4, 151, 2). V. L. MALTEN, o.c. [n. 60], p. 100-102; F. CHAMOUX, Cyrène sous la monarchie des Battiades (= $B E F A R$, 171), Paris, 1952 [cité Cyrène], p. 92-114. - Pour la fondation de Cyrène, la Cbronique d'EUSẼBE donne trois dates différentes : 632/631 av. J.-C. $(96 \mathrm{k}$ ), qui est la plus vraisemblable; $762 / 761(87 \mathrm{~h})$, qui provient sans doute d'un autre mode de calcul à partir des mêmes événements (v. supra, n. 15; cf. A. BURN, o.c., p. 140); et $1336(52$ e), qui correspond cette fois à une anticipation de la fondation à l'époque des Retours de la Guerre de Trole. Pour la date la plus haute, Battos n'est pas mentionné dans la Cbronique, mais chez SiLIUS ITALICUS (Pun., 8, 57-64), Anna, la sœur de Didon, se réfugie à Cyrène auprès de Battos, ce qui en fait donc bien un contemporain d'Énée; et déja TIMACHIDAS, le rédacteur de la Cbronique du temple lindien (éd. par Chr. BLINKENBERG Lindos. Fouilles de l'Acropole 1902-1914. II. Inscrtptions, Berlin-Copenhague, 1941, $\mathrm{n}^{\circ} 2$ [1, c. 149-200], B XVII, lin. 109-117 [texte et commentaire du passage : c. 168-170]), situait les dédicaces faites dans le sanctuaire rhodien par les compagnons de Battos juste après celles des héros de la guerre de Troie.

71 C'est auprès du Ģ́avov crétois du dieu de Delphes - qui était peut-être l'antique statue de culte elle-même (cf. l'interprétation de G. ROUX, Pindare, le prétendu trésor des Crétois et l'ancienne statue d'Apollon à Delphes, in REG, 75 [1962], 366-380) - que Carrhôtos, l'aurige d'Arcésilas de Cyrène, dont PINDARE célèbre la victoire ( 462 av. J.-C.), a placé les objets d'art apportés en offrande à Apollon, et notamment son char, suspendu au plafond ( $P y t h ., 5,34-42$ [ $=47-$ 56]). Selon PAUSANIAS $(10,15,6)$, il y avait aussi, près du temple, une offrande des Cyrénéens représentant Battos sur un char, avec à ses côtés Cyrène comme aurige et la Libye le couronnant, cuvre du sculpteur crétois Amphion de Cnosos; en raison du sujet même du groupe, F. CHAMOUX Cyrène, p. 199-201, pense que c'est encore Arcésilas qui l'a dédié. - Des mercenaires crétois participent certainement à l'expédition de Thybron en Cyrénaïque, en 323-322; c'est sans doute ce qui explique l'abondance des monnaies surfrappées dans les années qui suivent à Gortyne et à Phaistos (cf. F. CHAMOUX, Cyrène, p. 242, n. 1; G. LE RIDER, Monnaies, p. 143-146). - Un peu avant 250 av. J.-C., la confédération des Oreioi, qui réunissait quatre cités du sud-ouest de l'île, conclut un traité d'amitié et d'alliance avec Magas, qui était alors roi de Cyrène $(I C, 2,17$ Lisos $1=S V A, 3$, 468).

72 Une autre cité de la région, 'lotol, au nord de la presqu'île d'Akrotiri, rattachait aussi son origine au «retour» de Ménélas, puisqu'elle passait pour avoir été fondée par son fils Nicostratos dont la mère était selon certains Hélène (HES.,'Hoĩa, fr. $99 \mathrm{Rzach}^{3} /$ fr. $175 \mathrm{MW}=$ ap. Schol. in SOPH., El., 539 [p. 128 Papageorgios]; LYSIMACHOS, N6oTol, FGH, 382 F $12 \mathrm{~J}=$ ap. Scbol. MNOA in EUR., Andr., 898 Schwartz; Schol. Ven. A in HOM., Il., 3, 175; EUST., in HOM., Il., 3, 175 / 400, 32; cf. APOLLOD., Btbl., 3, 11, 1; TZETZ., in LYK., Alex., 851), selon d'autres une esclave (PAUS, 2, 18, 6). Mais le fait qu'elle ait eu pour premier nom celui de l'une des nourrices du Zeus de l'Ida, Kuvóoupa, 
conservé ensuite comme nom de son port - localisé à Stavros ou à Kalathos, sur la côte nord-ouest de la péninsule, par P. FAURE, o.c. [n. 7] in $B C H, 84$ (1960), p. 214 - et d'une partie de son territoire (v. AGLAOSTHENES, Naķıaká, FGH, 499 F 1 Jacoby [= ap. HYG., Astr., 2, 2, 1; Schol. BP in GERMAN., Arat., 25 / 3, 318 Dell'Era; et aussi, avec le nom corrompu en'A $\gamma a \sigma \theta t=\nu \eta$, ap. PS. ÉRATOSTH., Catast., 2; Schol. in ARAT, Lat., 42-44, p. 185 Maas; en Agasterenis, ap. Scbol. $S$ in GERMAN., Arat., 25

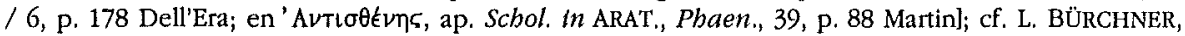
s.u. Kynosura 2, in $R E, 12,1$ [1924], 36), laisse supposer l'existence antérieure d'une agglomération «minoenne» ( $\mathrm{v}$, ci-dessus, p. 57, n, 10). - Histol a dû perdre assez vite son indépendance sans doute au profit de Cydonia, car elle n'a pas laissé d'autre trace dans la tradition que cette allusion à sa fondation légendaire.

73 D'autres cités de Crète occidentale passaient pour avoir été fondées par des héros de la guerre de Troie : Tégée par Agamemnon (VELL. PATERC., 1, 1,2) ou par Talthybios, fils de Ménélas

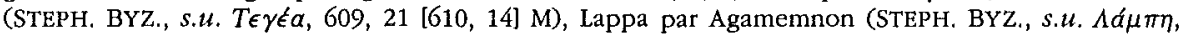
$410,5 \mathrm{M}$ [qui précise que XÉNION, $K \rho \eta \tau \iota \kappa a ́, F G H, 460 \mathrm{~F} 9 \mathrm{~J}$, donne la forme plus courante $\Lambda a ́ m \pi a]$ ), tandis que des traditions divergentes attribuaient la fondation de Pergame (sur la situation de la cité, v. P. FAURE, Nouvelles localisations de villes crétoises, in KrKhr, 17 [1963], 16-26, p. 20, $\mathrm{n}^{\circ} 70$ ) à Énée (VERG., Aen., 3, 132-134; D. SERV., Aen., 3, 132), à Agamemnon (VELL. PATERC., 1, 1, 2), ou à des prisonniers troyens échappés de la flotte de ce dernier (D. SERV., Aen., 3, 133).

74 Selon ÉPHORE (Iotoplaı, 4 Eúpórm, FGH, 70 F $146 \mathrm{~J}$ = ap. STRAB., 10, 4, 15, 479-480 C), dix cités auraient été fondées en Crète juste après la guerre de Troie, ce qui expliquerait la différence entre les quatre-vingt-dix villes comptées par Ulysse dans l'Odyssée $(19,174)$ et les cent villes que le poète, se référant la situation de son temps, attribue à l'ile dans l'Illade (2, 649); cf. EUSTATHE, in HOM., Il., 2, $649(313,30)$.

75 Le développement de PAUSANIAS $(10,5,9-13)$ décrit au total quatre temples qui se seraient succédé à Delphes, tous caractérisés au moins par un élément merveilleux : le premier aurait été en forme de cabane, fait de rameaux de laurier provenant du Tempè; le troisième aurait été en bronze et passait pour l'œuvre d'Hèphaistos; le quatrième, en pierre, aurait été construit par Trophonios et Agamède. - Pour le second temple, fait de plumes d'oiseaux et de cire d'abeilles, v. aussi le témoignage de PHLOSTRATE (V. Apoll., 6, 10, 4; 11, 14).

76 Sur ce personnage, v. U. HÖFER, s.u. Pteras, ap. W.H. ROSCHER, LM, 3 (1897-1909), 32593261; G. RADKE, s.u. Pteras, in $R E, 23,2$ (1959), 1485-1488. Il n'y a aucune raison de confondre Pteras et Apteras, comme le proposent ces deux auteurs, puisqu'il n'y a aucun point commun dans les données les concernant. Et les noms sont même, interprétés en grec, de sens opposés, puisque

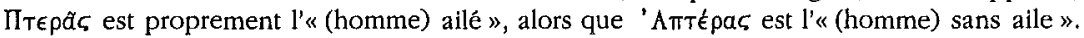

77 Il n'y a pas lieu de modifier en "A $\pi$ tepav la désignation de la cité dans le texte de PAUSANIAS, comme le propose le dernier éditeur, M.H. ROCHA-PEREIRA (Teubner, Leipzig, 1981), alors que tous les mss. s'accordent pour donner'A $\pi \tau \epsilon \rho a l o v \varsigma$ - ou, par simplification orthographique, 'A - Les trois versions concurrentes concernant le second temple sont toutes construites autour de

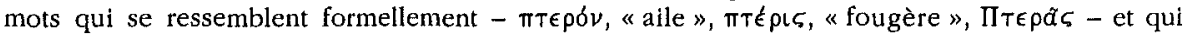
devaient fournir chacun une explication au nom même du temple. La version «fougère » appartient au même registre "naturaliste » que celle du « laurier " du premier temple. La version «ailes et cire d'abeilles » pourrait s'expliquer par le fait que le temple aurait eu la forme d'une ruche, tout en justifiant-par ailleurs son "envoi » - son envol - vers les Hyperboréens. Entre les deux, la version «Ptéras » parâttrait platement « évhèmériste », s'il n'y avait pas cette extension inattendue vers la Crète.

78 Selon R.F. WILLETTS, CCF [cité n. 18], p. 190, il s'agirait d'une «patriarchal tradition", concurrente de la tradition matriarcale (p, 181) que représentent Dictynna et Artémis Aptera (cf. infra, p. 46-50); mais ce trait même nous semble un argument de plus en faveur d'une origine extérieure à la Crète.

79 Il convient cependant de noter que le rapport traditionnel est plutôt en sens contraire : ce sont des marins crétois qui, selon l'Hymne bomérique à Apollon (v. 388-544) auraient ćté conduits par le dieu jusqu'au site de son nouveau sanctuaire pour devenir ses prêtres (v. e.g. W. ALY, Der kretiscbe Appollonkult, Leipzig, 1908; M.H. SWINDLER, Cretan elements in the Cult and Ritual of 
Apollo, Bryn Mawr, 1913 [spec. p. 26-28]; M. GUARDUCCI, Creta e Delfi, in SMSR, 19-20 [1943-1946], 84-114). Mais la propagande delphique a pu essayer d'inverser les choses. - Sur la présence d'Apollon à Aptera même, v. infra, p. 52, et n. 189.

80 On peut ajouter que le merveilleux temple volant construit avec des plumes et de la cire d'abeille, fait penser par son mode de fabrication aux «ailes 》 de Dédale et Icare, les « aviateurs " crétois; v. DIODORE $(4,77,8)$ et surtout la minitieuse description d'OVIDE (Met., 8, 188-202), mais aussi les représentations figurées, comme une bulle d'or étrusque de la Walters Art Gallery de Baltimore (n. inv. $57.371 \mathrm{~B}$ ), datant du début du $\mathrm{V}^{\mathrm{e}} \mathrm{s}$. (c'est la plus ancienne représentation du mythe) et provenant de Comacchio, donc probablement de Spina (v. G.M.A. HANFMANN, Daidalos In Etruria, in AJA, 39 [1935], 189-194; E. FIESEL, The Inscription of the Etruscan Bulla, ibid., 195197; C. BECCATTI, Oreficerle Anticbe dalle minoicbe alle barbariche, Rome, 1955, p. 186, pl. LXXVIII, 316; cf. F. FRONTISI-DUCrOuX, Dédale. Mythologle de l'artisan en Grèce ancienne, Paris, 1975, p. 154-155 [+ fig. II]). - Peut-être convient-il aussi de mentionner les statues de six Sirènes d'or qui se trouvaient sur le fronton du troisième temple, selon la description contenue dans un poème

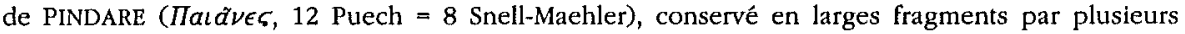
papyrus (surtout le Pap. Oxyrh. 1791), mais dont les vers qui nous intéressent ici étaient déjà cités

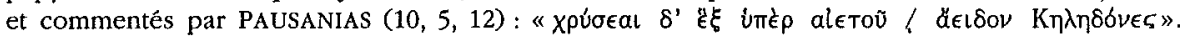

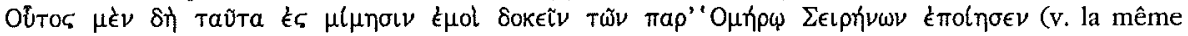
citation chez GALIEN in HIPPOCR., Artic., $23 / 18,1,519$ Kühn et un commentaire analogue chez ATHÉNÉE, 7, 36, 290 e; cf. PHILOSTR., V. Apoll., 6, 11, 14; EUST., in HOM., Od., 11, 333 / 1689, 37; 12, $167 / 1709,56-60)$. On verra en effet plus loin (p. 50-52) l'importance des Sirènes dans la mythologie d'Aptera.

81 Les cultes des sommets sont parmi les plus caractéristiques de la Crète; v. les nombreuses identifications de P. FAURE, Spéléologie et topographie crétoises, in $B C H, 82$ (1958), 495-515, p. 511515; Nouvelles recherches de spéléologie et de topographie crétoises, in $B C H, 84$ (1960), 189-220, p. 189-196; Cavernes et sites aux extrémités de la Crète, in $B C H, 86$ (1962), 36-56; Cultes de sommets et cultes de cavernes en Crète, in $B C H, 87$ (1963), 493-508; Rechèrches sur le peuplement des montagnes de Crète: sites, cavernes et cultes, in $B C H, 89$ (1965), 27-63; Nouvelles recherches sur trois sortes de sanctuires crétois, in $B C H, 91$ (1967), 114-150, p. 115-133; Sur trois sortes de sanctuaires crétois (suite), in $B C H, 93$ (1969), 174-213, p. 174-194; Cultes populatres dans la Crète antique, in $B C H, 96$ (1972), 389-426, p. 390-402.

82 C'est le site qui est le plus couramment cité par la tradition littéraire; ainsi DIODORE DE SiCile $(5,70,2)$, Callimaque ( $H$. Iou. [1], 6), ANTONINUS liberalis (Met., 19, 1), d'après Bolos

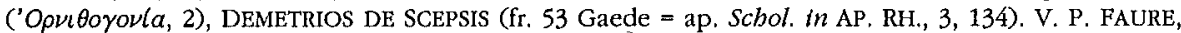
Fonctions des cavernes crétolses (= École Françatse d'Atbènes. Travaux et mémotres des anciens membres étrangers de l'École et de divers savants, 14), Paris, 1964 [cité Fonctions], p. 110.

83 HÉSIODE (Th., 477-484) semble vouloir respecter les prétentions de Lyttos en y faisant naître le jeune dieu, que sa mère Rhéa transporte ensuite dans une grotte d'un mont Alyaĩov, non attesté par ailleurs, qui doit probablement être l'Ida. Lyttos, cité réputêe pour son conservatisme (cf. STRAB., 10, 4, 17, $481 \mathrm{C}$ ), célébrait encore au II ou $\operatorname{III}^{\mathrm{e}} \mathrm{s}$. ap. J.-C. une fête appelée B€ $\lambda \chi \alpha \dot{\nu} \iota \alpha(I C$, 1, 18 Lyttos, 11, lin. 3), du nom de $(F) \in \lambda \chi a ́ v o \zeta$, le dieu minoen identifié à Zeus par les Grecs

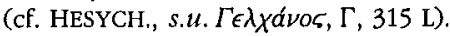

84 Selon DIODORE DE SICILE $(5,70,6)$, une légende locale (transmise par les sources indiquées en 5, 80, 4; v. Infra, n. 91) faisait naître Zeus sur le Dictè, montagne sacrée de l'est de l'île identifiée aujourd'hui avec le Modhi, au-dessus de Palaeokastro -, sur laquelle il aurait ensuite fondé

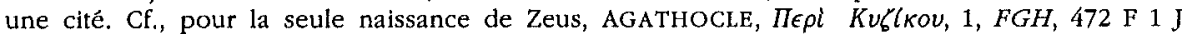
[= ap. ATH., 9, 18, 375 f- 376 a]; NÉANTHE DE CYZIQUE, $\Pi \epsilon \rho l ~ \tau \epsilon \lambda \epsilon T \pi \zeta, 2, F G H, 84 \mathrm{~F} 15 \mathrm{~J}$ [= ap. ATH., 9, 18, 376 a]; STAPHYLOS DE NAUCRATIS, $F G H, 269$ F 12 J [= ap. STRAB., 10, 4, 6, 475 C]; APOLLOD., 1,

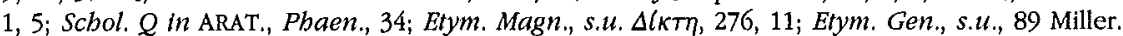

85 Une autre localisation, presque oubliée, paraît attestée par l'épithète $\Sigma \kappa u ́ \lambda_{\text {loc }}$ attribuée à Zeus dans deux inscriptions de Gortyne (IC, 4, Gortyna, 174, lin. 58; 73 [début du II ${ }^{\mathrm{e}}$ s. av. J.-C.]; IC, 1, 29 Rhytion, 1, lin. 7; 18 [sous Hadrien, en 120 ap. J.-C.]), qu'il faut sans doute mettre en rapport avec l'oronyme $\Sigma \kappa u ́ \lambda \lambda \iota o v$ mentionné par ÉTIENNE DE BYZANCE (s.u., 579, $9 \mathrm{M}$ ). La localisation de 
l'épithète suggère d'identifier cette montagne avec les Monts Asterousia, au sud de Gortyne (cf. R.F. WILLETTS, CCF [cité n. 18], p. 247-248; P. FAURE, VQ [cité n. 68], p. 298).

86 On sait que le mot $\delta \emptyset$ - forme ionienne - est utilisé comme nom commun par HÉRODOTE pour désigner une forêt $(1,110 ; 4,109 ; 4,175 ; 5,23 ; 7,111)$. Les lexicographes, tels que HÉsYCHIUS

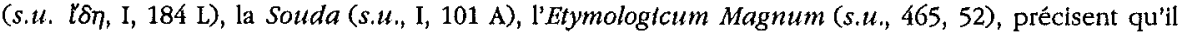

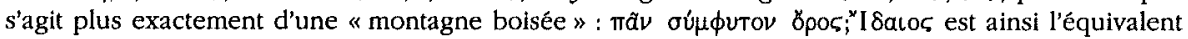
du latin Stlutus.

87 Cf. M. GUARDUCCI, IC, 2, 3 Aptera, p. 10. Le massif renferme des mines de cuivre et de fer; il était jadis boisé, ce qui permit le développement de la métallurgie ( $\mathrm{v}$. P. FAURE, oo.cc. [n. 81], in $B C H, 89$ [1965], p. 60; 93 [1969], p. 188-190).

88 Selon P. FAURE, o.c. [n. 81] in $B C H, 93$ (1969), p. 190, n. 1, ce nom serait aussi préhellénique,

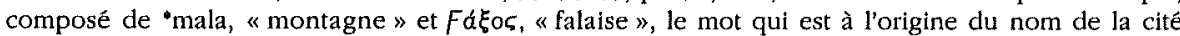
$\mathrm{d}^{\prime \prime} \mathrm{O} a \xi \circ \varsigma_{-}$- où le $\mathrm{O}$ est une transcription approximative du $F$, attesté par les inscriptions (v. STEPH.

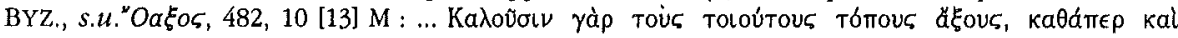

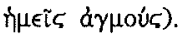

89 La montagne la plus proche d'Aptera, aujourd'hui le $\Psi \alpha \dot{\rho}$, qui culmine au pic Zoúpßa (610 $\mathrm{m}$ ), à $4,5 \mathrm{~km}$ au NNE d'Aptera, ne contient que des traces insignifiantes de métal (v. P. FAURE, o.c. [n. 81] in $B C H, 93$ [1969], p. 188).

90 Cf. P. FAURE, oo.cc. [n. 81] in BCH, 84 (1960), p. 208; 93 (1969), p, 188-190, - Les autres sources

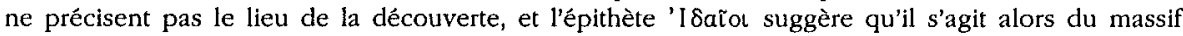
même de l'Ida (v. HÉs.,'ISaĩo $\Delta$ ák $\tau u \lambda o l$, fr. 282 MW [= ap. PLINE, N.H., 7, 197]; Schol. in AP. RH., 1, 1129; EUS., Chron. can., 48 e Helm ${ }^{2}$ [1418 av. J.-C.]); la seule anomalie est chez CLÉMENT D'ALEXANDRIE, qui situe d'abord ces Dactyles Idéens à Chypre (Strom.1, 75, 4), puis se rallie apparemment à l'opinion commune (Strom., 1, 136, 5).

91 ÉPIMÉNIDE (FGH, $457 \mathrm{~T} 9 \mathrm{~b}=\mathrm{F} 17$ [VI-V $V^{\mathrm{e}}$ s.]), DOSIADAS DE CYDONIA (FGH, $458 \mathrm{~F} 1 \mathrm{~J}$ [300250 ?]), SOSICRATE (FGH, $461 \mathrm{~T} 2 \mathrm{~J}$ [c. 150]), et LAOSTHENIDAS $\left(F G H, 462\right.$ [F] $1 \mathrm{~J} \mathrm{[1}{ }^{\mathrm{er}} \mathrm{s}$. av. J.-C.]), tous auteurs de $K \rho \eta \tau \imath \kappa d$, cités $(5,80,4)$ collectivement comme sources des paragraphes 64 à 80 (= "Anhang ", $F G H, 468 \mathrm{~F} 1 \mathrm{~J}$ ), sans privilégier le second comme le fait P. FAURE, o.c. [n. 81] in $B C H, 93$ (1969), p. 188.

92 Sur le marbre de Paros (IG, 12, 5, 444 H.v.G. / FGH, $239 \mathrm{~J}[264 / 263$ av. J.-C.)), l'invention de la métallurgie - par les Dactyles de l'Ida - est associée à la fondation par Minos d'une ville qui pourrait être $K v \delta \omega v$ la (lin. 21-23 / A 11, cité ici dans la restitution de F. HILLER VON

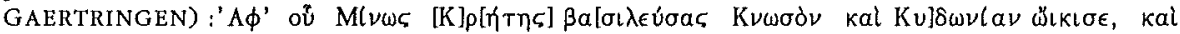

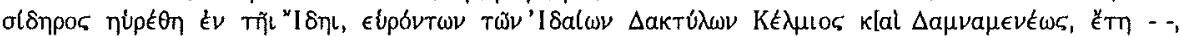

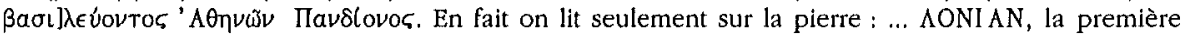
lettre pouvant être un $\Delta$ ou un $\Lambda$, d'où une restitution également possible en [' $A \pi 0 \lambda$ ] $\lambda \omega v l a \nu$; mais à

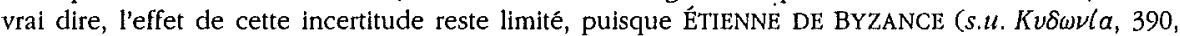
$17 \mathrm{M}$ ) indique que Cydonia s'est appelée antérieurement Apollonia; il s'agirait donc de toute façon de la grande cité de l'ouest et non pas de la cité d'Apollonia proche de Cnosos (cf. STEPH. BYZ., s.u. 'Amoג $\omega v(a, 105,20[106,4] \mathrm{M})$.

93 Sur cette déesse et son mythe, v, notamment G. GLOTZ, L'ordalie dans la Grèce primitive. Étude de droit et de mytbologie, Paris, 1904, p. 40-41; 51-52; O. JESSEN, s.u. Dictynna, in RE, 5 (1905), 584-588; M. GUARDUCCI, Dictynna, in SMSR, 11 (1935), 187-203; R.F. WILLETTS, CCF [cité n. 18], p. $179-193 ; 275-277$.

94 C'est une déesse spécifiquement crétoise, comme l'attestent toutes nos sources - qui, à date tardive, en font une hypostase d'Artémis (cf. PALAEPHATOS, Incred., 31 [32], 6 Festa; APUL, Met., $11,5,2)$. On la rencontre uniquement dans les cantons de l'ouest, notamment à Polyrhenia (STRAB., 10, 4, 13, 479 C), Phalasarna (DIONYS. CAllipH., Descr. Gr., 118-122), Lisos (IC, 2, 17 Lisos, 1 , lin. 7-8; 15-16). C'est vraisemblablement elle que l'on honorait aussi dans lẹs grottes de l'Akrotiri, appartenant à Cydonia et à Histoi, mais l'une d'elles probablement à Aptera (cf. infra, p. 48, et n. 124). À l'époque impériale, elle est mentionnée dans deux inscriptions latines de Gortyne (CIL, 3 , $13566=I C, 4$, Gortyna, 334, lin. 79-81; $C I L, 3,14120=I C, 4, G ., 333$, lin. 15-16), mais il s'agit d'une référence au trésor du grand Dictynnaion (v. infra, n. 122). 
95 Selon HÉRODOTE $(3,59)$, ce sanctuaire, comme les sanctuaires urbains de Cydonia, aurait été fondé par des Samiens qui arrivèrent en 524 dans la région, installèrent dans la cité une colonie, qui ne dura que cinq années, et furent chassés par les Éginètes. On peut cependant admettre, avec R.F. WILLETTS, CCF [cité n. 18], p. 184, qu'un lieu de culte de la déesse existait antérieurement (cf. G. WELTER, U, JANTZEN, Das Dikiynnaion, ap. F. MATZ, o.c. [n. 4], 106-117 [+ pl. 1-2; 76-104], p. 116, qui signalent la découverte de tessons géometriques et l'existence d'un grand oñ $\mu \alpha$, antérieur au grand temple).

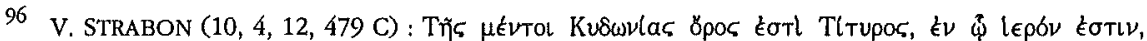

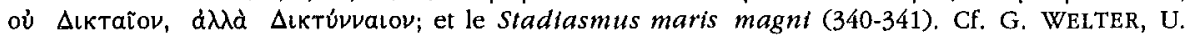
JANTZEN, o.c.; P. FAURE, Spéléologie crétolse et bumanisme, in BAGB (1958), 3, 27-50, p. 41, n. 6 ; o.c. [n. 81] in $B C H, 82$ (1958), p. 498, n. 1 (qui fournit des dimensions différentes de celles des archéologues allemands). La presqu'île porte aujourd'hui le nom de 'Poઠ́́nou. - Le promontoire terminal était dans l'antiquité le $\Psi$ ákov (PTOL., 3, 15, 5); il s'appelle aujourd'hui $\Sigma \pi d \theta a$, nom qui lui vient probablement de sa ressemblance avec une lame d'épée; ce nom n'apparaît pas chez les géographes anciens, mais c'était déjà le Capo Spada au temps des Vénitiens).

97 Ce nom de mois n'est pas attesté ailleurs, commme l'indique le relevé de R.F. V/ILLETTS, $C C F$ [cité n. 18], p. 106 (cf. p. 188), qui suppose l'existence d'une fête. - Un autre des décrets pour

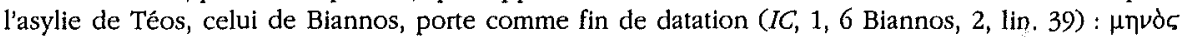
'E $\mathrm{\lambda} \epsilon[v \sigma \iota \nu(o u]$; ce mois, connu également à Olonte, semble se situer vers septembre-octobre, puisqu'il coïncide avec le mois $\Sigma \pi \epsilon ́ p \mu l o \zeta$ de Cnosos (cf. IC, 1, 16 Lato, 4 A, lin. 6), mois des "semailles » - et aussi parce qu'il semble impliquer une fête ressemblant aux mystères d'Eleusis, qui se célèbrent en septembre. Comme on peut penser que tous les décrets ont été émis dans un laps de temps assez bref, c'est vers la même période de l'année qu'il faut situer le mois $\Delta$ ¿ктúvvalos.

98 Cf. M. BILE, o.c. [n. 2], p. 163.

99 Cf. e.g. M. GUARDUCCI, $I C, 3,2$ Dictaeum fanum, p. 5; R.F. WILLE'TS, $C C F$, p. 183. H. USENER, Götternamen: Versuch einer Lebre von der religtösen Begriffsbildung, Bonn, 1896, p. 41, considère

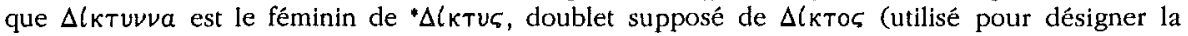
montagne crétoise par ARATOS, Pbaen., 33), dont $\Delta(\kappa \tau \eta$ serait le féminin (cf. M. BILE, o.c., p. 154 et n. 334).

100 Dans l'antiquité déjà CALLIMAQue semble avoir été la source la plus ancienne, puisque STRABON (10, 4, 12, $479 \mathrm{C}$ ) - d'après ARTÉmIDORE (cf.' supra, n. 3) - le critique, mais sans lui opposer d'autres témoignages; et que c'est à lui que le scholiaste d'EURIPIDE (in Hipp. , 146)

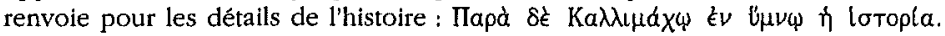

$101 \mathrm{~V}$. ANTONinus liberalis (Met., 40), dont la source, non indiquée dans le manuscrit, pourrait être le poète NICANDRE (selon O. SCHNEIDER, Nicandrea, Leipzig, 1856, p. 43; suivi e.g. par M. GUARDUCCI, o.c. [n. 93] in SMSR, 11 [1935], p. 187-188; et plus timidement par $M$. PAPATHOMOPOULOS, éd., CUF, Paris, 1968, Introduction, p. XXI); PAUSANIAS $(2,30,3)$; ainsi que Myth. Vat. (2, $26 \mathrm{M} / 36 \mathrm{~K}$ ), Schol, in EUR. (Hipp. , 1130), TZETZ., Scbol. in AR. (Ran., 1359), Comm. Bern. in LUC. $(6,214)$; et peut-être aussi un poème en dialecte dorien, du second siècle ap. J.-C., conservé dans un papyrus d'Oxyrhinchus (B. GRENFELL, A.S. HUNT, The Oxyrbincus Papyri, 4, Londres, $1904, \mathrm{n}^{\circ} 661$, p. 62-64) : d'un texte très mutilé, il semble ressortir que la protagoniste a été

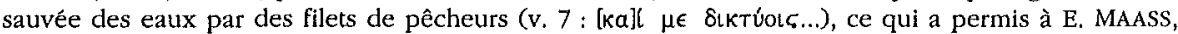
Diktynna, in Hermes, 58 (1923), 175-186, de proposer d'y reconnaître notre déesse (cf. les remarques complémentaires de R. HOLLAND, Britomartls, in Hermes, 60 [1925], p. 59-65). V. encore une allusion chez NONNOS (Dion., 33, 333-335; 343); et en latin, PS. VERG., Cirts, 283-309; D. SERV., Aen, 3, 171.

102 Selon DIODORE $(5,76,3)$, le nom de Dictynna lui aurait été attribué parce qu'elle aurait inventé le filet de chasse (cf. Scbol. in AR., Ran., 1356 / 310 b 27-29 Dübner; Myth. Vat., 3, 7, 4 M). Une version sans doute plus récente, attestée seulement par un scholiaste d'ARISTOPHANE (Schol. In Ran., 1356 / 310 b 29-32 D), indique que Britomartis fut sauvée par Artémis alors qu'elle était tombée dans des filets de chasseurs et qu'elle aurait elle-même donné l'épithète de Dictynna à la

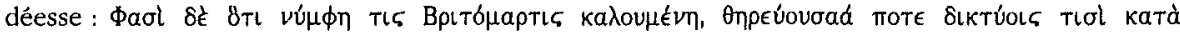




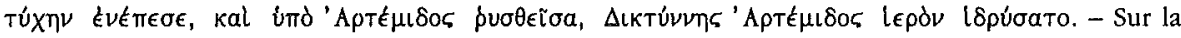
valeur sacrée du filet, v. G. GLOTZ, o.c. [n. 93], p. 51-54.

103 À la suite de P. MiNGazZINI, Culti e mitt preellenici in Creta, in Religio, 1 (1919), 241-314, p. 276 (tiré à part, Rome, 1920, p. 35), quelques exégètes ont admis que la déesse aurait pu être invoquée à l'ouest de l'île sous cet appellatif qui l'aurait reliée à sa montagne d'origine, le Dictè, alors même que, dans cette région, elle portait le nom propre de Britomartis (v. A.W. PERSSON, o.c., p. 129; et avec quelque réserve, M.P. NILSSON, $M M R^{2}$ [cité n. 33], p. 512). Mais v. plutôt la proposition de P. FAURE, citée infra (n. 110).

104 V. J.-N. SVORONos, Numismatique, s.tu. Monnaies de la Province, 334-356, p. $343, \mathrm{n}^{\circ} 55$ (= pl. XXXIII, 17); il s'agit d'une pièce de bronze de l'époque de Domitien, portant au droit la tête laurée de l'empereur, avec la légende [ $\triangle \mathrm{OMIT]I} A N O \Sigma$ $\Gamma E P M A . .$. , au revers une chasseresse courant, portant un carquois et brandissant un arc, accompagnée d'un lévrier et identifiée par la légende comme $\triangle$ IKTYNNA $\Sigma E B A \Sigma T H$ : cette titulature apparaît déjà dans un règlement religieux du Dictynnaion, datant de 6 av. J.-C. $(I C, 2,11$ Dictynnaeum, 3, lin. 32; 40). Au règne du même empereur appartient un type iconographiquement semblable, mais plus petit, sans légende pour la chasseresse (J.-N. SVORONOS, ibid., p. $343, \mathrm{n}^{\circ} 51=\mathrm{pl}$. XXXIII, 13). On peut encore lui attribuer trois autres pièces (J.-N. SVORONOS, Numismatique, s.u. Dictynna, 121-124, p. 121-122, $\mathrm{n}^{\text {os }} 1-3$ ), portant au droit le nom de $\triangle I K T Y N N A$ et l'image d'un cerf, au revers une grappe de raisin et deux ou trois épis, avec la légende EY $\Theta H N I A$ CEBACTH, qui apparaît aussi - et seulement - sur deux pièces du même empereur (J.-N. SVORONOS, p. 343, n ${ }^{\text {os }}$ 53-54 = pl. XXXIII, 15-16). - Une pièce de Trajan, avec buste lauré et cuirassé de l'empereur au droit, présente également au revers une chasseresse courant,

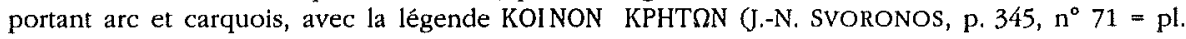
XXXIV, 10). Sur une autre pièce du même empereur, la chasseresse est au repos, tenant son arc dans la main gauche et tirant de la main droite une flèche de son carquois, avec un faon à ses pieds; faute d'inscription lisible, J.-N. SVORONOS (p. 344, $n^{\circ} 63=$ pl. XXXIV, 1) considère l'origine crétoise comme incertaine.

${ }^{105}$ V. J.-N. SvORONOS, s.u. Dictynna, p. 123-124, $\mathrm{n}^{\circ} 4$ (= pl. XXXIII, 23-24); il s'agit d'une pièce de l'époque de Trajan, portant au droit la tête laurée de l'empereur, au revers une jeune femme vêtue d'un court chiton, assise sur un rocher, tenant une flèche dans la main droite et portant sur le bras gauche un enfant que l'on identifie comme Zeus nouveau né en raison de la présence de deux

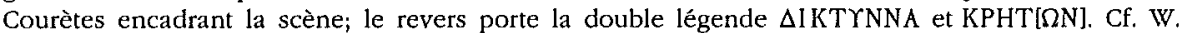
WROTH, BMCC [cité n. 25], p. 3, pl. 1, 9; A.B. COOK, Zeus [cité n. 50], p. 541-543 et fig. 412; M. GUARDUCCI, $I C$, 2, 11 Dictynnaeum, p. 129-130; R.F. WILLETTS, $C C F$ [cité n. 18], p. 191).

106 Les légendes de certaines plèces indiquent bien qu'elles sont émises au nom du Kotvdv

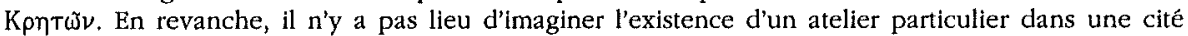
de Dictynna, comme le suppose J.-N. SVORONOS, Numismatique, s.u. Dictynna, p. 121-124, alors que les seuls ateliers "fédéraux» se trouvaient à Cydonia et Gortyne (cf. F. IMHOOF-BLÜMER, Nymphen und Cbarten auf grecbischen Minzen, in JAN, 11 [1908], 1-213, p. 142-144, $\mathrm{n}^{\circ} 414 ; \mathrm{M}$. GUARDUCCI, o.c. [n. 93] in SMSR, 11 [1935], p. 193-194). C'est probablement dans le premier d'entre eux que ces pièces ont été frappées, et la légende est bien le nom de la déesse représentée.

107 Aucune source d'origine crétoise, aucune représentation figurée ne corrobore l'histoire racontée par CALLIMAQUE - et P. FAURE, o.c. [n. 81] in $B C H, 82$ (1958), 495-515, p. 498, n. 1, a même constaté qu'un saut dans la mer était impossible à partir du site du Dictynnaion, concluant: "Dictynna n'a rien à voir avec Síkтvov, le filet ». Au reste l'incertitude sur la nature même du filet filet de pêcheurs ou filet de chasseurs - ne plaide pas non plus en faveur de l'authenticité de cette étymologie et a fortiorl d'aucun des altiı qui impliquent un «filet». - Il est néanmoins troublant de constater que la baie située au pied des ruines du temple porte le nom de $\sigma \tau i \zeta \mu \epsilon \nu \nu t \epsilon \epsilon_{6}$, mot apparenté sans doute au grec moyen $\mu t v v o t a$, désignation populaire de l'oiseau dit "plongeon" (cf. Ch. DU FRESNE DU CANGE, Glossarium ad scriplores mediae et infimae graecitatis, Lyon, 1688

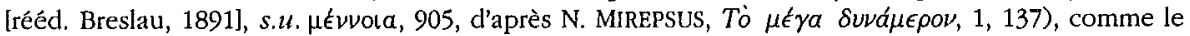
relèvent G. WELTER, U. JANTZEN, o.c. [n. 95], p. 106, n. 1. Doit-on y chercher le souvenir; complètement transformé, de coutumes comprenant des sauts dans la mer? - Par ailleurs, l'une des personnes qui se seraient jetées du haut du «Saut de Leucade» (v. infra, p. 50, n. 155), selon la

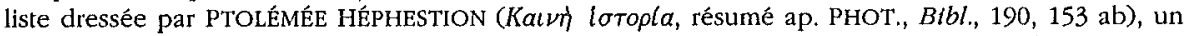
certain Nireus de Catane, aurait été sauvé en tombant dans un filet de pêcheur (153 b 14). 
108

La première allusion connue au filet de Dictynna apparaît dans un vers d'ARISTOPHANE (Vesp., 368), qui semble se référer à une expression proverbiale. Mais le contexte indique qu'il s'agit en l'occurrence d'un filet de chasseurs, puisque c'est ce avec quoi a été entourée la maison de Philocleon, pour empêcher ce dernier de sortir.

109 Pour la plupart des commentateurs modernes, le nom de Dictynna est lié à celui du mont Dictè; v. e.g. O. JESSEN, s.u. Dictynna, in RE, 5 (1905), 584-588, c. 584; A.B. COOK, Zeus [cité n. 105], 1 (1914), p. 541-543; U. VON WILAMOWITZ-MOELLENDORF, Der Glaube der Hellenen, 1, Berlin, 1931 , p. 57, n. 1; p. 119; M. GUARDUCCI, o.c. [n. 93] in SMSR, 11 (1935), p. 192; 202 (avec circonspection); W. FAUTH, Htppolytos und Pbaldra. Bemerkungen zum religiósen Hintergrund eines tragiscben Konflikts II, in $A A W M, 1959, \mathrm{n}^{\circ} 8(=385-516)$, p. 109; $114(=493 ; 498)$; R.F. WILLETTS, $C C F$ [cité n. 18], p. 183; M.P. NILSSON, $M M R^{2}$ [cité n. 33], p. 512; Gescbicbte der griecbiscben Religion ${ }^{3}$ (= Handbuch der Altertumswissenschaft, 5, 2), 1, Munich, 1967, p. 311-312.

${ }^{110} \Delta \mathrm{lkT \eta}$ est généralement considéré comme un mot pré-hellénique (v. e.g. A. FICK, o.c. [n. 2], p. 32; J.B. HALEY, The Coming of the Greeks. I. The Geographical Distribution of Pre-Greek Place Names, in $A J A$, 2nd s. 32 [1928], 141-145, p. 145); cependant P. FAURE, Fonctions [cité n. 82], p. 99, a proposé pour ce mot une étymologie indo-européenne (qui n'apparaît pas dans les dictionnaires) : $<" \delta\llcorner F-(\alpha) \kappa T \eta$, " montagne divine ". On hésitera bien sûr à accepter une telle analyse pour un mot sur lequel aurait été formé le nom d'une déesse minoenne, mais le sens global paraît acceptable. Il semble bien en effet que le nom ne se soit pas d'emblée fixé sur un massif particulier, si l'on en juge par les incertitudes de certains mythographes - et aussi par l'existence de formes apparentées, comme précisément le $\Delta \iota \kappa т a \tilde{o}$ vo ou $\Delta \iota \kappa т u ́ v v a ı v$ de la Crète occidentale. En revanche, il est tout à fait improbable que ce nom de montagne dérive de celui du filet, comme le prétend CALLIMAQUE. - En latin, Dictaeus peut être l'équivalent de Cretaeus, et se référer à l'île toute entière : cf. VERG., Aen., 3, 171; 4, 73; LUC., Pbars., 6, 214; SIL. ITAL., 13, 184; 15, 631; mais le Deutero-SERVIUS (Aen., 3, 171), fait sauter Dictynna du haut du mont Dictè où Zeus aurait grandi (!).

111 P. FAURE, o.c. [n. 81] in BCH, 93 (1969), p. 176-177, pense que plusieurs des sommets appelés aujourd'hui 'EvTl $\chi T \eta \zeta$, nom compris d'ordinaire comme se rattachant à $\varepsilon \nu \delta \epsilon(\kappa \nu v \mu \iota$ et signifiant «Indicateur" (cf. encore ID., Fonctlons [cité n. 82], p. 97-99), pourraient en fait avoir porté anciennement le nom de $\Delta l \mathrm{kT} \eta$, justifié par la présence d'un sanctuaire de sommet. Les 14 sommets dont il dresse la liste se trouve tous dans la partie orientale de líle, justement dans la région où se situait le Dictè par excellence (v. note suivante). - C'est également à cette montagne

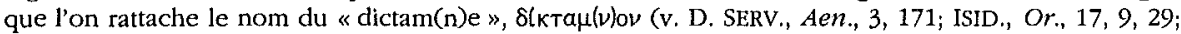
cf. VERG., Aen., 12, 411-413; SERY, Aen., 12, 412.

112 Le nom est particulièrement associé aux enfances de Zeus (v. VERG., G., 4, 152; SERV., Aen., 3 , 171; D. SERV., ibtd.; cf. Etym. Magn., s.u. $\Delta i \kappa T \eta, 276,12$; Etym. Gen., s.u., 89 M; ZONARAS, Lex., s.u., 520, 1 Tittmann, qui attestent l'existence d'une statue de Zeus imberbe sur le Dictè); et son dérivé $\Delta ı$ เка̃oб semble appliqué à Zeus dès l'époque mycénienne (KN Fp 1: di-ka-ta-jo/di-we= $\triangle$ เктаlџ $\triangle \mathrm{lFl}$ ?; cf. M. VENTRIS, J. CHADWICK, o.c. [n. 2], n² 200 [= Fp 1], p. 305-307 [spéc. p. 306]; M. GÉRARD-ROUSSEAU, Les mentions religieuses dans les tablettes mycéntennes [= Incunabula Graeca, 29], Rome, 1968, p. 61). Le mot finit par désigner spécifiquement la montagne sacrée des

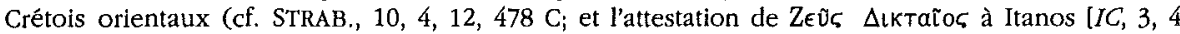
Itanos, 8, lin. 3; début du III $^{\mathrm{e}}$ s. av. J.-C.], Praisos (IC, 3, 6 Praesos, 7 A, lin. 15-16; III $^{\mathrm{e}}$ s.], Hierapytna $\left[I C, 3,2\right.$ Dictaeum fanum, 1 , lin. 4; deuxième moitié du II ${ }^{\mathrm{e}} s$. $-I C, 3,4$ Itanos, 9, lin. 38, 48, 82; 112/111 av. J.-C.]), identifiée avec l'actuel Móó (cf. P. FAURE, o.c. [n. 81] in BCH, 84 [1960], p. 193-194; Fonctions, p. 94-99) - tandis que ceux du centre adoptent l'Ida.

113 Il convient de remarquer qu'une forme $\Delta(\kappa \mathrm{r}$ a pu exister pour le nom de la nymphe, si l'on en croit SERvius (Aen., 3, 171), pour qui c'est le nom du mont qui est dérivé : Dictaeus mons Cretae est, dictus a Dicte nympba, quae illic colltur (cf. D. SERV., tbid.).

114 Cf. supra, n, 86.

115 Ces nourrices incarnent la fécondité de la Terre-Mère ou plus présicément de la MontagneMère, dont la grotte est comme la matrice. Elles sont associées à des représentantes du monde animal, qui incarnent une autre forme de fécondité et finiront par être transformées elles aussi en nymphes, comme Melissa, l'abeille, et Amalthée, la chèvre. Cf. e.g. H. VerbrugGen, Le Zeus 
crétots, Paris, 1981, p. 39-45 (avec toutes les références aux sources anciennes); et les réflexions de E.F. BLOEDOW, C. BJÖRK, The Mallia Pendant: A Study in Iconography and Minoan Religion, in Studi Micenei ed Egeo-Anatolict, 27 (= Incunabula Graeca, 89), Rome, 1989, 9-67 (+ pl. I-XIX), notamment p. 49-56, sur l'importance du miel dans les pratiques religieuses crétoises.

116 La chasse au filet, avec des rabatteurs, est l'une des techniques les plus anciennement

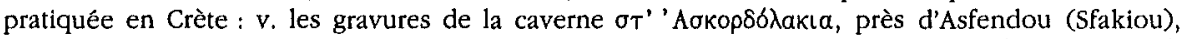
avec, entre autres motifs, un cerf pris dans un filet (cf. P. FAURE, o.c. [n. 81] in BCH, 96 [1972], p. 406413 [début du $\mathrm{II}^{\mathrm{e}}$ millénaire av. J,-C]); la scène de capture d'un taureau sauvage sur un des gobelets de Vaphio (Laconie), ouvre minoenne du début du XV $\mathrm{XV}^{\mathrm{e}}$ s. av. J.-C. (auj. au Musée National d'Athènes, $\mathrm{n}^{\circ}$ inv. 1758; cf. S. KAROUzOU, Musée National. Gulde illustré du Musée, Athènes, 1981,

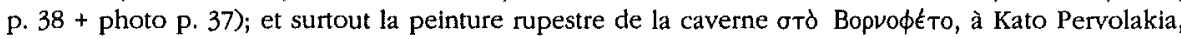
sur le mont Kapparoukephala, dans l'éparchie de Sitia, tout à fait à l'est de l'île - la seule du genre en Crète -, décrite par P. FAURE, o.c. [n. 81] in BCH, 93 (1969), 174-213, p. 196-199 (+ fig. 14-15, p. 195; résumé dans VQ [cité n. 68], p. 159-162), qui la date de c. 1400 av. J.-C. : on y observe notamment un bouquetin entouré de deux filets, mais également des poissons pris de même dans des filets.

117 Chez EURIPIDE (Hipp. , 148-150), Dictynna apparaît comme la maîtresse de la terre et de

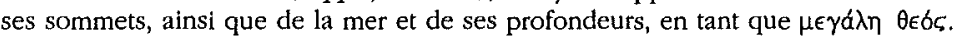

118 Avec déjà B. SCHWEITZER, c. r. de M.P. NILSSON, MMR [cité n. 33, éd. de 1927], in Gnomon, 4 (1928), 169-193, p. 181-184, on peut considérer que les diverses déesses locales sont chaque fois la "grande déesse » du lieu; l'un des arguments est justement le nom de Dictynna, qui n'est pas un nom de fonction, mais un nom tiré d'un toponyme. Pour W.K.C. GUTHRIE, Early Greek Religion in the Light of the Decipherment of Linear B, in BICS, 6 (1959), 35-46, p. 39, ce sont les Grecs continentaux qui en transformé en êtres autonomes ce qui à l'origine n'était qu'une collection d'adjectifs - Pasiphae, Ariadne, Phaedra, Dictynna ... -, épithètes de la Grande Déesse.

119 CALLIMAQUE (v. 204-205) semble indiquer que l'identification a été admise en Crète, mais lui-même ne la reprend pas à son compte.

${ }^{120}$ C'est sans doute aussi à Athènes que s'est produite cette assimilation, dont les premiers témoignages apparaissent chez EURIPIDE (Iph. Taur., 126-127 lentre 417 et 412 av. J.-C.]) et ARISTOPHANE (Ran., 1359 [405 av. J.-C.]).

121 Dictynna est souvent utilisé comme une épithète d'Artémis, crétoise (AR., Ran., 1356-1359; Scbol. ad v. 1356 / 310, 27 Dübner; cf. TZETZ., Schol. ad v. 1359) ou non (PLUT., Soll. animi, 8, 965 cd; 36, 984 a; PAUS., 3, 24, 8; 10, 36, 5 (Aırtuvvala); [ORPH.], Hymn., 36, 3; OV., Met., 2, 441; TiBUL., 1, 4, 25; SERV., Aen., 2, 116; cf. HYG., Fab., 261, où le nom n'apparaît qu'après correction).

122 Même à l'époque romaine, Dictynna est toujours indépendante, au moins dans son grand sanctuaire: cf. une inscription de l'époque d'Hadrien sur une borne miliaire proche du Dictynnaion, indiquant que la route a été financée par le trésor du temple $(I C, 2,11$ Dictynnaeum, 6); et deux inscriptions de Gortyne concernant également des travaux publics financés par ce même trésor $(C I L, 3,14120=I C$, 4, Gortyna, 333, lin. 15-16 [sous Marc-Aurèle et L. Verus, 169 ap. J.C.]; $C I L, 3,13566=I C, 4$, G., 334, lin. 7-9 [sous Commode, entre 180 et 192]).

123 Elle n'apparaissent en tout cas jamais ensemble - contrairement par exemple a Britomartis, qui figure avec Artémis dans le serment des Drériens (IC, 1, 9 Dreros, 1, lin. 26 [Art.] 29 [Brit.])

${ }^{124}$ Cf. la description de P. FAURE, Fonctions [cité n, 82], p. 186-187; reprise sommairement dans o.c. [n. 81] in $B C H, 91$ (1967), p. 114-115; et développée, avec photo, dans o.c. in $B C H, 96$ (1972), 389-426, p. 423-424 (+ fig. 15).

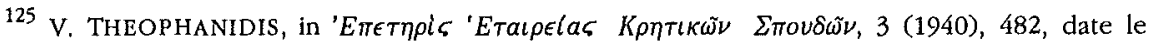
péribole et les murailles de $1000-800$ av. J.-C., N. PLATON, de l'époque archaïque (cités par P. FAURE, Fonctions, p. 186).

${ }^{126}$ La disposition du site rappelle celle des sanctuaires créto-mycéniens (v. P. FAURE, Fonctions, 186-187). 
127 Le début du nom - qui correspond à celui de la baie voisine (cf. supra, n. 8) - est identique à celui de la ville de Mapá $\theta \omega \nu$, dont on sait qu'il s'agit d'un mot préhellénique, désignant le « fenouil » (cf. P. CHANTRAINE, DELG, 3, 1974, s.u., 666).

128 Cf. H. DRERuP, Spatminoiscber Vasenfund bet Suda, ap. F. MATZ, o.c. [n. 4], 82-88 (+ pl. 3, 2; 64-65). - On peut en rapprocher les trouvailles Minoen Récent de Cydonia : cf. U. JANTZEN, Die spatminotsche Nekropole von Kydonia, ibid., $72-81$ (+ pl. 3, 1; 48-63).

129 Le second rocher, plus petit, pourrait représenter ce parèdre, fils et/ou amant, selon le schéma habituel en Crète, où la Grande Déesse est accompagnée d'un compagnon masculin subordonné.

130 Sur l'association de Pan et de Dictynna dans le sanctuaire du Rhodopou, v. P. FAURE, o.c. [n. 81] in $B C H, 93$ (1969), p. 190.

131 Le nom Tltupos, porté par la montagne, pourrait être apparenté à $\Sigma a ́$ Tupos, comme l'indiquent quelques scholiastes, en fournissant des origines dialectales diverses ( $S c b o l$. in THEOCR, 3, 2 a [sicilien ? texte incertain]; 2 d; 7, 72 c; 72 d; EUST., in HOM., Il., 18, $495 / 1157,39$

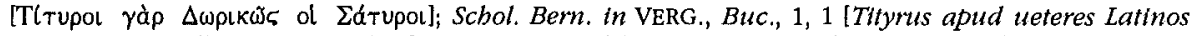

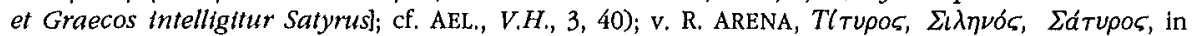
AION - Linguistica, 8 (1968), p. 31-40. Selon STRABON (10, 3, 14, $470 \mathrm{C})$, les Titupol sont des êtres analogues aux Cabires, Corybantes, Pans et Satyres (cf. R.F. WILLETTS, CCF [cité n. 18], p. 193). Le

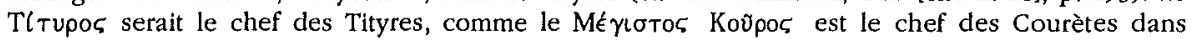
l'Hymne de Palaikastro (IC, 3, 2 Dictaeum fanum, 2); et son nom a été donné à la presqu'île sur laquelle se trouve le sanctuaire (cf. supra, n. 96).

132 Des inscriptions trouvées dans les montagnes au nord de Gortyne (IC, 1, 25 Pyloros ?, 3; 31 Tituli locorum incertorum (In montibus septemtriones versus a Gortyna), 7; 8; $B C H, 82$ [1959], p. 742) et datant du $\mathrm{II}^{\mathrm{e}}$ ou du $\mathrm{I}^{\mathrm{er}}$ s. av. J.-C., mais reprenant sans doute des formules beaucoup plus anciennes - attestent que l'on demandait aux Courètes leur protection pour les troupeaux (cf. l'Hymne, IC, 3, 2 Dictaeum fanum, 2, lin. 24)

133 V. la description de P. FAURE, o.c. [n. 81] in $B C H, 84$ (1960), p. 208. L'auteur indique que $\Lambda a \chi T a \rho l \delta \epsilon \varsigma$ doit être une déformation de $\nu \nu \kappa T \epsilon \rho(\delta \epsilon \zeta$, " chauves-souris »; la grotte, en forme de bouclier bilobé, comporte une concrétion ressemblant à une idole et des colonnes; on y a retrouvé du matériel d'époque romaine. - Une autre caverne est aujourd'hui consacrée à la Dame de

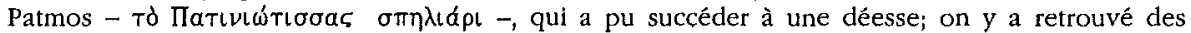
tessons de la mème ancienneté que ceux de l'acropole de la cité (cf. P. FAURE, ibid.).

134 Il est difficile de dire si c'est elle que représentent les nombreuses monnaies de la cité qui

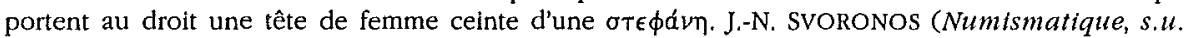
Aptera, p. 14-17, $\mathrm{n}^{\text {os }} 1-22$ [= pl. I, 7-25]; p. 18-20, nos $24-38$ [= pl. I, 27-35]; p. 22-24, n ${ }^{\text {os }}$ 51-73 [= pl. II, 915]) propose pour certaines Artémis, pour d'autres Hèra ou Athèna, ou bien n'avance aucune identification. La présence, au revers de plusieurs d'entre elles, d'un arc $\left(\mathrm{n}^{\mathrm{os}} 6-10[=\mathrm{pl}\right.$ I, 12-13]; 21 [= pl. I, 24]; $43\left[=\mathrm{pl}\right.$. II, 4) ou d'une pointe de flèche $\left(\mathrm{n}^{\text {os }} 17-18[=\mathrm{pl}, \mathrm{I}, 21]\right.$; 47; 66 [non représentées]), voire des deux ( ${ }^{\circ s} 67-71$ (non représentées]), indique qu'il s'agit probablement d'une déesse chasseresse, mais ce pourrait être déjà Artémis (cf. infra).

135 Comme l'a révélé la découverte de C. WESCHER, oo.cc. [n. 4], les actes officiels étaient antérieurement apposés sur un mur spécial, appartenant sans doute au prytanée (v. C. BURSIAN, Geographie des Grlechenlands, Leipzig, 1862-1872, 2, p. 543; L. MARIANI, o.c. [n. 4], p. 209-210).

${ }^{136}$ H. DRERUP, Zweizelliges Helligtum in Aptara, ap. F. MATZ, o.c. [n. 4], 99-105 (+ pl. 71-75 [plans $=\mathrm{pl} .73-74]) .-$ On songe à l'association ancienne, au sommet du panthéon minoen, d'une Grande Déesse et d'un jeune dieu, qui apparaît être tour à tour comme son fils et son amant. Une telle structure semble avoir été connue dans l'ensemble du monde égéen : c'est elle qui explique au mieux, par exemple, le sanctuaire de Kition à Chypre, qui comprend deux temples inégaux, des installations industrielles pour la fonte du cuivre et un jardin sacré, remontant au moins au XIII ${ }^{\mathrm{e}}$ s. av. J.-C. (v. V. KARAGEORGHIS, Le quartier sacré de Kition : campagnes de foullles 1972 et 1973, in CRAI [1973], p. 520-530; repris dans Kitton. Mycenaean and Pboentcian Discoveries in Cyprus, Londres, 1976 , p. 54-57; 62-76; 82-89). À l'époque historique, la déesse a perdu sa prééminence, et les deux cellae sont égales; c'est le cas aussi pour le temple d'Aphrodite et d'Arès découvert près de 
Agios Nicolaos, sur le territoire de l'ancienne Lato (II ${ }^{\mathrm{e}} \mathrm{s}$. av. J.-C.; cf. J. BOUSQUET, Le temple d'Apbrodite et d'Arès à Sta Lenikà (Crète orientale), in BCH, 62 [1938], p. 386-408 [+ pl. XIIII XLIIID. On peut se demander quelle était la seconde divinité honorée à Aptera dans le même temple qu'Artémis, dont la virginité se prêtait mal à une association du type ancien; peut-être Apollon, son frère dans la mythologie classique.

137 Le caractère propre de l'Artémis grecque, surtout dans ses manifestations les plus primitives, comme divinité de la nature sauvage et de la fécondité des animaux, la rendait particulièrement apte à hériter de cet aspect de la Grande Déesse crétoise; v. e.g. M.P. NILSSON, $M M R^{2}$ [cité n. 33], p. 503-509.

138 Reprenant une observation de M.P. NILSSON, $M M R^{2}$, p. 507, R.F. WILLETTS, CCF [cité n. 18], p. 190, note que dans la Crète minoenne la Maîtresse des Animaux est toujours sans ailes, alors qu'elle est ailée en Asie Mineure; les deux types ne coexistent qu'en Grèce, par suite d'un double héritage. On peut donc effectivement conclure qu'une Artémis aptère est l'héritière attendue de la Grande Déesse minoenne - mais non qu'il fût nécessaire de préciser cette particularité dans sa titulature officielle.

139 Cf. R.F. WILLETTS, $C C F$, p. 188, qui relève à juste titre que le cas de la cité crétoise de Lato est différent, puisqu'elle porte le nom propre d'une déesse et non une simple épithète.

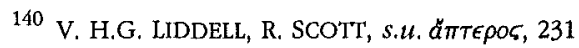

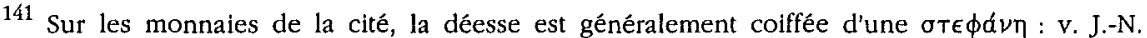
SVORONOS, Numismatique, s.u. Aptéra, p. 14-16, n ${ }^{\text {os }} 1-10$ (= pl. I, 7-11; 13); p. 16-17, n ${ }^{\text {os }} 15-22$ (= pl. I, 21-25); p. 22-23, n ${ }^{\text {os }}$ 51-62 (= pl. II, 9-15); G. LE RIDER, Monnates, p. 36, $\mathrm{n}^{\text {os }}$ 268-274; p. 112, $\mathrm{n}^{\text {os }} 1-4$ ) et, comme on l'a vu plus haut (n. 20), elle est souvent associée au héros fondateur, figuré au revers (SVORONOS, ll.cc., $\mathrm{n}^{\text {os }} 1-5 ; 15$; 53-59; LE RIDER, ll.cc., $\left.\mathrm{n}^{\text {os }} 268-274 ; 1\right)$. Sur une série seulement, elle porte un simple bandeau, ce type étant associé à des revers variés : v. J.-N. SvORONOS, p. 16, nos 11 14 (= pl. I, 14-18).

${ }^{142}$ L'explication « étymologique » $d^{*} A \pi T \epsilon \rho a$ entraîne la plupart des commentateurs à admettre que la cité a été nommée d'après l'épithète de la déesse - tout en reconnaissant que le cas est sans autre exemple; ainsi P. KRETSCHMER, Einlettung in die Geschichte der Griechischen Sprache,

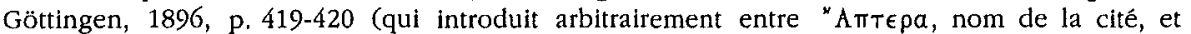
- 'AтTÉ $\rho a$, épithète de la déesse, une différence d'accent qu'il est seul à constater); K. MEISTER, Der syntaktische Gebrauch des Genetivs in den kretischen Dialektinscbriften, in $I F, 18$ (19051906), p. 150; suivis par R.F. WILLETTS, CCF, 188. C'est ne pas tenir compte du fait que la forme ancienne du nom de la cité est "ATrapa, non analysable.

143 Le délaissement de Dictynna au profit d'Artémis peut être une conséquence de la détérioration des rapports entre Aptera et Cydonia.

${ }^{144}$ La littérature sur les Sirènes est assez abondante, mais souvent décevante, car riche surtout d'hypothèses mal étayées; un inventaire critique commode est fourni par E. KAISER, OdysseeSzenen als Topot, in MH, 21 (1964), 109-136 +197-224, p. 111, n. 7. Les études de base restent celles de G. WEICKER, De Sirenibus quaestiones selectae, Leipzig, 1895, et surtout Der Seelenvogel in der alten Litteratur und Kunst. Eine mytbologisch-arcbaeologische Untersuchung, Leipzig, 1902 [cité Seelenvogel], p. 76-77, résumé s.u. Sirenen, ap. W.H. ROSCHER, LM, 4 (1909-1915), c. 601-639; même si l'on n'adhère pas à la thèse qu'exprime le titre de l'ouvrage principal, on y trouve toutes les références anciennes, que reprennent ensuite les articles, sans grande originalité, des encyclopédies : Ch. MICHEL, s.u. Strenes, in DA, 4/2 (1911) [réimpr. Graz, 1969], 1353-1355; J. ZWICKER, s.u. Sirenen, in $R E, 3$ A (1927), 288-308; H. v. GEISAU, s.u. Seirenes, in $K P, 5$ (1975), 7980. Parmi les autres travaux, on citera E. BUSCHOR, Die Musen des Jenseits, Munich, 1944; J.R.T. POLLARD, Muses and Sirens, in CR, NS 2 [= 67] (1952), 60-63; Seers, Shrines and Sirenes. The Greek religious revolution in the 6th cent. B.C., Londres, 1965 [cité SSS]; Birds in Greek Life and Myth (Aspects of Greek and Roman Life), Londres, 1977, p. 188-190]; G.K. GRESSETH, The Homerlc Sirens, in TAPbA, 101 (1970), 203-218; L. KAHN, Ulysse, ou la Ruse et la Mort, in Critlque, 36 (1980), 116-134. D'une manière générale, c'est surtout l'épisode de l'Odyssée qui intéresse les comentateurs, qui n'accordent pas grande attention à la légende d'Aptera, à l'exception de G. WEICKER, Seelenvogel, p. $76-77 ;$ o.c. in $L M$, c. 616. 
145 Une généalogie des Sirènes développée à l'époque hellénistique leur donne pour père Achéloos, en raison de leur nature infernale, et comme mère l'une des Muses, pour justifier leurs talents musicaux. Ce sont LYCOPHRON (Alex, 712) et ses scholiastes qui fournissent les premiers cette version, dont l'origne remonte sans doute à TIMÉE. Mais l'identité de la Muse ne semble pas fondamentale, puisqu'à côté de Terpsichore (v. infra, n. 148), l'on rencontre aussi Melpomène avec une autre série de noms pour les Sirènes elles-mêmes (APOLLOD., Bibl., 1, 3, 4; Epit., 7, 18; D. SERV., G., 1, 18; Myth. Vat., 1, 186 Mai / 183 Kulcsár; 2, 101 M/123 K; HYG., Fab., 125, 13; 141, 1; LACT, PLAC., Narr. fab. Ouid., 5, 9; TZETZ., Cbll., 1, 342; 351; mais la curieuse "reconstitution " en latin [!] du texte de TIMÉE par J. GEFFKEN, Timatos' Geographie des Westens [= Pbilologische Untersucbungen, 13], Berlin, 1892, p. 144, avec Melpomène, prétendûment à partir de LYCOPHRON, est évidemment sans valeur, puisque les commentateurs du poète ne connaissent que Terpsichore), tandis que des sources latines citent Calliope (SERV., Aen., 5, 864; D. SERV., G., 1, 8; Myth. Vat., 1, 42 $\mathrm{M} / \mathrm{K} ; 3,11,9 \mathrm{M})$.

146 Selon G. WEICKER, Seelenvogel, p. 77, n. 2, c'est sans doute aussi à lui que remontent aussi tous les autres témoignages (IVLIAN., Ep. , 40, 3 : PAUS., 9, 34, 3; EUSTATHE, in HOM., Il., 1, 201 / 85 ,

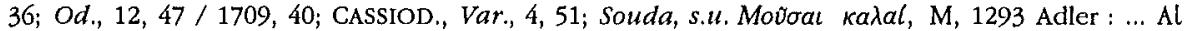

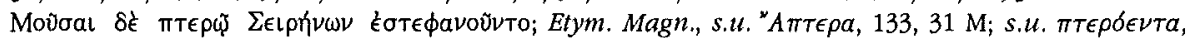
694, $15 \mathrm{M})$.

147 Cela vaut aussi pour les représentations figurées, qui n'apparaissent que dans le monde romain : sarcophage du palais de la famille Neri à Florence, montrant à la fois la confrontation musicale et le châtiment des Sirènes (dessin ap. J. MILlingeN, Statues, Busts, Bas-Reliefs and other remains of Grecian Art, from Collections in various countries [= Anctent Unedited Monuments, S. 2], Londres, 1826, p. 28-30, pl. XV; cf. A. BAUMEISTER, Denkmäler des klassischen Altertums zur Erlauterung des Lebens der Griechen und Römer in Religion, Kunst und Sitte, Munich - Leipzig, 1885-1888, 3 (1888), s.u. Seirenen, 1642-1646, p. 1646 et fig. 1704 [sans indication d'origine !]; relief se trouvant autrefois dans la maison Odam à Rome et perdu depuis, représentant une Muse arrachant les plumes des ailes d'une Sirène (v. le dessin de P.L. GHEzzI reproduit par G. WINCKELMANN, Monumenti anticht ineditl splegatt ed illistrati, 2a ed., Rome, 1821, 2, 1, p. 56, fig. 46). Cf. H. SCHRADER, Die Sirenen nach ibrer Bedeutung, Berlin, 1868, qui fournit (p. 70-112) une liste de monuments.

148 Ainsi G. WEICKER, Seelenvogel, p. 76: « Sie ist gelehrt aitiologisch, ohne den mindesten Kern echter, alter Volkssage. »Un trait du sentimentalisme alexandrin serait selon lui à reconnaître dans l'attitude de Terpsichore, la seule des Muses à ne pas prendre part à la confrontation (Schol. et TZETZ., in LYK, Alex., 653/218, 5 Scheer), parce qu'elle est la mère des Sirènes dans la version qui provient vraisemblablement de TIMÉE (Parapb. antlq. et Metaphr. in LYK., Alex., 712-713; Scbol. et TZETZ., in LYK., Alex., 712; TZETZ., Cbil., 1, 341; 351; 6, 711-712; cf. AP. RH., Arg., 4, 893-896; NONN., Dion., 13, 313-314; Schol. VHQT in HOM., Od., 12, 39 Dindorf; EUST., in HOM., Od., 12, 47 / 1709, 38).

${ }^{149}$ G. WEICKER, Seelenvogel, p. 76, rappelle que l'art hellénistique représente souvent des divinités comme Hermès, Apollon, ou les Muses, avec des symboles de feuilles ou de plumes, mal expliqués, mais remontant peut-être à un modèle égyptien; c'est du reste ce qu'avait déjà noté, pour

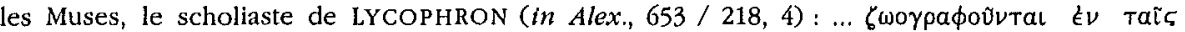

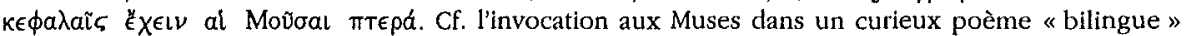

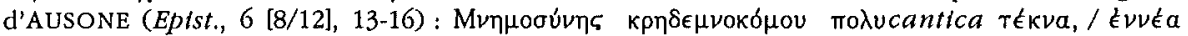

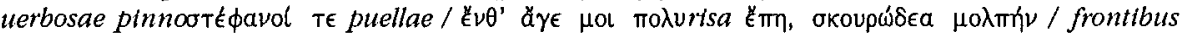

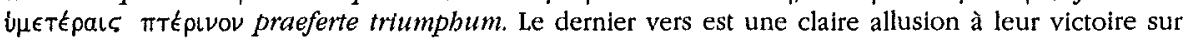
les Sirènes.

150 Un autre rapprochement, tout aussi artificiel, puisque fondé uniquement sur le chiffre trois, semble avoir provoqué une localisation de l'affrontement en Sicile, l'île triangulaire, ou Trinacria; ainsi chez AUSONE (Griphus, 20-23) : Tris in Trinacria Sirenes, et omnia terna: / tris uolucres, tris semideae, tris semipuellae, / ter tribus ad palmam iussae certare Caments, / ore, manu, flatu buxo, fide, uoce canentes. 
151 Pour G. WEICKER, Seelenvogel, cette localisation est "grob ailtiologische[s] Charakters " (p. 62, n, 4), «so naiv aitiologisch» (p. 76). On a vu que celle-ci aurait influé en retour sur le timbre de la voyelle médiane du nom de la cité.

152 Malgré son scepticisme, G. WEICKER, Seelenvogel, p. 62, n. 4, admet qu'ont pu exister des sanctuaires locaux des Sirènes, versions « régionales » des Kères ou des Erinyes, et que c'est autour d'un de ces sanctuaires qu'aurait pu se fixer la légende; ceci est contradictoire avec l'opinion tranchée exprimée plus loin, sur l'absence de tout «noyau d'authentique et ancienne légende populaire " (p. 76, cité supra, n. 148). Notons aussi qu'en l'occurrence c'est un Movotĩov, et non un lieu associé aux Sirènes, qu'évoque ÉTIENNE DE BYZANCE comme point de fixation du mythe; mais en l'absence de tout autre témoignage, l'existence de ce lieu sacré reste très incertaine.

153 Curieusement, G. WEICKER, Seelenvogel, n'en mentionne aucun autre, à l'exception d'un très timide rapprochement avec Leucade, à travers les roches blanches (p. 77, n. 1).

154 Sur ce thème, v. notamment G. GLOTZ, o.c. [n. 93], p. 34-50; J. HUBEAUX, Le plongeon rituel, in $M B, 27$ (1923), 5-81; H. JEANMAIRE, Couroi [cité n. 68], p. 324-327; Dionysos. Histoire du culte de Bacchus, Paris, 1951 [rééd. Paris, 1970], p. 61-62; 75-76; M. DELCOURT, Héphatstos ou la légende du magicien (= Bibliothèque de la Faculté de Pbilosophie et Lettres de l'Université de Liège, 146), Paris, 1957 [2 éd. Paris, 1982], p. 115-120; et surtout C. GAlLIN1, "Katapontismos ", in SMSR, 34, $1965,61-90$, qui donne (p. 62, n. 2) une rapide évaluation critique des travaux antérieurs.

155 En plus des travaux généraux mentionnés à la note précédente, v. la série des articles suscités par la découverte de la basilique de la Porte Majeure à Rome, notamment S. EITREM, Der Leukas-Sprung und andere rituelle Springe, in Laog, 7 (1923), 127-136; s.u. Leukotbea, in RE, 12 (1924), 2293-2306, c. 2303-2304; K. KERÉNYI, Der Sprung vom Leucasfelsen. Zur Wilrdigung des unterirdischen Kultraumes von Porta Maggiore in Rom, in ARW, 24 (1926), 61-72; Th. ZIELINSKI, Sappbo und der leukadische Sprung, in Kllo, NF 5 [= 23] (1930), 1-19 (+ pl. 1); et plus récemment, dans ue autre perspective, E. JANSSENS, Letucade et le pays des morts, in $A C, 30$ (1961), 381-394.

156 Un inventaire des "roches blanches " dans le monde grec est dressé par G. GLOTZ, o.c., p. 34-50, qui relève leurs différentes appellations : $\lambda \in U k \alpha l, d \rho \gamma a l$, qui évoquent la couleur blanche, et

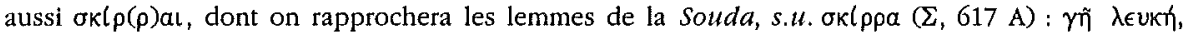

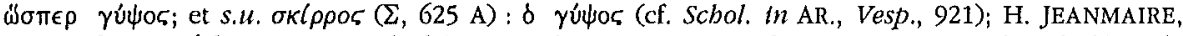
Couroi [cité n. 68], p. 325, note la fréquence des noms propres formés sur ce mot dans la légende de Thésée, dont l'un des exploits est précisément le plongeon dans la mer, qu'il effectue au cours

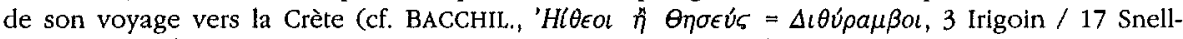
Maehler, 52-76 [ $=90-129]$ ), et qui meurt lui-même par précipitation dans l'île de Scyros (cf. PLUT., Th., 35, 6); v, aussi D.G. ROBERTS, Theseus and the Robber Sciron, in JHS, 32 (1912), 105-110.

157 E. JANSSENS, o.c. [n. 155], a montré que le Saut de Leucade pouvait être réellement considéré comme un porte de l'Enfer, dans la mesure où c'était une étape obligatoire sur la route du Nekyomanteion des Thesprotes, où l'on consultait les âmes des morts.

158 Des divergences existent sur la localisation, l'appartenance politique et même le nombre des vĩool $\Lambda \in U$ Kal mentionnées dans plusieurs sources (v. M. GUARDUCCI, o.c. [n. 9] in RFIC, NS 14 [= 64], 1936, p. 158-162). Mais il faut éviter de mettre tous les documents sur le même plan, car les plus fiables permettent, nous semble-t-il, une identification non équivoque. Le premier est une inscription mutilée d'Aptera même - un traité avec un partenaire inconnu, peut-être une cité grecque d'Asie (c. $\operatorname{III}^{\mathrm{e}}$ s. av. J.-C.) - qui atteste l'existence d'« îles sacrées ", dans une phrase tronquée $(I C, 2,3,16$, lin. 2) : ... kal Tà $\zeta$ váooc lepàc ... ; or il n'y a pas d'autre possibilité que de les identifier avec les trois îles qui se trouvent à l'entrée du golfe de la Sude et lui donnent son nom: l'une, $\Sigma o v \delta \delta$, à peu près équidistante des deux rives, une autre, beaucoup plus petite et

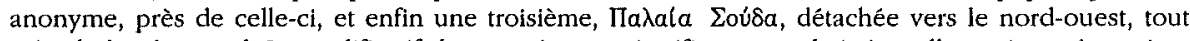
près de la côte nord. Le qualificatif de «sacrées » se justifie sans mal si c'est elles qui représentaient les Sirènes (plutôt que de penser banalement, avec M. GUARDUCCI, ad loc. [p. 30] : « De Apteraeorum insulis agi uidetur, quae hospitall iure sacras decernitur »); il s'agit donc certainement des Îles Blanches d'ÉTIENNE DE BYZANCE. Leur localisation précise et leur nombre sont du reste confirmés par le Stadiasmus marts magni (344), qui les place bien dans la région d'Aptera et plus

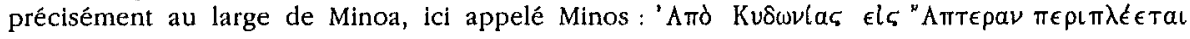




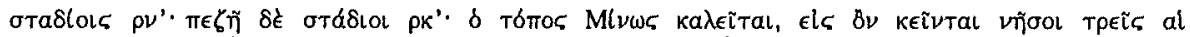

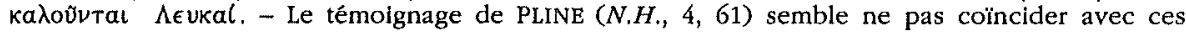
données; citant les îles qui couronnent la Crète, il mentionne : ... contra Cydoneam Leuce et duae Budroe .... Mais l'on peut supposer que Budroe était effectivement le nom des deux îles inégales du milieu du golfe et Letuce celui de l'île plus au nord-ouest, ce qui n'exclut pas que ce dernier nom ait pu désigner aussi tout l'archipel (cf. M. GUARDUCCI, o.C., p. 161-162; résumé in $I C, 2$, p. 101; 106); quant à l'expression contra Cydoneam, elle doit correspondre à un moment où Cydonia contrôlait effectivement toute la péninsule de l'Akrotiri - et Minoa (cf. supra, n. 9) - ou bien, plus approximativement, à une désignation par le nom de la principale cité de l'ensemble de la région des Cydoniens; dans un cas comme dans l'autre, elle ne peut remettre en cause l'appartenance, au moins temporaire, des îles à Aptera au moment de la constitution de la légende des Sirènes et des Muses, puisque c'est à Aptera et non à Cydonia que celle-ci s'est fixée (contra M. GUARDUCCI, o.c., p. 162). Il est de toute façon exclu que Leuce désigne l'île appelée dans l'antiquité 'Akoltıv (selon

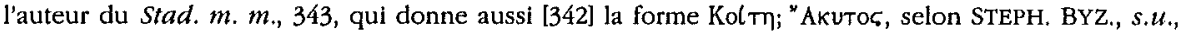

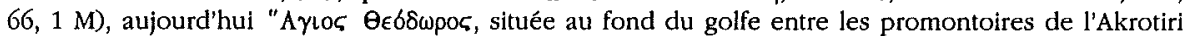
et du Rhodopou, puisque cette île est unique et que l'on ne saurait donc pas où placer les deux autres; c'est certainement elle, au singulier et sans nom propre, qui est mentionnée dans l'inscription de Cydonia concédant des terres aux proxènes de la cité (IC, 2, 10 Cydonia, 1): l'un

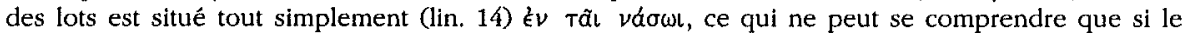
territoire de Cydonia ne comportait alors qu'une seule île (v. déjà Th. REINACH, Une inscription crétoise méconnue, in $R E G, 10$ [1897], 138-156, p. 148 [le premier à avoir identifiée la cité d'origine de l'inscription]; approuvé par L. ROBERT, o.c. [n. 9], p. 251[-252], n. 8). Quant au mópoc cité par la

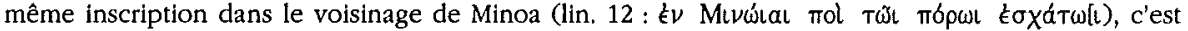
probablement le détroit qui sépare l'archipel de la presqu'île de l'Akrotiri, comme le pense M. GUARDUCCI, o.c. in RFIC, NS 14 [=64] (1936), p. 160 [le golfe de La Sude lui-même pour Th. REINACH, o.c., p. 151-152], mais cela n'oblige nullement à penser que les îles aient été aussí la propriété de Cydonia.

159 Le motif de la pétrification des Sirènes apparâit dans les Argonautlques attribuées à ORPHÉE (v, 1284-1290), dans des circonstances assez voisines; reconnaissant la supériorité musicale

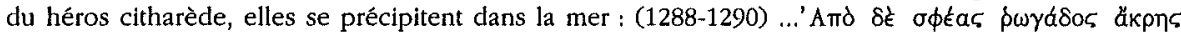

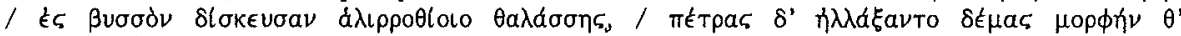

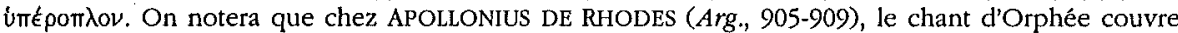
seulement celui des Sirènes, sans conséquence apparente pour celles-ci, qui réussissent même à attirer l'un des Argonautes dans les flots (v. infra, n. 163)

160 C'est aussi sur trois petites îles, surveillant vers le sud la sortie du détroit de Capri, qu'ont été

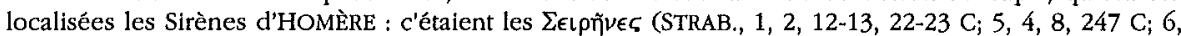
1, 6, $258 \mathrm{C}$; d'où Sirenum scopulos ap. VERG., Aen., 5, 864; OV., Met., 14, 88; et Sirentos scopulos ap. GELL., N.A., 16, 8, 17; of. [TTBUL.] 3, 7 [= 4, 1], 69; STAT., Silu., 3, 1, 64; POMP. MELA, Chor., 2, 4, 69), appelées aujourd'hui Li Galli; le promontoire qui les domine au nord et sur lequel se dressait un

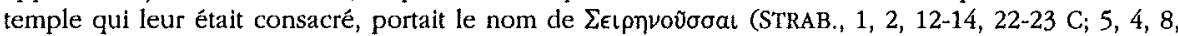
247 C; 5, 4, 13, 251 C; 6, 1, 1, 252 C; PLIN., N.H., 3, 62; cf. ARSTT., Mir. ausc., 103, 839 a 26; PTOL, 3, 1, 69, qui donnent par erreur ce nom aux îles mêmes; et l'allusion chez HEDYLE, Suppl. Hell., $\mathrm{n}^{\circ} 456$ Lloyd-Jones, Parsons [= ap. ATH., 7, 48, 297 ab]). V. e.g. la description de V. BÉRARD, Les navigations d'Ulysse. IV. Nausicaa et le retour d'Ulysse, Paris, 1929, p. 377-383; et la carte de l'édition de G. AUJAC, CUF, Paris, 1969, p. 189.

161 Chez HOMÈrE, les Sirènes semblent n'être que deux (cf. EUST., in HOM., Od., 12, 167 / 1709, 44; In DION. PER., 358), car le poète emploie à deux reprises le duel (Od., 12, 52; 167: vñoov

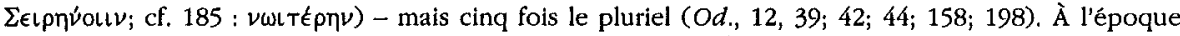
hellénistique - en fait à partir de LYCOPHRON (Alex., 720-726), selon EUSTATHE (in HOM., Od., 12, $167 / 1709,45$ ) - elles sont généralement trois (cf. SERV., Aen., 5, 864), rarement quatre (v. Scbol. $V$ in HOM., Od., 12, 39). Il n'y a donc pas de raison de considérer qu'elles ne sont que deux à Aptera, comme le fait P. FAURE, o.c. [n. 81] in $B C H, 96$ (1972), p. 389-426, p. 424. Certes, les îles sont, comme on l'a vu (n. 158), de taille très inégale, mais la correspondance reste « mythologiquement valable ». - PLATON augmente leur nombre jusqu'à huit, dans le mythe d'Er de la République (10, $617 \mathrm{~b}$ ), mais ce chiffre n'a pas de fondement mythologique, pas plus que la fonction qu'il leur 
attribue (v. PLUT., Quaest. conu., 9, 14, 4-6, 745 cf; cf. PROCLUS, in PLAT., Rp., 5, 10 / 1, 69, 10 Kroll; $16 / 2,100,8-13 \mathrm{~K} ; 16 / 2,185,17-18 \mathrm{~K}$; in PLAT., Tim., $35 \mathrm{~b} / 2,208,12 ; 210,26 ; 234,20$ Diehl [à propos de $R p .10,617$ b]).

162 HOMÈRE ne dit rien sur le devenir des Sirènes après le passage d'Ulysse (Od., 12, 197-198:

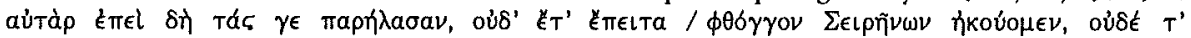

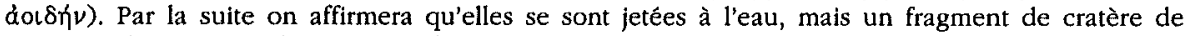
Naucratis (auj. au British Museum, $n^{\circ}$ inv. B 103, 19) permet de faire remonter le motif du saut dans la mer jusqu'à c. 600 av. J,-C. (cf, G. WEICKER, Selenvogel, p. 45); c'est en tout cas cet épisode qui, pour les modernes, a transformé en femmes-poissons des êtres qui, pour les Anciens, sont toujours des femmes-oiseaux, le premier témoignage littéraire explicite étant chez EuRIPIDE (Hel., 167 [cité infra, n. 170]; cf. LYK., Alex., 653; 731; Metaph. In LYK., Alex., 731; Scbol. HQT in HOM., Od., 12, 39; TZETZ., Cbil., 1, 339; et OV., Met., 5, 552-563; HYG., Fab., 125, 13; SERV., Aen., 5, 864 : ... parte uirgines fuerunt, parte uolucres...), et les représentations figurées confirmant parfaitement ces attestations. - Leur plongeon n'est clairement donné comme suicide qu'à partir de LYCOPHRON

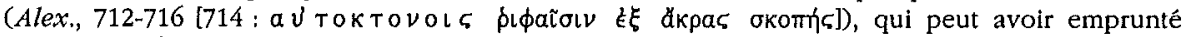
l'idée à TIMÉE (p. 144, 28 Geffken; d'où Paraph. ant., Metaphr., Schol. et TzETZ., ad loc.; cf. STRAB., 6, 1, 1, 252 C; Scbol. HQT in HOM., Od., 12, 39; EUST., in HOM., Od., 12, 167 / 1709, 48; et HYG., Fab., 141, 2; LACT. PLAC., Narr. fab. Outd., 5, 9; Mytb. Vat., 1, $186 \mathrm{M} / 183 \mathrm{~K}$ ). Mais la présentation littéraire est souvent ambigue : v. e.g. SERV., Aen., 5, 864: Has Vitixes contemnendo deduxit (coegit D. SERV.) ad mortem (repris par Myth. Vat., 1, $42 \mathrm{M} / \mathrm{K} ; 2,101 \mathrm{M} / 123 \mathrm{~K}$ ); et chez certains auteurs la mort des Sirènes semble la conséquence en quelque sorte automatique de leur défaite (HYG., Fab., 125, 13; APOLLOD., Epit., 7, 19; Myth. Vat., 3, 11, 9 M; EUPHORBE, De Sirenis, in Anth. Lat., 637, 15-18).

163 Elles provoquent aussi le plongeon de l'un des Argonautes, Butes, qui sera sauvé par Aphrodite (AP. RH., 4, 912-919; APOLLOD., 1, 9, 25, 1; HYG., Fab., 14, 27). Le fils de la déesse et du héros, Éryx, fondera pour sa mère le célèbre sanctuaire sicilien, qui vaudra à Aphrodite l'épithète d'Ericyne (DIOD., 4, 83, 1).

164 Dans leur légende affleure dès HOMÈre le motif de l'« Île Blanche », bien qu'une explication «prosaique » soit donnée de cette couleur, en rapport avec le rôle de naufrageuses que leur attribue

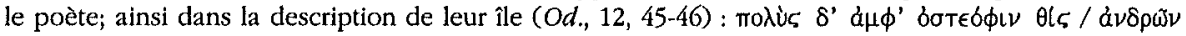

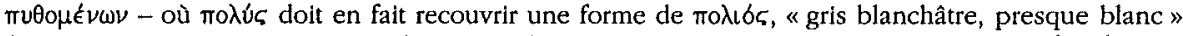
(ChaNTRAine, DELG, s.u., p. 925), comme le montre l'imitation de Virgile (Aen., 5, 864-865) : ... scopulos Sirenum ... / ... multorumque ossibus albos ... Par ailleurs, l'une d'entre elles s'appelle

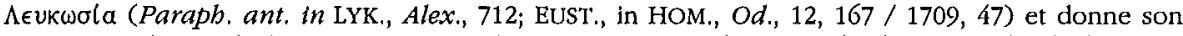
nom à une île ou plutôt à une «pierre » (LYK., Alex., 723-724:

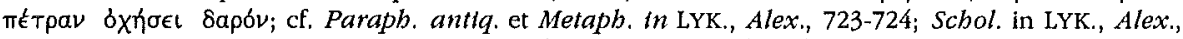
723; Paraph. ant. in LYK., Alex., 712; STRAB., 6, 1, 1, 252 C [cf. 6, 1, 6, 258 C]; PLIN., N.H., 3, 85 [cf. 2, 204]; EUST., in DION., Per., 358; cf. SOLIN., 2, 13; FEST, s.u. Lectosia, 102, 27 L (pour qui l'éponyme de l'île - dont le nom est corrompu chez le lexicographe - est une cousine, consobrina, d'Énée).

${ }^{165}$ Il s'agit de deux groupes féminins qui cultivent la musique et certains auteurs semblent les considérer comme équivalentes; v. l'expression citée sans source par PLUTARQue (Curios., 6,

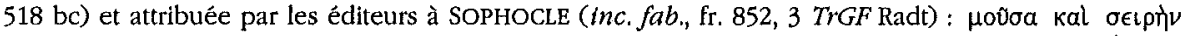
$\mu l a$; ou ce vers d'ALCMAN (inc. lib., fr. 10 Diehl / 86 Calame [= ap. AEL. ARISTID., Or. $\Pi \epsilon \rho i$ tỗ

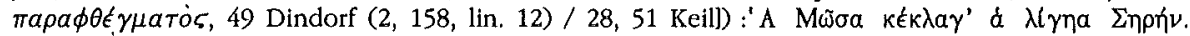
L'adjectif $\lambda(\gamma \in t a / \lambda(\gamma \eta$ a, associé ici à la Sirène, qualifie habituellement les Muses (cf. ALCMAN, 1, fr. 4, 1; lnc. lib. fr. 85), mais l'une des Sirènes s'appelle $\Lambda$ ( $\gamma \in$ la (TiMÉE, fr. 99 Geffken, Timaios, 1892, p. 145 = ap. LYK., Alex., 712; Schol. et TZETZ., in Alex., 732 [v. réf. n. 164]). Dans une légende évoquée dans un argument d'une comédie d'ARISTOPHANE (Batr., Hypotb., 4, p. 274, 38 Dübner), les Sirènes et les Muses sont associées contre Thamyris; mais c'est sans doute une erreur du rédacteur, car dans le récit originel, attesté par HOMÈRe (Il., 2, 594-600), les Muses sont seules, ce qui est du reste le plus vraisemblable (cf. EUST., in HOM., Il., 2, 596/298, 37; et aussi une allusion ap. [EUR.], Rbes., 923-925; c'était le sujet d'une pièce perdue de SOPHOCLE, fr. 236 a - 245 TrGF Radt); JULIEN (EP. , 41, p. 542, lin. 18-22 Hertlein) précise bien que Thamyris n'aurait affronté que les Muses, tandis que celles-ci auraient vaincu également les Sirènes (cf. V. GEBHARD, s.u. Thamyrts 1, in $R E, 5$ A [1934], 1236-1245, c. 1240-1242). - En revanche, il y d'autres traits moins heureux : les 
Muses sont neuf, les Sirènes seulement trois; les Sirènes sont filles de l'une des Muses, ce qui, dans une société humaine, correspondrait à des classes d'âge très êloignées.

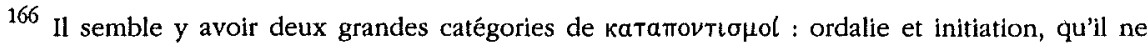
faut sans doute pas réduire à l'unité, comme le fait G. GLOTZ, o.c. [n. 93], par des artifices de langage; cf. l'appréciation critique de C. GALliNI, o.c. [n. 154], p. 62, n. 2, et ses propres distinctions dans la suite de son étude.

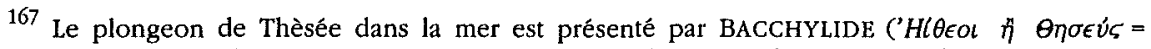
$\Delta \iota \theta \dot{p} \rho \mu \beta \beta \iota, 3$ Irigoin $/ 7$ Snell-Maehler, $18-20[=33-39] ; 34-37[=57-63], 45-48[=76-84])$ comme une réponse au défi de Minos, contestant la filiation divine du héros; celui-ci en rapporte la couronne donnée par Amphitrite, qui confirme son droit à la royauté (cf. HYG., Astr., 2, 5); c'est donc une ordalie de légitimité en même temps qu'une épreuve physique. Une légende semblable devait exister pour Achille, représenté sur un vase attique en train de recevoir au fond de la mer un diadème de Nérée et Thétis (v. L. BLOCH, s.u. Nereus, ap. W.H. ROSCHER, $L M, 3,240-250$, c. 249; cf. P. WEIZSÄCKER, s.u. Nerelden, ibid., 207-240, c. 217).

168 La chute de Glaucos dans une jarre de miel (APOLLOD., Bibl., 3, 3, 1-2; HYG., Fab., 136; TZETZ,, in LYK., Alex., 811; cf. EUST., in HOM., Il., 12, 102 / 894, 42) a été interprétée comme une épreuve d'initiation, substitut du saut dans la mer : v. R.F. WILLETTS, The myth of Glaukos and the Cycle of Birth and Death, in Klio, 37, 1959, 21-28; repr. in CCF [cité n. 18], p. 60-67 (cf. p. 189); B. DEFORGE, o.c. [n. 68] - tandis que P. FAURE, VQ [cité n. 68], p. 166-167, y décèle avec (trop d' [?]) ingéniosité une allégorie de la fabrication du cuivre à partir du minerai.

169 Sur la constitution des àyétal et le programme d'éducation, les informations les plus

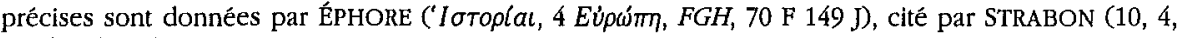
$20,482-483 \mathrm{C})$

170 Les sources insistent sur la qualité de vierges des Sirènes : ainsi dans l'invocation d'Hélène,

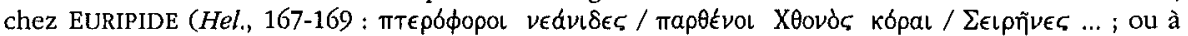

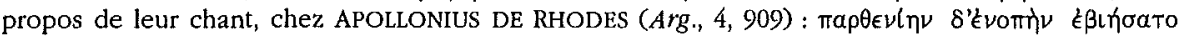
$\phi$ óput $\xi$; et c'est leur voix que veut imiter la jeune fille qui entonne l'un des Parthénées de PINDARE

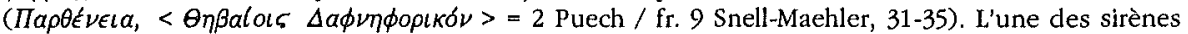

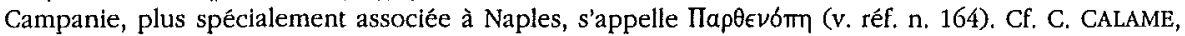
Les chceurs de jeunes filles en Grèce archaique. II. Alcman (= Filologia e critica, 21), Rome, 1977, p. 81 : «Les Sirènes dénotent donc non seulement les qualités d'harmonie de la voix féminine, mais également ses qualités adolescentes ».

171 Pour les initiations féminines, v. R.F. WILlETTs, CCF [cité n. 18], p. 189-190.

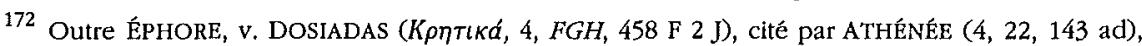
qui renseigne notamment sur les banquets collectifs, auxquels les jeunes garçons accompagnaient leurs pères et recevaient une demi-part de viande, avant d'entendre chanter les exploits guerriers

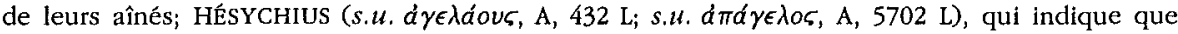
l'enrôlement dans les á $\gamma \in \lambda a l$ devait avoir lieu dans l'année des dix-huit ans; et plusieurs inscriptions (v. infra, n. 174).

173 ÉPHORE ( $l . c .=$ ap. STRAB, 10, 4, 21, $483 \mathrm{C}$ ) décrit pour son époque une situation où l'initiation complète, avec retraite dans la montagne, paraît réservée à une petite élite d'adolescents, sêlectionnés sur des affinités homoérotiques.

$174 \mathrm{~V}$. encore ÉPHORE (l.c. = ap. STRAB, , 10, 4, 20, $482 \mathrm{C}$ ). Le fait que le mariage soit l'une des étapes finales de l'initiation, survenant juste au sortir de l'á $\gamma \hat{\epsilon} \lambda \eta$, est confirmé par deux épitaphes (IC, 2, 23 Polyrhenia, 20, lin. 5 [III ${ }^{\mathrm{e}}-\mathrm{II}^{\mathrm{e}}$ s.]; IC, 3, 4 Itanos, 38, lin. 7 [I $\mathrm{I}^{\mathrm{er}}$ s. av. J.-C.]).

175 On peut bien admettre, avec G. WEICKER, Seelenvogel [cité n. 144], p. 76, que l'abstention de Terpsichore, dans la confrontation entre ses sœurs et ses filles, est un trait de sensiblerie alexandrine; cela ne signifie pas que toute la légende doive être considérée comme récente.

${ }^{176}$ Les commentateurs admettent que le rite du saut dans la mer est d'origine préhellénique; $\mathrm{v}$. e.g. M. GUARDUCCI, o.c. [n. 93 ] in SMSR, 11, 1935, p. 195; W. FAUTH, o.c. [n. 109] in AAWM (1959), $\mathrm{n}^{\circ} 8$, p. 507; C. GALLINI, o.c. [n. 154], p. 90, n. 91. 
177 En Crète même, on relève la représentation d'une Sirène sur un fragment de vase de Praisos : v. E. KUNZE, Sirenen, in $M D A I(A), 57$ (1932), 124-141 (+ Taf. V, Beil. XXI-XXXIII), p. 135141, qui propose une datation au minoen récent ou au sub-minoen. - Comme on l'a noté plus haut, aucune source ne semble pouvoir être invoquée pour le récit du saut de Dictynna chez CALLIMAQUE.

${ }^{178} \mathrm{Ch}$. PICARD, Néréides et Sirènes: Observations sur le folklore bellénique de la mer; in Études d'Archéologte grecque (a Annales de l'École des Hautes Études de Gand, 2), Gand, 1938, 125-153 (+ pl. I-X), p. 144, n. 6, considère comme seule authentique la version de Coronée et situe l'événement lui-même en Béotie, considérant la localisation à Aptera comme le résultat d'un calembour. Mais PAUSANIAS ne dit nullement que la statue représente un épisode de la mythologie locale, et l'explication peut donc parfaitement se référer à la légende d'Aptera, bien attestée.

179 Sur cette statue, v. J. OVERBECK, Die antiken Scbriftquellen zur Gescbichte der bildenden Künste bei den Griechen, Leipzig, 1868, p. 91, $\mathrm{n}^{\circ} 485$; E. KUNZE, o.c. [n. 177], p. 132; J. POLLARD, SSS [cité n. 144], p. 140; I.B. ROMANO, Early Greek cult images, Philadelphie, 1980, p. 402; A. SCHACHTER, Cults of Boetia ( $=$ BICS, Suppl., 38), 1, Londres, 1981, p. 239; A. KOSSATZ-DEISSMANN, s.u. Hera, in LIMC, 4 (1988), 1, 659-719 (+ pl. 2, 405-435), n 15, p. 663.

${ }^{180}$ Le sculpteur de la statue, IIU $\theta \delta \delta \omega \rho \circ \varsigma$, porte le même nom que le graveur de certaines monnaies d'Aptera (v. J.-N. SVORONOS, Numismatique, p. 15-16, $\mathrm{n}^{\text {os }}$ 5-9 [= pl. I, 10-13]; G. LE RIDER, Monnaies, p. 36, $\mathrm{n}^{\circ}$ 268), et aussi de Polyrhenia (v. J.-N. SVORONOS, ibid., p. 278-279, $\mathrm{n}^{\text {os }} 15-16[=\mathrm{pl}$. XXVI, 4-5]; G. LE RDER, ibid., p. 114-116, $n^{\text {os }} 3-6$ [= pl. XXVII, 19-37]), actif vers 280 av. J.-C. (v. G. LE RIDER, tbid., p. 198; cf. une nomenclature de ses pièces par L. FORRER, Les signatures de graveurs sur les monnaies grecques (suite), in RBN, 61 [1905], 387-436, p. 407-414; et encore A. STAZIO, s.u. Pythodoros 2, in $E A A, 6$ [1965], 578 (pas d'article dans la RE]). Mais sans doute n'est-ce qu'une coïncidence, puisque le sculpteur est qualifié de Thébain. En l'absence d'autre témoignage, les commentateurs le situent à l'époque archaïque, parce que PAUSANIAS qualifie la statue d'àpXaĩov et à cause de la présence des Sirènes (v. e.g. A. RUMPF, s.u. Pythodoros 18, in RE, 24 [1963], 596); par ailleurs, un manche de miroir en bronze, trouvé dans le sud de l'Ukraine, près de Kherson, juste au nord de la Crimée, mais probablement corinthien et datant du $\mathrm{VI}^{\mathrm{e}}$ s., représente de même une figure féminine debout, tenant dans la main droite un oiseau à tête humaine: $v$. G. WEICKER, Seelenvogel, p. 149, n. 2; E. KUNZE, o.c. [n. 177], p. 132 et n. 1, d'après la publication de E.H. MINNS, Scythians and Greeks. A survey of ancient bistory and archaeology on the north coast of the Euxine from the Danube to the Caucasus, Cambridge, 1913, p. 375-377, fig. 279-280, qui cite comme identifications proposées Cybèle et Aphrodite, mais refuse de se prononcer personnellement; on pourrait donc penser également à Hèra (cf. L. GUERrINI, s.u. Pytbodoros 1, in EAA, 6 [1965], 578).

181 G. WEICKER, Seelenvogel [cité n. 144], p. 13 (cf. p. 76; 149), explique la présence de Sirènes sur la main de la statue d'Héra comme traduisant la domination de la déesse sur le monde des morts et donc sur les âmes, que symbolisent celles-ci, précisément caractérisées comme les filles d'Achelous.

182 Bien qu'étant pour nous faiblement attestée, la confrontation des Muses et des Sirènes a connu une certaine faveur chez les écrivains tardifs, qui y font des allusions dans lesquelles les Sirènes, associées au monde sensible, représentent en quelque sorte des Muses inférieures, tandis que les véritables Muses correspondent au monde intellectuel. La formulation la plus explicite est chez Proclus (in Plat., Rp., 16/2, 239, 7-12 Kroll [à propos de $R p ., 10,617$ b, 5-8], qui, tout en paraphrasant le développement philosophique de PLATON, évoque la confrontation légendaire des

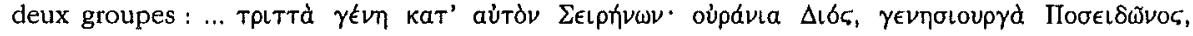
u்

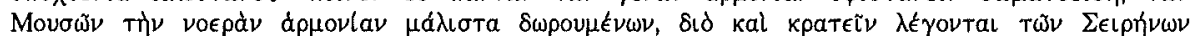

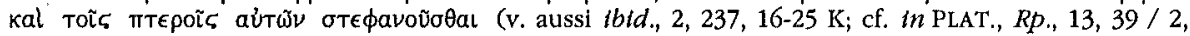
68, 3-16 K [à propos de $R p ., 8,546 \mathrm{c}$ ); selon CLÉMENT D'ALEXANDRIE (Strom., 1, 48, 6) et THÉODORET DE CYR (Graec. affect. cur., 8, 1), l'image remonterait à PYTHAGORE (cf. PORPH., $V$. Pyth., 39); chez BOÈCE (Cons., 1, 1), les véritables Muses accompagnent la philosophie, tandis que les Sirènes représentent la poésie et sont qualifiées dédaigneusement de scaenicas meretriculas ce qui est la transposition d'une interprétation «évhèmériste » que l'on trouve dans des sources 


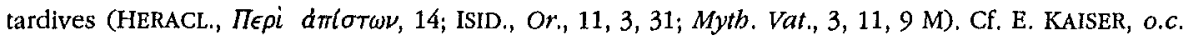
[n. 144], p. 118; 127).

183 Hestia n'apparaît pas comme divinité à Aptera. Mais la cité avait un "foyer commun", désigné par son nom, auprès duquel on recevait les délégations étrangères; ainsi les envoyés de

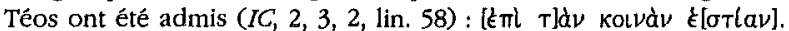

${ }^{184}$ La représentation d'une divinité sur des monnaies indique l'existence d'un culte local; cf. J. BAYET, Idéologie et plastique. I. L'expression des énergles divines dans le monnayage grec, in MEFR, 71 (1959), 65-106 (+ planches I-IV) [repr. in Idéologie et plastique (= Collection de l'École Françatse de Rome, 21), Rome, 1974, 499-544 (pl. I-IV)], p. 65 [499] : " Le caractère poliade de ces effigies en garantit la conformité à une mentalité populaire commune. »

185 Hèra est bien représentée sur les monnaies d'Aptera, avec une couronne sur la tête, ce qui symbolise sans doute sa souveraineté : v. J.-N. SVORONOS, Numismatique, p. 18-20, nos $24-35$ (= pl. I, 27-33) et probablement p. 19-20, $\mathrm{n}^{\text {os }} 36-38\left(=\right.$ pl. I, 34-35), p. 23-24, $\mathrm{n}^{\text {os }}$ 65-73 (non représentées), bien que pour ces deux séries l'auteur ne propose pas d'identification; v. IC, 2, 3 Aptera, Nummt, p. 13). Cf. R.F. WILLETTS, CCF [cité n. 18], p. 255, et pour les autres attestations dans l'île, p. 252-255.

186 Zeus ne figure que sur un seul type, la tête ceinte de laurier: v. J.-N. SvOrONOS, Numismatique, p. $18, \mathrm{n}^{\circ} 23(=$ pl. I, 26). La rareté de la représentation de ce dieu peut indiquer que l'élément féminin est resté prépondérant dans le panthéon local d'Aptera. Cf. R.F. WILLETTS, $C C F$, p. 231, et pour les autres attestations dans l'île, p. 231-233.

187 Les monnaies représentant Zeus Ammon appartiennent à la dernière série du monnayage d'Aptera (après 250 av. J.-C.) : v. J.-N. Svoronos, Numismatique, p. 21, n 50 (non représenté), et peut-être $\mathrm{n}^{\text {os }}$ 48-49 ( $=\mathrm{pl}$. II, 7-8). Les liens étroits entre la Crète et l'Égypte peuvent expliquer le rapprochement entre Zeus et Ammon-Ra, confirmé pour une période très ancienne par la découverte, dans l'antre de Psychro, d'une statuette en bronze du dieu égyptien, couronné de plumes, datant de c. 900 av. J.-C., publiée sommairement par D.G. HOGARTH, The Dictaean Cave. Preliminary Report, in $A B S A, 6$ (1899-1900), p. 94-116 (+ pl. X), p. 107 (+ pl. X, 1-2), qui la présente ainsi : «A small statuette, crowned with the plumes of Ammon Ra (accidentally bent back), is of good early New Empire work, and may be held to have been dedicated in the cave about 900 B.C. by an anticipator of the classical identification of Zeus with the Egyptian "Ammon ». " Cf. A.B. COOK, Zeus [cité n. 105], qui mentionne (1 [1914], 371-376) plusieurs monnaies représentant Zeus Ammon - mais non celle d'Aptera -, et évoque plus loin $(2,926)$ la statue (cf. encore 1 bid., 1, 348 353). Pour les diverses attestations dans l'île, cf. R.F. WILETTS, CCF, p. 235.

${ }^{188}$ Hermès n'est figuré qu'une fois, au revers de la monnaie avec Zeus, dans la dernière sêrie du monnayage de la cité (J.-N. SvORONOS, p. 18, $\mathrm{n}^{\circ} 23 \approx \mathrm{pl}$. I, 26); il porte sa baguette et un chapeau de voyage : il est vraisemblable qu'à cette époque il corresponde au type grec du dieu des voyageurs et des commerçants. Mais le type spécifiquement crétois de ce «dieu du tas de pierres » marquant les frontlères et les tracés des chemins doit se relier au culte minoen du pilier et du Maître des Animaux, d'où sa fonction de dieu chasseur, particulière à l'île (v. J. CHITTENDEN, The Master of Animals, in Hesperia, 16 [1947], 89-114 (+ pl. XV-XXI); avec les réserves de M.P. NILSSON, $M M R^{2}$ [cité n. 33], p. 406; 411; 513-518 - qui ne distingue pas suffisamment la physionomie du dieu en Crète et sur le continent; et l'approbation de W.K.C. GUTHRIE, The Greeks and their Gods, Boston, 1951, p. 92-94 (tr. franc., Les Grecs et leurs dieux, Paris, 1956, p. 110-113]). Cf. R.F. WILLETTS, CCF, p. 287, et pour les autres attestations dans l'île, p. 287-288.

189 Apollon figure nu, assis sur un rocher, une patère dans la main droite, le coude gauche sur une cithare posée à terre, au revers d'une monnaie qui porte au droit une tête d'Artémis (J.-N. SVORONOS, Numismatique, p. 16, $\mathrm{n}^{\circ} 11$ [= pl. I, 15], postérieure à 270 selon G. LE RIDER, Monnaies, p. 182, n. 4). On le retrouve au droit d'une série plus récente, associé successivement à des revers représentant Apteros (J.-N. SvORONOS, Numlsmatique, p. 20, $\mathrm{n}^{\text {os }} 39-41$ [= pl. II, 1-2]), une lyre (ibid, p. $21, \mathrm{n}^{\circ} 42$ [= pl. II, 3]), un arc (ibid., $\mathrm{n}^{\circ} 43$ [= pl. II, 4]), une torche (ibid., $\mathrm{n}^{\text {os }} 44-46$ [= pl. II, 5-6]), une torche et un fer de flèche ( $i b i d ., \mathrm{n}^{\circ} 47$ [non repr.]). On peut penser que cette apparition modeste et ces associations sont en rapport avec le développement du culte de sa sœur jumelle Artémis. Cf. R.F. WILLETTS, CCF, p. 256, et pour les autres attestations dans l'île, p. 256-258. 
190

On peut se demander si c'est Apollon qu'il faut reconnaître dans une statue masculine acéphale, acquise lors de son voyage par R. PASHLEY, o.c. [n. 4], 1, p. 42, qui en fournit un dessin (2, p. 1), sans commentaire.

191 Eleuthyia, c'est-à-dire Ilithye dans la transcription courante (v, n. suiv.), est une déesse particulièrement honorée en Crète, où il faut vraisemblablement chercher son origine (cf. P. BAUR, Eileithia [Diss. Heidelberg], Tübingen, 1901 [repr. in Pbllologus, Suppl. 8 (1899-1901), p. 451-512]; P. FAURE, Fonctions [cité n. 82], p. 82-94; R.F. WILLETTS, Cretan Eileithyla, in CQ, NS 8 [= 52] [1958], 221-223; repr, dans CCF, p. 168-172); selon PAUSANIAS $(1,18,5)$, c'est de Crète que proviendraient les statues d'Ilithye dans son temple d'Athènes, où elles auraient été consacrées par Phèdre. - Son principal sanctuaire dans l'île était la grotte située sur le territoire de cnosos, à l'embouchure de l'Amnisos, déjà évoquée par HOMÈre $(O d ., 19,188-189$; v. STRAB., 10, 4, 8, 476 C; PAUS., 1, 18, 5;

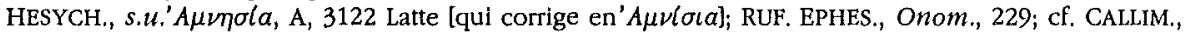

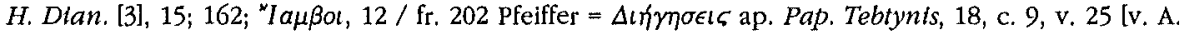
VOGLIANo, Papirl della R. Università di Milano, 1, Milan, 1937 - repr. anast., Milan-Varèse, 1966 p. 66-173]; AP. RH., Arg., 3, 876-883 lassimlilation avec Artémis]; et plus loin NONN., Dton., 8, 115; 13, 251); v. M. GÉRARD, La grotte d'Elleitbyia à Amnisos, in SMEA, 3 [= Incunabula graeca, 21], Rome, 1967, 31-32, avec cinq photos de la grotte. Les traces de culte y remontent au moins au Minoen Récent III - avec déjà des objets d'époque néolithique, dont la valeur religieuse n'est pas certaine (cf. P. FAURE, Fonctions, p. 82-90 [spéc. p. 82-83]; contra B. RUTKOWSKI, Das Siedlungsuesen von Amnisos in Neolithikum und Bronzezett, in OAth, 14 [= Skrtfter utgivna av Svenska Institutet 1 Athen, $4^{\circ}, 31$ ], Stockholm, 1984, 147-153, qui pense [p. 153] que l'on peut remonter au moins jusqu'au Minoen Moyen I et peut-être plus haut) -, mais on n'a pas retrouvé d'inscription portant son nom (v. IC, 1, 2 Amnisos, p. 2; les seules dédicaces portant un nom de destinataire concernent Zeus Gevátas: v. C. Davaras, O. MASSON, Crettca : Amnisos et ses inscriptions, in BCH, 107 [1983], 383403, p. 389-403 [O.M.], $\mathrm{n}^{\text {os }} 1-2$ [+ 3-13 sans indication de destinataire] = BILE, 87-88 [+ 89-99]). En revanche, une tablette mycénienne de Cnosos (KN Gg 705, lin. 1; v. J. CHADWICK, L. GODART e. a., o.c. [n. 2], p. 268) associe le nom de la déesse et celui du fleuve : a-mi-ni-so / e-re-u-ti-ja; ce fut l'une des premières identifications de divinités grecques en écriture mycénienne, due à E. SITTIG, Sprachen die Minoer griechisch? in Minos, 3 (1954), 87-99, p. 89-90 (cf. M. VENTRIS, J. CHADWICK, o.c. [n. 2], p. 310-311 [cf. p. 127]; M. GÉrARD-ROUSSEAU, o.c. [n. 112], p. 101-102).

192 C. WESCHER, o.c. [n. 4] in $R A$, NS 10 (1864), p. 78. - Si son nom apparaît sous des formes

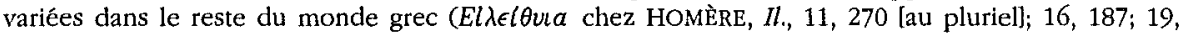
103; 119 [pl.]; Od., 19, 188; STRAB., 10, 4, 8, 476 C; PAUS., 1, 18, 5; 'Edelovia chez PINDARE, Pyth., 3, 9

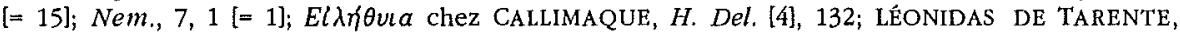

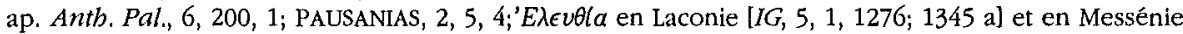

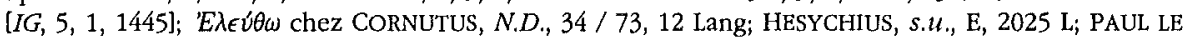
Silentiaire, ap. $A n t b . P a l ., 7,604,3$; ANTIPATER DE TheSSAlONIQUe, ap. Anth. Pal., 9, 268, 3), en Crète c'est toujours'E $\lambda \epsilon v$ $\theta v i a$, qui correspond à la forme mycénienne indiquée ci-dessus (cf. IC, 1 , 16 Lato, 2 , lin. $31 ; 3$, lin. 18; 4 A, lin. 13-14; 5, lin. 48; 15, lin. 35; 26, lin. 8; 4, Gortyna, 174, lin. 60-61; 76), sauf dans une inscription tardive de Lato (IC, 1, 16 Lato, 27, lin. 3; deuxième moitié du II ${ }^{e} s$. av.

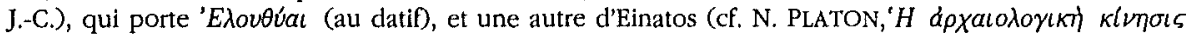

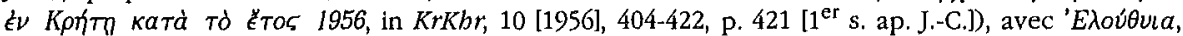
sans doute par déformation dialectale pour la diphtongue centrale (cf. F. BECHTEL, Die Griecbiscbe Dialekte, 2, Berlin, 1923, 661-662 - qui ne cite pas ce nom parmi les exemples fournis). Beaucoup de commentateurs considèrent que le mot est probablement pré-hellénique (v. H. FRISK, GEW, s.u.

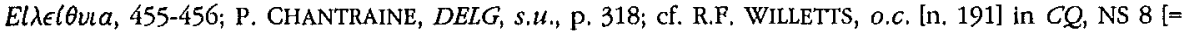
52] [1958], p. 221; CCF, p. 169), mais d'autres ont proposé une étymologie indo-européenne séduisante : J. PUHVEL, Eleuther and Oinoâtls: Dionysiac Data from Mycenaean Greece, in Mycenaean Studies. Proceedings of the third international Colloquium for Mycenaean Studies beld at "Wingspread", 4-8 September 1961, edited by E.L. BENNETT, Jr., Madison (Wisc.), 1961, 161-170, p. 165, fait dériver son nom d'un verbe "É $\lambda \epsilon u ́ \theta \omega$, et, dans le même sens, P. FAURE, Fonctions [cité n. 82], p. 87-88, propose de le rattacher à la famille d' $€ \lambda \in u ́ \theta \epsilon$ pos, qui reposerait sur i-e "Jleudh, en pensant à la fonction de «libératrice » qu'exerce cette déesse accoucheuse (cf. $M$. GÉRARD-ROUSSEAU, l.c. [n. 191]). 
193 Sur cette déesse, v. W. WROTH, Hygtela, in JHS, 5 (1884), 82-101; E. MITROPOLOU, 'H

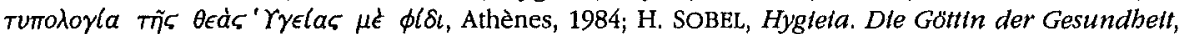
Darmstadt, 1990; F. CROISSANT, s.u. Hygiela, in LIMC, 5 (1990), 1, 554-572 (+ pl. 2, 380-395). - Hygie

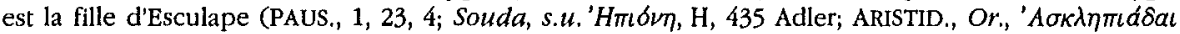
$=7$ Dindorf (1, 79, lin. 5) / 38, 22 Keil; PLINE, N.H., 35, 137; son épouse chez [ORPH.], Hymn., 67, 7), qu'elle accompagne notamment dans son voyage d'Épidaure à Athènes, en 420 av. J.-C. (v. $S I G^{3}, 88=I G, 2-3^{2}, 4960$ a, lin. 9-10; cf. F. SOKOLOWSKI, Lois sacrées des cités grecques [= École Françatse d'Athènes. Travaux et mémoires des anctens membres étrangers de l'Ếcole et de divers savants, 181, Paris, 1969, p. $74-75, n^{\circ} 40 ;$ p. 80-81, $n^{\circ} 44$ ). Le culte du dieu lui-même est assez répandu en Crète, particulièrement en Crète centrale, avec surtout le grand sanctuaire de Lebena (v. IC, 1,17 Lebena, p. 150-178), mais aussi en d'autres lieux, chez les Arcadiens, à Chersonesos, Cnosos, Lasaia, Olonte, Gortyne, Pyloros (cf. R.F. WILLETTS, CCF, p. 224-227). Les guerres incessantes provoquaient de grands besoins sanitaires, et les cités crétoises faisaient couramment appel à des médecins étrangers, spécialement de Cos : c'est le cas d'Aptera, dont un décret de reconnaissance pour un tel praticien, datant du second siècle av. J.-C., a été retrouvé dans le temple d'Esculape à Cos où il avait été déposé $(I C, 2,3,2)$. Des liens devaient aussi exister avec Épidaure même : un ou peut-être deux citoyens d'Aptera sont proxènes de cette cité dans le troisième quart du III $^{\mathrm{e}} \mathrm{s}$, av. J.-C. (v. M.

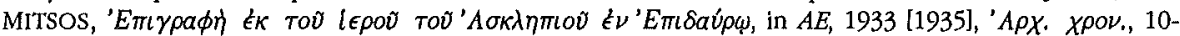

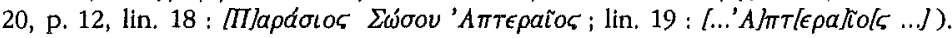

194 Le culte d'Hygie est attesté en Crète par quatre autres statues plus ou moins fragmentaires, toutes conservées aujourd'hui au musée d'Hèraclion et provenant, pour deux d'entre elles de Lyttos ( $\mathrm{n}^{\circ}$ inv. 312; v. E. MITROPOLOU, o.c., $\mathrm{n}^{\circ} 163$, pl. 21; F. CROISSANT, o.c., $\mathrm{n}^{\circ} 116, \mathrm{p} .562 / \mathrm{n}^{\circ}$ inv. 313; $\mathrm{v}$. E. MITROPOLOU, o.c., $\mathrm{n}^{\circ} 216$, pl. 30; F. CROISSANT, o.c., $\mathrm{n}^{\circ} 47$, p. 559), pour les deux autres de Gortyne ( $n^{\circ}$ inv. 351; v. E. MITROPOLOU, o.c., $n^{\circ} 154$, pl. 21; H. SOBEL, o.c., p. 102-103, $n^{\circ} 3$; F. CROISSANT; o.c., $\mathrm{n}^{\circ} 117$, p. $562 / \mathrm{n}^{\circ}$ inv. 350; v. E. MITROPOLOU, o.c., $\mathrm{n}^{\circ} 155$, pl. 20; F. CROISSANT, o.c., $\mathrm{n}^{\circ} 170$, p. 565). - On a voulu parfois reconnaître une autre représentation de la déesse sur un type monétaire de Priansos (c. 300 av. J.-C. ?), qui montre une femme assise, la main droite posée sur un serpent qui se dresse devant elle (v. J.-N. SVORONOS, Numismatique, s.tu. Priansos, 193-299, p. 295-296, $\mathrm{n}^{\text {os }} 1-6$ [= pl. XXVIII, 21-23]; E. MITROPOLOU, o.c., $\mathrm{n}^{\circ} 240 ; \mathrm{F}$. CROISSANT, o.c., $\mathrm{n}^{\circ} 14$, p. 557 lavec ?; non repr.]); mais on a également proposé Perséphone (cf. F. LENORMANT, Dionysos Zagreus, in Gazette Archéologique, 5 [1879], 18-37, p. 24; et aussi P. GARDNER, The Types of Greek coins, An Archaeological Essay, Cambridge, 1883, p. 162 [+ pl. IX, 5]; W. WROTH, o.c. [n. 193] in $J H S, 5$ [1884], p. 87-88; BMCC [cité n. 25], p. XXXII-XXXIII; B.V. HEAD, Historia Numorum. A Manual of Greek Numismatics ${ }^{2}$, Oxford, 1911, p. 476, qui hésitent entre les deux), ou bien un avatar de la Grande Déesse minoenne, dont on ne saurait dire sous quel nom elle était honorée à la date de la monnaie (cf. A.B. COOK, Zeus [cité n. 50], 1 [1914], P. 402; [G.F. HILL,] A Guide to the principal Coins of the Greeks, from circ. 700 B.C. to A.D. 270, based on the work of B.V. Head, Londres, 1932; M. GUARDUCCI, IC, 1, 24 Priansos, p. 280; R.F. WILLETTS, CCF, p. 150-151).

$195 \mathrm{~N}^{\circ}$ inv. $49 \lambda\left(\theta \iota v a\right.$. Cf. E. Mitropolou, o.c., $\mathrm{n}^{\circ} 150$, pl. 19; H. SOBEL, o.c., p. 89, $\mathrm{n}^{\circ} 6$; F. CROISSANT, o.c. [n. 193], n ${ }^{\circ} 176$, p. 565 [non reproduite]. La statuette appartient au "type Hope", représenté notamment par une grande statue du musée du Pirée ( $\mathrm{n}^{\circ}$ inv. 244; v. E. MITROPOLOU, o.C., $\mathbf{n}^{\circ} 154$, pl. 20; CROISSANT, o.c., $n^{\circ} 177$, p. 565 [fig. p. 393]).

196 L'adjectif est courant pour qualifier les grands jeux panhelléniques (v. e.g. XEN., Mem., 3, 7, 1; LYCURG., Leocr., 51; DEM., Lept. (20), 141; PLUT., Praec. ger, rep. , 27, 820 c; SIG 3 , 577, 55-56 [Milet, 200/199 av. J.-C.J), dans lesquels les prix étaient des couronnes symboliques, alors que dans les jeux locaux il s'agissait souvent de récompenses de valeur; on le rencontre cependant aussi pour qualifier les jeux pentaétériques institués en l'honneur d'Artémis Leucophrynè à Magnésie du Méandre, une cité dont les liens avec la Crète sont particulièrement étroits (IM, 18, lin. 14-15 [206 av. J.-C.]; cf. $I M, 38$, lin. 49-50 [fin du $\mathrm{III}^{\mathrm{e}}$ s. av. J.-C.] : décret de Megalopolis alignant ces jeux sur les autres grands jeux à couronne). On peut remarquer le parallélisme avec le trophée conquis par les Muses sur les Sirènes.

197 La principale compétition était la course à pied, exercice de base des jeunes Crétois ( $\mathrm{V}$. ÉPHORE, 'Iotoplal, 4 Eúómm, FGH, 70 F 149 J, cité par STRABON, 10, 4, 20, 483 C). L'un des verbes

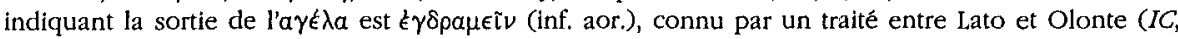
1, 16 Lato, 5, lin. 20-21 [deuxième moitié du $\mathrm{II}^{\mathrm{e}} \mathrm{s}$. av. J.-C. ?]). On sait par un passage mutilé du 
serment des éphèbes de Dréros [III ${ }^{\mathrm{e}} \mathrm{s}$, ou début du $\mathrm{II}^{\mathrm{e}} \mathrm{s}$. av. J.-C.] qu'il s'agissait d'une véritable

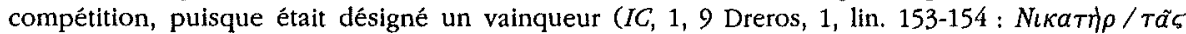
a' $\gamma(\lambda a 5)$. - Sur l'importance des jeux dans le processus d'initiation des sociétés "méditerranéennes ", v. notre communication Jeux atblétiques et riluels de fondation, in Spectacles sportifs et scéntques dans le monde étrusco-italique. Actes de la table ronde organisée par l'Équipe de recherches étrusco-italiques de l'UMR 126 (CNRS, Paris) et l'École Française de Rome. Rome, 3-4 mai 1991 [= Collection de l'École Française de Rome, 172], Rome, 1993, 141187.

198 Comme les autres Crétois, les gens d'Aptera devaient être de bons coureurs. Lors de la guerre de Pyrrhus contre Sparte (273/272 av. J.-C.), le fils ainé du roi d'Épire fut tué par un mercenaire crétois originaire d'Aptera, qualifté, sans raison particulière dans le contexte, d'« agile à

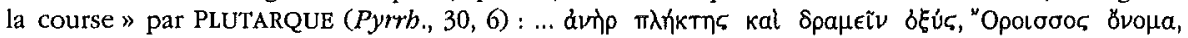

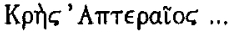

199 L'obligation de ce renouvellement figure dans de nombreux traités : v. e.g. les traités entre Malla et Lyttos (IC, 1, 19 Malla, 1, lin. 16-26 [III ${ }^{\mathrm{e}}$ s. av. J.-C.], Hierapytna et les Arcadiens (IC, 3, 3 Hierapytna, $1 \mathrm{~B}$, lin. 18-20 [deuxième moitié du $\mathrm{III}^{\mathrm{e}} \mathrm{s}$.], Hierapytna et Priansos $(I C, 3,3 \mathrm{H}$., 4, lin. 4047 [début du $\mathrm{II}^{\mathrm{e}} \mathrm{s}$.]), Cnosos et Hierapytna (IC, 1, 8 Cnosos, 13, lin, 16-30 [II ${ }^{\mathrm{e}} \mathrm{s}$ ], Lato et Olonte (IC, 1,16 Lato, 5 lin. 20-30 [deuxième moitié du $\mathrm{II}^{\mathrm{e}} \mathrm{s}$., Lyttos et Olonte $(I C, 1,18$ Lyttos, $9 \mathrm{~b}$, lin. 8-10 [111/110 av. J.-C.]). Des sanctions pécuniaires sont généralement prévues contre les cosmes qui omettraient de faire accomplir cette formalité.

${ }^{200}$ Notre unique source ne permet pas d'identifier la ou les divinités tutélaires de ces jeux. On peut penser à Artémis, en s'appuyant sur le parallèle spartiate d'Artémis Orthia, et plus anciennement à Dictynna. Mais peut-être faut-il songer aussi aux Sirènes, puisqu'elles subissent elles-mêmes au moins l'une des épreuves initiatiques - et l'on se souviendra que des jeux gymniques étaient célébrés près du tombeau de l'une d'entre elles, Parthénopè, à Naples, en vertu

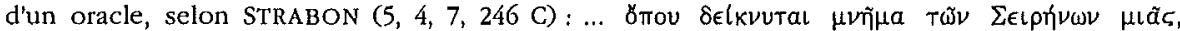

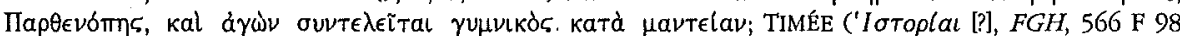
$\mathrm{J}$ (= ap. Schol, et TZETZ, in LYK., Alex., 732]), la source la plus ancienne sur ce point, indique qu'il s'agit d'un oracle rendu au navarque athénien Diotimos (vers 432 av. J.-C.), mais ne parle que d'une lampadodromie. Ce sont peut-être ces jeux qui furent plus tard transformés en manifestations pentaétériques en l'honneur d'Auguste (VELL. PATERC., 2, 123, 1; SUET., Aug., 989; D. CASS., 55, 10, 9 ; $56,29,2$ ), comprenant à la fois des concours sportifs, musicaux et littéraires (STRAB, , 5, 4, 7, 246C; cf. STAT., Stlu., 2, 2, 6; 3, 5, 92) : les récompenses y étaient des couronnes végétales (Inscbr. Olymp., 56 , lin. 15), et STACE, qui célèbre les victoires de son père (Silu., 5, 3, 112-115; 133-140), l'emporta lui-même une fois (Sllu., 5, 3, 225); v. l'ensemble des données chez R.M. GEER, The Greek Names at Naples, in TAPbA, 66 (1935), p. 208-221 - qui lui-même ne croit pas que ces jeux aient remplacé ceux de Parthénopè (contra, e.g. H. FRÈre, éd. des Silves, CUF, Paris, 1944 [3 $3^{\mathrm{e}}$ tir., 1992, 1, p. 157, n. 4 [à p. 65]). 